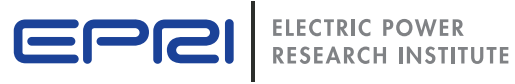

Quantifying the Value of Hydropower in the Electric Grid: Final Report 



\section{Quantifying the Value of Hydropower in the Electric Grid: Final Report}

1023144

Final Report, February 2013

EPRI Project Manager

T. Key 


\section{DISCLAIMER OF WARRANTIES AND LIMITATION OF LIABILITIES}

THIS DOCUMENT WAS PREPARED BY THE ORGANIZATION(S) NAMED BELOW AS AN ACCOUNT OF WORK SPONSORED OR COSPONSORED BY THE ELECTRIC POWER RESEARCH INSTITUTE, INC. (EPRI). NEITHER EPRI, ANY MEMBER OF EPRI, ANY COSPONSOR, THE ORGANIZATION(S) BELOW, NOR ANY PERSON ACTING ON BEHALF OF ANY OF THEM:

(A) MAKES ANY WARRANTY OR REPRESENTATION WHATSOEVER, EXPRESS OR IMPLIED, (I) WITH RESPECT TO THE USE OF ANY INFORMATION, APPARATUS, METHOD, PROCESS, OR SIMILAR ITEM DISCLOSED IN THIS DOCUMENT, INCLUDING MERCHANTABILITY AND FITNESS FOR A PARTICULAR PURPOSE, OR (II) THAT SUCH USE DOES NOT INFRINGE ON OR INTERFERE WITH PRIVATELY OWNED RIGHTS, INCLUDING ANY PARTY'S INTELLECTUAL PROPERTY, OR (III) THAT THIS DOCUMENT IS SUITABLE TO ANY PARTICULAR USER'S CIRCUMSTANCE; OR

(B) ASSUMES RESPONSIBILITY FOR ANY DAMAGES OR OTHER LIABILITY WHATSOEVER (INCLUDING ANY CONSEQUENTIAL DAMAGES, EVEN IF EPRI OR ANY EPRI REPRESENTATIVE HAS BEEN ADVISED OF THE POSSIBILITY OF SUCH DAMAGES) RESULTING FROM YOUR SELECTION OR USE OF THIS DOCUMENT OR ANY INFORMATION, APPARATUS, METHOD, PROCESS, OR SIMILAR ITEM DISCLOSED IN THIS DOCUMENT.

REFERENCE HEREIN TO ANY SPECIFIC COMMERCIAL PRODUCT, PROCESS, OR SERVICE BY ITS TRADE NAME, TRADEMARK, MANUFACTURER, OR OTHERWISE, DOES NOT NECESSARILY CONSTITUTE OR IMPLY ITS ENDORSEMENT, RECOMMENDATION, OR FAVORING BY EPRI.

THE FOLLOWING ORGANIZATION PREPARED THIS REPORT:

Electric Power Research Institute(EPRI)

\section{NOTICE}

NEITHER THE UNITED STATES GOVERNMENT NOR ANY AGENCY THEREOF, NOR ANY OF THEIR EMPLOYEES, MAKES ANY WARRANTY, EXPRESS OR IMPLIED, OR ASSUMES ANY LEGAL LIABILITY OR RESPONSIBILITY FOR THE ACCURACY, COMPLETENESS, OR USEFULNESS OF ANY INFORMATION, APPARATUS, PRODUCT, OR PROCESS DISCLOSED, OR REPRESENTS THAT ITS USE WOULD NOT INFRINGE PRIVATELY OWNED RIGHTS. REFERENCE HEREIN TO ANY SPECIFIC COMMERCIAL PRODUCT, PROCESS, OR SERVICE BY TRADE NAME, TRADEMARK, MANUFACTURER, OR OTHERWISE DOES NOT NECESSARILY CONSTITUTE OR IMPLY ITS ENDORSEMENT RECOMMENDATION, OR FAVORING BY THE UNITED STATES GOVERNMENT OR ANY AGENCY THEREOF.

THIS REPORT IS BEING DISSEMINATED BY THE DEPARTMENT OF ENERGY. AS SUCH, THE DOCUMENT WAS PREPARED IN COMPLIANCE WITH SECTION 515 OF THE TREASURYAND GENERAL GOVERNMENT APPROPRIATIONS ACT FOR FISCAL YEAR 2001 (PUBLIC LAW 106554) AND THE INFORMATION QUALITY GUIDELINES ISSUED BY THE DEPARTMENT OF ENERGY. THOUGH THIS REPORT DOES NOT CONSTITUTE "INFLUENTIAL" INFORMATION, AS THAT TERM IS DEFINED IN DOE'S INFORMATION QUALITY GUIDELINES OR THE OFFICE OF MANAGEMENT AND BUDGET'S INFORMATION QUALITY BULLETIN FOR PEER REVIEW (BULLETIN), THE STUDY WAS REVIEWED BOTH INTERNALLY AND EXTERNALLY PRIOR TO PUBLICATION. FOR PURPOSES OF EXTERNAL REVIEW, THE STUDY BENEFITED FROM THE ADVICE AND COMMENTS OF EIGHT MAJOR U.S. UTILITIES WITH EXISTING HYDROPOWER ASSETS, FEDERAL LABS, CONSULTANTS, AND HYDROPOWER EQUIPMENT MANUFACTURERS.

\section{NOTE}

For further information about EPRI, call the EPRI Customer Assistance Center at 800.313.3774 or e-mail askepri@epri.com.

Electric Power Research Institute, EPRI, and TOGETHER...SHAPING THE FUTURE OF ELECTRICITY are registered service marks of the Electric Power Research Institute, Inc.

Copyright @ 2013 Electric Power Research Institute, Inc. All rights reserved. 


\section{ACKNOWLEDGMENTS}

The following organization prepared this report:

Electric Power Research Institute

942 Corridor Park Blvd

Knoxville, TN 37932

Principal Investigators

T. Key

L. Rogers

D. Brooks

A. Tuohy

This report describes research sponsored by the U.S. Department of Energy. EPRI would like to acknowledge the support and contributions of the following organizations:

- HDR Engineering, Inc.

- Hydro Performance Processes Inc.

- Kirby Consulting

- $\quad$ LCG Consulting

- Oak Ridge National Laboratory

- Sandia National Laboratories

- AmerenUE
- Brookfield Power

- Chelan County PUD

- Duke Energy

- Exelon Generation

- Manitoba Hydro

- Tennessee Valley Authority

- Voith Hydro

This publication is a corporate document that should be cited in the literature in the following manner:

Quantifying the Value of Hydropower in the Electric Grid: Final Report. EPRI, Palo Alto, CA: 2013. 1023144. 



\section{ABSTRACT}

The report summarizes research to Quantify the Value of Hydropower in the Electric Grid. This 3-year DOE study focused on defining value of hydropower assets in a changing electric grid. Methods are described for valuation and planning of pumped storage and conventional hydropower. The project team conducted plant case studies, electric system modeling, market analysis, cost data gathering, and evaluations of operating strategies and constraints. Five other reports detailing these research results are available a project website, www.epri.com/hydrogrid.

With increasing deployment of wind and solar renewable generation, many owners, operators, and developers of hydropower have recognized the opportunity to provide more flexibility and ancillary services to the electric grid. To quantify value of services, this study focused on the Western Electric Coordinating Council region. A security-constrained, unit commitment and economic dispatch model was used to quantify the role of hydropower for several future energy scenarios up to 2020. This hourly production simulation considered transmission requirements to deliver energy, including future expansion plans. Both energy and ancillary service values were considered. Addressing specifically the quantification of pumped storage value, no single value stream dominated predicted plant contributions in various energy futures. Modeling confirmed that service value depends greatly on location and on competition with other available grid support resources. In this summary, ten different value streams related to hydropower are described. These fell into three categories; operational improvements, new technologies, and electricity market opportunities. Of these ten, the study was able to quantify a monetary value in six by applying both present day and future scenarios for operating the electric grid.

This study confirmed that hydropower resources across the United States contribute significantly to operation of the grid in terms of energy, capacity, and ancillary services. Many potential improvements to existing hydropower plants were found to be cost-effective. Pumped storage is the most likely form of large new hydro asset expansions in the U.S. however, justifying investments in new pumped storage plants remains very challenging with current electricity market economics. Even over a wide range of possible energy futures, up to 2020, no energy future was found to bring quantifiable revenues sufficient to cover estimated costs of plant construction.

Value streams not quantified in this study may provide a different cost-benefit balance and an economic tipping point for hydro. Future studies are essential in the quest to quantify the full potential value. Additional research should consider the value of services provided by advanced storage hydropower and pumped storage at smaller time steps for integration of variable renewable resources, and should include all possible value streams such as capacity value and portfolio benefits i.e.; reducing cycling on traditional generation.

\section{Keywords}

Hydropower

Conventional Hydropower

Electric Sector Modeling

Hydrologic Constraints
Energy and Ancillary Services Markets

Pumped Storage

Hydro Plant Optimization

Renewable Integration 



\section{EXECUTIVE SUMMARY}

Concerns about energy security and climate change are driving policies, regulations, and energy markets to encourage new renewables, such as wind and solar, and reconsider traditional renewables, primarily hydropower. Many in the traditional hydropower industry, including owners, operators, and developers, desire to better understand how these trends will affect investment decisions for conventional hydro and pumped storage. Examples of major policy and market changes that may affect the value of hydropower are the future limits on power plant $\mathrm{CO}_{2}$ emissions and the addition of a large amount of variable renewables. The market effects of either of these could shift economic break points in favor of hydropower options, including the addition of pumped storage. Wind power, in particular, by its large scale and general availability at night, introduces system-balancing challenges that could make many hydropower assets more valuable. The question is, can the benefits be monetized to justify the cost of hydropower investments in current and future market structures?

To answer this question, the study looked at existing large hydropower operations in the U.S., models for different electricity futures, markets, costs of existing and new technologies as well as trends related to hydropower investments in other parts of the world. The interest and participation of the hydro industry in this work was significant and included eight major U.S. utilities with existing hydropower assets, federal labs, consultants, and hydropower equipment manufacturers. The effort involved regular feedback on topic area presentations, progress reviews, discussions, and resulted in a number of adjustments to the depth and direction of the work. Stakeholder interactions and inputs were sustained over approximately a thirty-month period, achieving the goal to create a broad industry collaborative effort.

Through these collaboration efforts, the work has contributed to and built on other related industry efforts. Specifically, a whitepaper was written by the National Hydropower Association's Pumped Storage Development Council entitled Challenges and Opportunities for New Pumped Storage Development: A White Paper developed by NHA's Pumped Storage Development Council that addresses some of the key issues facing pumped storage in the current market and opportunities looking into the future. A recent U.S. Department of Energy (DOE) study on wind integration, entitled "Integrating Southwest Power Pool Wind Energy into Southeast Electricity Markets," was completed that provided enhancements and insights in the modeling of wind. Lastly, work done by the Western Electric Coordinating Council (WECC) and the National Renewable Energy Laboratory (NREL) to better define expansion planning with solar and wind power was vital to the project.

The DOE Office of Energy Efficiency and Renewable Energy, Wind and Water Power Program sponsored the work: "Quantifying the Value of Hydropower in the Electric Grid" (under contract DE-EE0002666). 
Completing a value analysis that included all the important assumptions and variables to accurately and credibly predict the future value of hydropower plants to the transmission grid was expected to be very challenging. In the past, electric capacity expansion models and resource plans have often taken ancillary services for granted and have tended to underestimate the potential value of hydropower. A key aim of this study was to overcome these historical limitations. The main approach here has been to develop methods for valuation and resource planning of pumped storage and conventional hydropower projects. The project employed several industry analyses and modeling tools for quantifying the benefits provided by hydroelectric projects to the electric transmission grid. These tools were applied at all levels: the hydro unit, the plant, the balancing area, and at the regional electric system operator level.

A diverse team was assembled, made up of organizations with experience in grid modeling, hydropower costs, and electricity markets, as well as experts in hydropower operations. Assignments included plant case studies, electric system modeling, electricity market analysis, costing modernization and new hydro plants, valuing different operating strategies and constraints, and policy impact analysis. The overall work scope was broken down into the following specific tasks:

Task 1 - Case Studies on Plant Operations and Utilization

Task 2 - Modeling Approach and Base Case Scenario

Task 3 - Existing Electricity Markets and Opportunities in Future Markets

Task 4 - Systemic Plant Operating Constraints

Task 5 - Plant Cost Elements

Task 6 - Modeling Results for Future Scenarios

Task 7 - Effects of Alternative Policy Scenarios on Value of Hydropower

Task 8 - Result Synthesis and Dissemination (to affect planning and operating strategies)

Case Studies (Task 1) - The task of investigating existing plants via case studies captured operating experience and specific ideas for future plant optimization improvements from operators at eight plants in both the eastern and western U.S. The case studies showed that hydro facilities in both structured market and non-market areas have opportunities to improve plant efficiency, leading to a more economic operation with the same water resource (particularly if the energy market is more lucrative than the ancillary services market). Conventional and pumped storage plants in non-market areas operated most efficiently. In general, a potential increase of $1 \%-3 \%$ in revenue could be expected from optimizing plant operations. For detailed case study results on pumped storage and conventional hydropower plants, refer to the EPRI reports Results from Case Studies of Pumped Storage Hydroelectric Plants (1023142) and Results from Case Studies of Conventional Hydroelectric Plants (1023143).

Electric Sector Modeling (Task 2) - Detailed electric system modeling was carried out for the WECC region of the U.S. and Canada. WECC was selected because of the expected growth in renewable generation and strong interest in pumped storage development. This region represents about $20 \%$ of the electricity use in the U.S. and Canada. The hourly modeling was set up to consider the role of hydropower with other renewable and non-renewable generation in the electricity sector. It consisted of a grid security-constrained unit commitment with economic 
dispatch, load shapes, TEPPC 2019 transmission expansion plan, consideration of likely generation capacity expansions, and within-hour reserve requirements. The 2010 and 2020 reference cases were developed to characterize hydropower plants performance against regional fuel mix, demand for energy, ancillary services, plant capability, and price metrics. For more details on the base case scenario and modeling approach, refer to the EPRI report Quantifying the Value of Hydropower in the Electric Grid: Modeling Approach and Base Case Scenario (1023139).

Markets (Task 3) - Existing and future electricity markets for energy and ancillary services were analyzed across the United States looking specifically at the role of hydropower. In particular, the role for ancillary services for hydro generation assets was investigated. The study found many different potential sources of revenue, and no single dominant value stream. It was confirmed that the value of services depends greatly on location and on the competition with other available grid support resources in a balancing region. Also, current market structures do not fully capture the actual costs and benefits from hydropower projects. For more details on the market structures in the United States, refer to the Sandia National Laboratories report Quantifying the Value of Hydropower in the Electric Grid: Role of Hydropower in Existing Markets (SAND2011-1009).

Operating Constraints (Task 4) - In nearly all practical cases, hydro plant operations will need to respect other systemic plant operating constraints. There are significant constraints in the WECC including water availability, irrigation, minimum flows and other environmental requirements related to fish passage as well as water reservoir/river recreational needs. These may be less of a concern for new off-channel pumped storage plants specifically designed and built to provide grid services, as opposed to the multi-purpose pumped storage schemes built in the $20^{\text {th }}$ century, which also focused on water supply. For example, designs such as closed-loop pumped storage are aimed to mitigate some of these environmental constraints. In general, the operating constraints are likely to impact the profitability of the plant especially in areas with more stringent requirements. A sample of the effects of these types of operating constraints in the mid-west can be found in the Oak Ridge National Laboratory report, Case Study: Hydropower Constraints on OSAGE and TAUM SAUK Facilities (ORNL/TM-2012/232).

Cost Elements (Task 5) - In order to develop cost information for future hydropower facility upgrades and new pumped storage plants, experience for specific cost elements from various past projects was used. Also, cost results on an element by element basis from the comprehensive EPRI report (Pumped-Storage Planning and Evaluation Guide, EPRI GS-6669), were escalated to present value and compared to the more recent experiences. This helped to define escalation rates that were then applied to various hydropower applications including greenfield projects and upgrades/improvements at existing facilities. These cost data are available for modeling capacity expansions, as well as providing a calibrated cost reference for current and projected additions and inprovements at conventional hydropower, pumped storage, and non-powered dams. Costs vary significantly depending on physical conditions at a site. New large scale pumped storage plants were estimated to cost between $\$ 1,000$ and $\$ 2,500 / \mathrm{kW}$. Upgrades to existing facilities were significantly less. For example, incorporating adjustable speed pump-turbines was in the range of only $\$ 100$ to 150 per $\mathrm{kW}$ more than the cost of a standard synchronous generator. Detailed cost information is available in the EPRI report, Quantifying the Full Value of Hydropower in the Electric Grid: Plant Cost Element (1023140). 
Electric System Modeling Future Scenarios (Task 6) - Based on work begun in the reference case hydro modeling, four additional energy futures for the year 2020 were evaluated based on different assumptions. These 2020 futures covered the range of renewable deployment, CO2 prices, natural gas prices and other market factors. In total twenty-three scenarios were run using the four energy futures to capture the value of both energy and ancillary services with increased reserve requirements from wind and solar. In general, the results showed that increases in system requirements for flexible reserves could double the income of pumped storage plants. In addition, when modeling pumped storage plants with increased operating capacity or variable speed pumps, the average income of the plant increased between $60 \%$ and $80 \%$. Based on the 2020 hourly modeling, the average annual market income of the conventional plants ranged from $\$ 175 / \mathrm{kW}$ to $\$ 291 / \mathrm{kW}$, while the pumped storage ranged from $\$ 22 / \mathrm{kW}$ to $\$ 48 / \mathrm{kW}$ depending on the WECC region in which the plants were sited. The capacity value of hydropower technologies was not assessed. For detailed results from the modeling of future scenarios, refer to the EPRI report Quantifying the Value of Hydropower in the Electric Grid: Modeling Results for Future Scenarios (1023141).

Details of the specific elements of the overall study are covered in individual reports available at www.epri.com/hydrogrid.

\section{Synthesizing Results and Effects to the Value of Hydropower (Task 7 \& 8 )}

This report summary provides the key conclusions and synthesizes all the results into recommendations of how to better capture the value of hydropower resources in the electricity enterprise. From the step-by-step project development, tasks areas of investigation, and interactions with key stakeholders, we are able to point out ten ways to potentially increase the value of hydropower to electric grid services. In this final report of the study, ten different value streams related to hydropower grid services are described. These are non-overlapping and identified as operational improvements, new technology advantages, or electricity market opportunities. Six of these ten value streams are included in this study and the other four (in italics below) are not. The value streams that were not quantified in this study may provide a different cost benefit balance and an economic tipping point for hydro. Ways to account for the value of hydropower, and the implied opportunities, are summarized in Table ES-1:

Table ES-1 Ways to increase the value of hydropower

\begin{tabular}{|c|c|c|c|c|}
\hline No. & $\begin{array}{c}\text { Value } \\
\text { Streams }\end{array}$ & Ways to Increase Value & Beneficiaries & $\begin{array}{c}\text { Potential } \\
\text { Value }\end{array}$ \\
\hline 1 & $\begin{array}{c}\text { Operational } \\
\text { Improvements }\end{array}$ & $\begin{array}{l}\text { Identify and make plant efficiency } \\
\text { improvements by modifying hydro unit } \\
\text { operations while respecting river } \\
\text { system optimizations and constraints }\end{array}$ & Plant owner & $\begin{array}{l}1-3 \% \\
\text { revenue } \\
\text { increase }\end{array}$ \\
\hline 2 & $\begin{array}{c}\text { Operational } \\
\text { Improvements }\end{array}$ & $\begin{array}{l}\text { Use hydro more frequently to address } \\
\text { other generation and load variability in } \\
\text { the power system, providing flexible } \\
\text { reserves, reducing wear and tear on the } \\
\text { thermal fleet, while increasing the } \\
\text { efficiency of other generation }\end{array}$ & $\begin{array}{l}\text { System operator } \\
\text { or vertically } \\
\text { integrated utility }\end{array}$ & $\begin{array}{l}40 \% \\
\text { annual } \\
\text { revenue } \\
\text { increase PS }\end{array}$ \\
\hline 3 & $\begin{array}{l}\text { Operational } \\
\text { Improvements }\end{array}$ & $\begin{array}{l}\text { Recognize hydro for allowing more } \\
\text { generation diversity and options, thus }\end{array}$ & $\begin{array}{l}\text { National interest, } \\
\text { general public, }\end{array}$ & $\begin{array}{l}\text { Not } \\
\text { quantified }\end{array}$ \\
\hline
\end{tabular}




\begin{tabular}{|c|c|c|c|c|}
\hline & & $\begin{array}{l}\text { enhancing energy security and } \\
\text { maintaining power supply reliability in } \\
\text { the face of uncertainties in future } \\
\text { energy resources }\end{array}$ & $\begin{array}{l}\text { and North } \\
\text { American } \\
\text { Electric } \\
\text { Reliability } \\
\text { Corporation } \\
\text { (NERC) }\end{array}$ & \\
\hline 4 & $\begin{array}{l}\text { New Hydro } \\
\text { Technologies }\end{array}$ & $\begin{array}{l}\text { Expand the effective operating range of } \\
\text { existing and new hydro units with } \\
\text { lower minimum load and higher peak } \\
\text { operating capabilities }\end{array}$ & $\begin{array}{l}\text { Plant owner and } \\
\text { operator }\end{array}$ & $\begin{array}{l}61 \% \\
\text { increase } \\
\text { annual } \\
\text { average } \\
\text { income PS } \\
\end{array}$ \\
\hline 5 & $\begin{array}{l}\text { New Hydro } \\
\text { Technologies }\end{array}$ & $\begin{array}{l}\text { Apply adjustable speed drive } \\
\text { electronics in new and selected existing } \\
\text { pumped storage units to enable } \\
\text { regulation of the pumping power } \\
\text { requirements, particularly at night }\end{array}$ & $\begin{array}{l}\text { Plant owner and } \\
\text { operator }\end{array}$ & $\begin{array}{l}85 \% \\
\text { increase } \\
\text { annual } \\
\text { average } \\
\text { income PS } \\
\end{array}$ \\
\hline 6 & $\begin{array}{l}\text { New Hydro } \\
\text { Technologies }\end{array}$ & $\begin{array}{l}\text { Design new pumped storage plants that } \\
\text { minimize environmental impacts such } \\
\text { as low profile or closed water supply } \\
\text { loop to shorten licensing lead times } \\
\text { and public approval process as } \\
\text { compared to recent conventional } \\
\text { experiences }\end{array}$ & $\begin{array}{l}\text { Plant developers, } \\
\text { general public }\end{array}$ & $\begin{array}{l}\text { Not } \\
\text { quantified }\end{array}$ \\
\hline 7 & $\begin{array}{l}\text { Electricity } \\
\text { Markets }\end{array}$ & $\begin{array}{l}\text { Settle energy markets sub-hourly, } \\
\text { increasing conventional and pumped } \\
\text { storage energy arbitrage opportunities } \\
\text { with grid demand load leveling benefits }\end{array}$ & Everybody & $\begin{array}{l}5 \% \\
\text { decrease in } \\
\text { electricity } \\
\text { prices }\end{array}$ \\
\hline 8 & $\begin{array}{l}\text { Electricity } \\
\text { Markets }\end{array}$ & $\begin{array}{l}\text { Have the Independent System } \\
\text { Operators (ISOs) scheduling hydro to } \\
\text { co-optimize energy and ancillary } \\
\text { services within a balancing authority }\end{array}$ & Everybody & $\begin{array}{l}63-77 \% \\
\text { increase in } \\
\text { profits PS }\end{array}$ \\
\hline 9 & $\begin{array}{l}\text { Electricity } \\
\text { Markets }\end{array}$ & $\begin{array}{l}\text { Treat pumped storage as a new storage } \\
\text { asset class capturing the full value of } \\
\text { services and improving the economics } \\
\text { in areas with resource constraints }\end{array}$ & $\begin{array}{l}\text { Developers, } \\
\text { owners, and } \\
\text { general public }\end{array}$ & $\begin{array}{l}\text { Not } \\
\text { quantified }\end{array}$ \\
\hline 10 & $\begin{array}{l}\text { Electricity } \\
\text { Markets }\end{array}$ & $\begin{array}{l}\text { Credit hydro for its very fast regulation } \\
\text { response in situations where resource } \\
\text { adequacy is a power system reliability } \\
\text { issue }\end{array}$ & $\begin{array}{l}\text { Developers, } \\
\text { owners, NERC } \\
\text { and general } \\
\text { public }\end{array}$ & $\begin{array}{l}\text { Not } \\
\text { quantified }\end{array}$ \\
\hline
\end{tabular}

Of the ten ways, the study was able to determine a monetary value for six using three separate modeling tools and provide general basis for the other four potential value streams. The four not covered are numbers \#3 operating characteristics that allow more diversification in generating options, \#6 technologies that streamline environmental approvals, \#9 markets that treat pumped storage as a special asset class, and \#10, markets that credit very fast regulation response. Several 
of these value streams provide broad public benefit and longer-term energy security, but are not easy to monetize.

Based on those value streams that could be monetized in competitive electricity markets, this study identifies many cost-effective improvements to existing hydropower plants. However, over the range of possible energy futures, standard cost/benefit analysis shows that market revenues alone (within existing market structures) do not provide enough value to justify the construction of pumped storage hydro plants in the U.S. in 2020. The value streams that were not quantified in this study may provide a different cost benefit balance and an economic tipping point for hydro. Future studies are essential in the quest to quantify the full potential value. Research should consider the value of services provided by advanced storage hydropower and pumped storage at smaller time steps for integration of variable renewable resources, and should include all possible value streams such as capacity value and portfolio benefits i.e.; reducing cycling on traditional generation.

Key stakeholder input argues that development of new hydro generation assets has stalled for many years. Stakeholders stated that policy and market incentives have been insufficient to overcome permitting difficulties and financial risks. However, hydro resources, particularly pumped storage are expected to play a more prominent role as the need for flexibility in the system increases. Furthermore, as the evolution of wholesale markets expands and markets become more fine-tuned through application of "Pay for Performance," compensation opportunities to flexible and quick-response resources such as pumped storage may increase the financial and economic incentives to more fully utilize existing facilities. This could, in turn, provide incentives to build new pumped storage facilities.

As shown for each of these value streams, the benefits are spread around among different stakeholders. Some of the value streams are not well defined and recognized and others are highly dependent on local conditions and the state of competing energy resources. A standard cost-benefit analysis is complicated with time-dependent variables and cannot by itself capture full value. This study has aimed to highlight all of the different elements of the actual costs and benefits from hydropower projects that are not fully recognized under existing policies and market structures.

Several recent studies have investigated high penetrations of renewable generation - mostly from wind power - and have analyzed strategies for offsetting the increase in net-load variability and uncertainty that this would introduce into reliability management of the interconnected electrical grid. Most hydro facilities have the ability to cycle to help manage net-load variability and uncertainty that results with high wind and solar penetration. The assumption is that if used in this manner, hydro facilities would be able to provide a more valued service to the grid than the manner in which they have historically been used and that hydro facilities would, accordingly, be compensated more for this service. Further, this greater compensation would then provide the economic impetus for more hydro facilities to be developed.

As the need for generation resources that can provide system flexibility increased with an increased proportional penetration of variable renewables, the value of hydropower and pumped storage will become more significant. One example of this is the increase in the use and construction of storage facilities in Europe as renewable penetration increases. While this study looked at several aspects of value, the general conclusion is that more work needs to be done to quantify the full value stream of hydropower resources. Specifically, modeling on shorter time 
scales may be beneficial to capture the value on a within-hour basis. The new DOE project led by Argonne National Laboratory will follow the work discussed here and focus directly on this uncertainty and granularity. Additionally, work needs to be done to better understand hydropower's role in supporting a reliable grid and preparing the power system for an uncertain energy market future. These are items that benefit the electric grid (e.g black-start capability), but are hard to quantify and attribute to one technology or another on a countrywide scale. Ultimately, hydropower will have to compete with other generation resources, demand response, and better forecasting within the market and non-market structures efficiently and effectively to capture value.

Overall, this study has aimed to assist the utility and hydroelectric industries to better understand the value and economic viability of existing and future hydropower assets providing both energy and ancillary services. It shows how value will be sensitive to different future energy scenarios including high levels of renewable integration, variations in fossil plant operations and commodity prices such as $\mathrm{CO} 2$ credits and natural gas. Results will also be useful in formulating policies and regulations, for developing fair markets, and for investing in energy and transmission infrastructure to ensure energy security and to address climate change concerns. Uses include quantifying benefits provided by conventional and pumped storage hydro projects to the transmission grid, validating a power and market systems model, analyzing scenarios, and examining the implications of alternative market structures. 



\section{CONTENTS}

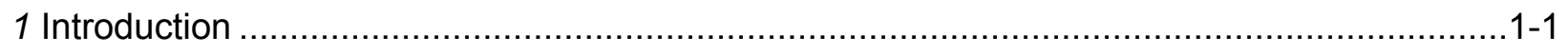

2 Current State of Hydropower in the United States .................................................... $2-1$

Market Structures: Real-Time Economics .............................................................. $2-1$

Formal Markets- ISO/RTO Auction Markets.................................................................... $2-1$

Non-Market Traditional Scheduling Areas......................................................................2-2

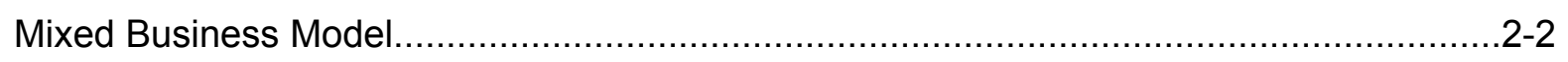

Significance of Real-Time Markets ....................................................................... $2-2$

Role of Generation and Contribution of Hydro ...................................................... $2-3$

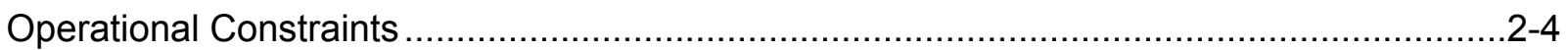

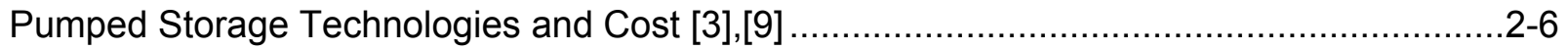

Pumped Storage Equipment Overview ................................................................... $2-8$

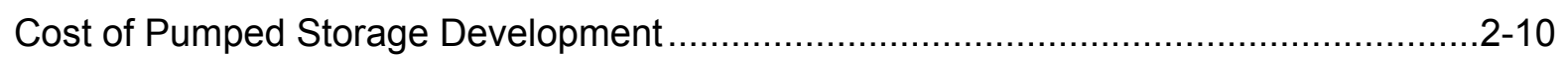

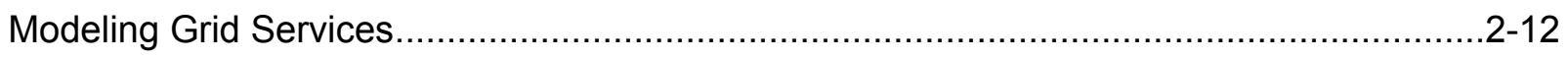

3 Ways to Increase the Value of Hydropower .............................................................

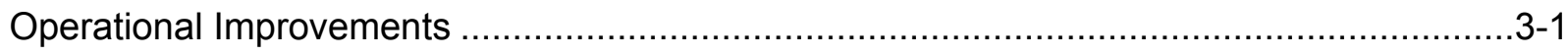

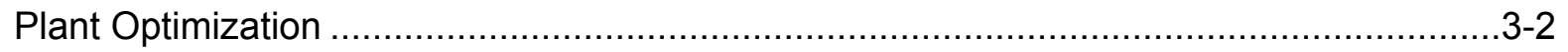

Use Hydro to Address System Variability ...............................................................

Recognize Hydro for Providing Reliability Amidst Resource Diversity ........................... 3-7

Japanese Pumped Storage Experience ........................................................... $3-8$

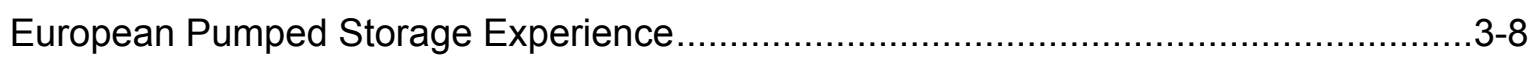

New Hydropower Technologies ...........................................................................

Expand Operating Range of Existing Units ..............................................................

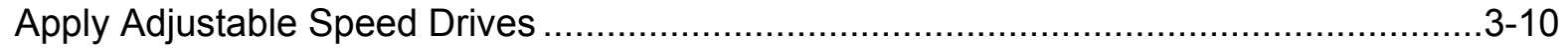

Design New Pumped Storage Plants to Minimize Environmental Impact .......................3-12

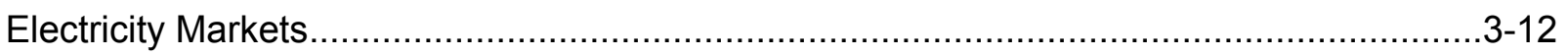

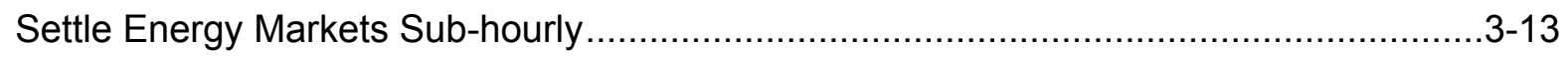

Conventional Hydro Plants .......................................................................... $3-14$

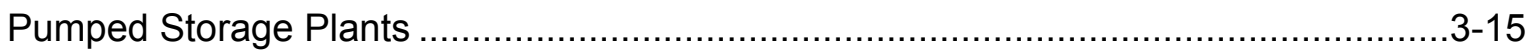

ISOs Scheduling Hydro to Co-optimize Resources .................................................. 


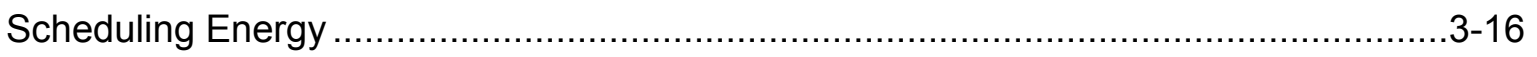

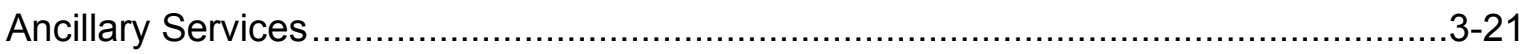

Extending Co-optimization .............................................................................. $3-23$

Treat Pumped Storage as a New Storage Asset Class........................................... $3-23$

Credit Hydro for Fast Regulation ....................................................................... $3-24$

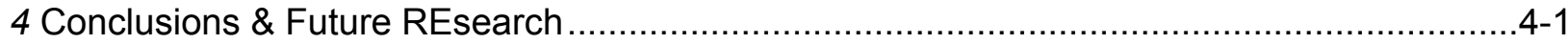

Ten Ways to Increase the Value of Hydropower Assets ........................................... $4-1$

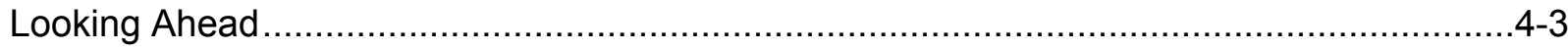

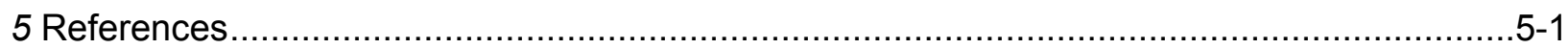

A Recent Enhancements to Market Access for Energy Storage Technologies ...................... A-1 


\section{LIST OF FIGURES}

Figure 1-1 Strategic approach to valuing hydropower $1-1$

Figure 2-1 Organization structure of North American electric industry ..................................2-1

Figure 2-2 Typical operational constraints on hydropower facilities...................................2-5

Figure 2-3 Pump Storage use in night to day energy shifting ..........................................2-6

Figure 2-4 Grid power control issue and energy management timeframes ...........................2-7

Figure 2-5 Change in renewable energy generation in Germany ....................................... 2-7

Figure 2-6 Head and power ranges of modern advanced pumped storage equipment............2-8

Figure 2-7 Relative grid service capability of advanced pumped storage units .......................2-9

Figure 2-8 Mode change times for various advanced PS concepts.................................2-10

Figure 2-9 Timeframes for modern advanced PS unit regulation .................................... 2-10

Figure 3-1 Conventional and pumped storage case study locations ................................. 3-2

Figure 3-2 Difference in Conventional hydro performance with increased reserves..................3-5

Figure 3-3 Difference in pumped storage performance with increased reserves.....................3-6

Figure 3-4 Difference in starts and stops with increased pumped storage ............................ 3-6

Figure 3-5 Pumped storage units balancing forecast error ........................................... 3-7

Figure 3-6 Timeframes for advanced pumped storage unit regulation .............................. 3-11

Figure 3-7 Ancillary service procurement with and without hydro participation .....................3-14

Figure 3-8 Conventional plant revenues $(\$ 1000)$ in base case ......................................... 3-15

Figure 3-9 Ancillary service and energy revenue when adding one new pumped storage

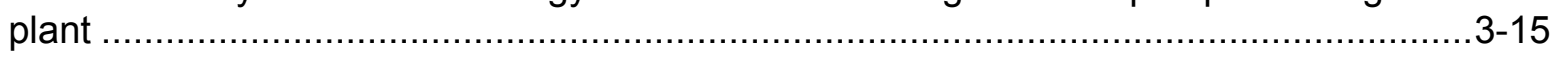

Figure 3-10 Pumped storage revenues $(\$ 1000)$ in base scenario ....................................... $3-16$

Figure 3-11 A fossil fueled generator maximizes its profits by bidding its variable cost; $\$ 35 / \mathrm{MWh}$ in this example ............................................................................ $3-17$

Figure 3-12 Variable renewables bid zero or negative and typically clear the market every hour they are available. ..............................................................................

Figure 3-13 Hourly energy markets do not optimize the scheduling of energy-limited hydro.

Figure 3-14 Energy-limited hydro must either explicitly schedule production during expected high price hours or it must bias its offer price during expected lower price hours

Figure 3-15 Pumped storage operators must forecast both high and low prices and adjust both the buy and sell bids based on both the expected buy and sell prices 
Figure 3-16 Energy-limited hydro cost to supply spinning reserve depends on the hour it is delivered and on how many other hours of spin are being provided

Figure 3-17 Example of pumped storage as a new storage asset.................................... 3-24 


\section{LIST OF TABLES}

Table ES-1 Ways to increase the value of hydropower 10

Table 2-1 Functions and services provided by generation [14] ........................................... $2-3$

Table 2-2 Pumped Storage Construction Cost Data [9]............................................ 2-11

Table 2-3 Energy futures and modeling scenarios ...................................................... 2-13

Table 3-1 Operational ways to increase the value of hydropower ..................................... 3-1

Table 3-2 Conventional hydro performance by region with increased reserve

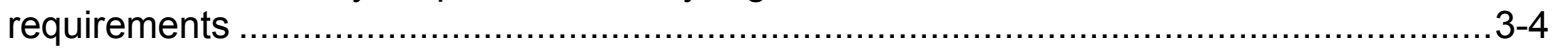

Table 3-3 Pumped storage performance by region with increased reserve requirements.........3-5

Table 3-4 Drivers leading to energy storage investment in Europe ........................................ $3-8$

Table 3-5 Installed and planned pumped storage developments in Europe and U.S. [3] ..........3-9

Table 3-6 Technological ways to increase the value of hydropower.................................... $3-9$

Table 3-7 Performance of pumped storage plants with upgrades ...................................... 3-10

Table 3-8 Features and benefits of variable speed pumped storage [6]............................ 3-11

Table 3-9 Performance of variable speed pumped storage units .................................... 3-12

Table 3-10 New variable speed pumped storage plant performance ................................... $3-12$

Table 3-11 Market ways to increase the value of hydropower.......................................... 3-13

Table 4-1 Ways to increase the value of hydropower ................................................. $4-2$ 



\section{1 \\ INTRODUCTION}

In the last 25 years, U.S. development of new hydropower, both conventional and pumped storage, has faced multiple challenges. These include limited siting opportunities, large initial capital investment requirements, and diverse value streams that have been difficult to quantify in a deregulated electric sector. Hydropower has generally not been considered in planning for generation capacity planning. Day-to-day grid operation decisions in resource selection and electricity production are driven by economic dispatch, resource allocations, unit commitment, and the selection of required reserve resources. Hydropower must compete with many other energy and ancillary services generation options as well as load demand response alternatives.

Development of new hydropower plants has been stalled, in part, due to the lack of clear financial incentives and stable, long term energy markets to compensate for the cost of permitting and constructing new facilities. In the coming years, wind and solar generation are expected to increase volatility and uncertainty in the electric grid. Hydropower, including pumped storage, has the potential to help manage these variable resources. However, it has been difficult to capture the full and long-term value that hydropower may bring.

Given the challenges, the goal of this project has been to identify and calculate the value of energy production, services, and reliability attributes of hydropower. The approach has been to define the flexibility and limitations of existing hydropower plants, simulate operations in an economic model for present and future scenarios, analyze the operating constraints and opportunities, develop cost data, and evaluate existing and potential market operations through industry outreach and feedback. This analysis, and the detailed modeling, has focused on the WECC area because of the traditional importance of hydropower and the significant growth in variable wind and solar generation in the region. Figure 1-1 shows the strategic approach for quantifying the value of hydropower is defined by four components.

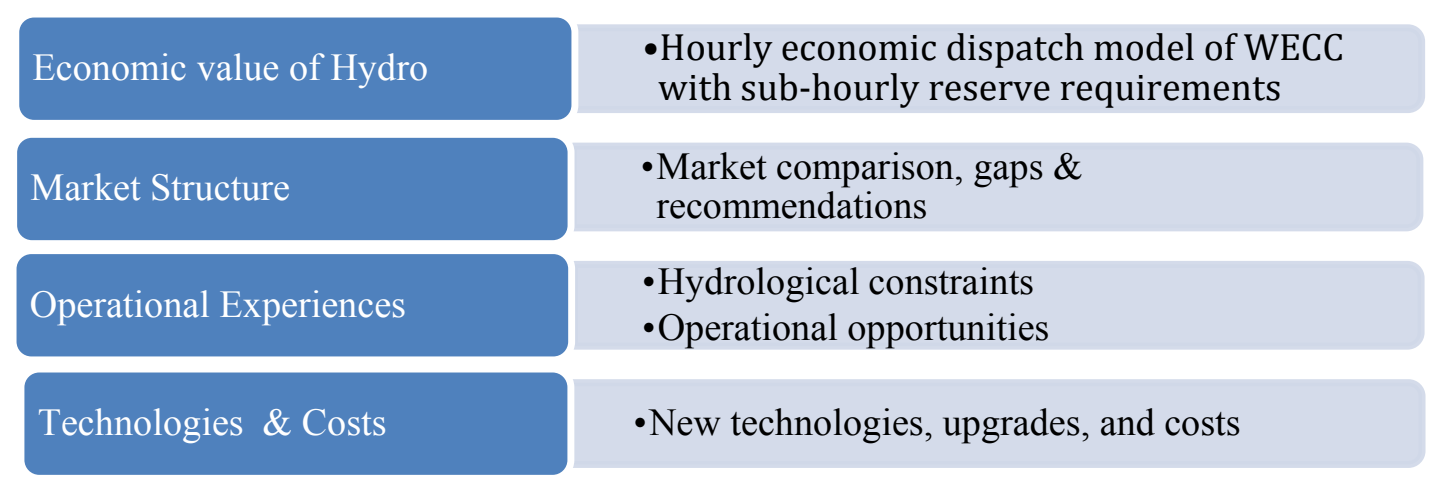

Figure 1-1 Strategic approach to valuing hydropower 
This final report summarizes findings of the study and defines the current state of hydropower in the U.S. including market structures and operational experiences. Ten opportunities to increase or further capture the value of hydropower through operations, technology, and markets are defined. 


\section{CURRENT STATE OF HYDROPOWER IN THE UNITED STATES}

\section{Market Structures: Real-Time Economics}

The role and contribution of hydro resources is impacted by the nature of system and market institutions under which they operate. The exchange of electricity products occurs through various market structures that overlay physical and operational organization of the grid. Figure 2-1 shows a map delineating the areas of the North American Continent governed by formal markets for generation resource acquisition. In areas outside markets, bilateral transaction approaches are used for generation resource acquisition and are referred to as Traditional Scheduling Areas. Generally, formal markets operate in conjunction with an Independent System Operator (ISO) or Regional Transmission Organization (RTO). The current market structures are each outlined below with a brief summary of their potential value. For more details on the market structures in the United States, refer to the Sandia National Laboratories report Quantifying the Value of Hydropower in the Electric Grid: Role of Hydropower in Existing Markets [5].

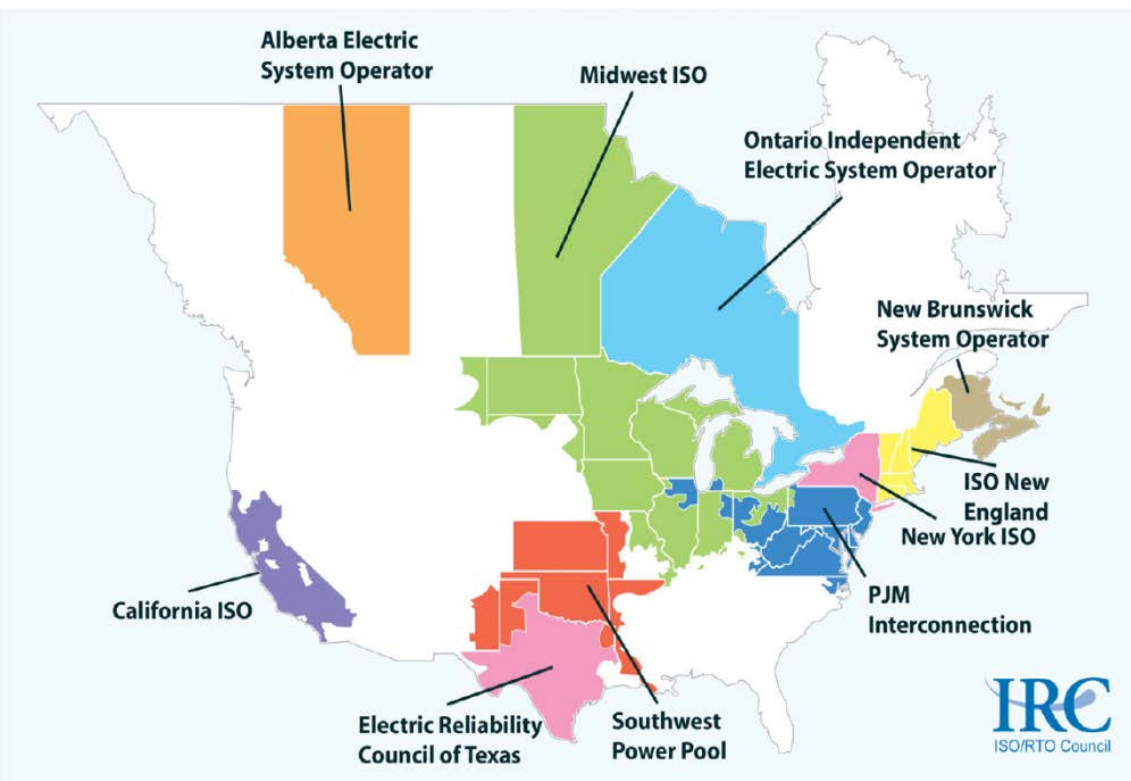

Figure 2-1 Organization structure of North American electric industry

\section{Formal Markets- ISO/RTO Auction Markets}

The colored areas in Figure 2-1 represent the geographic coverage of ISOs and RTOs. These entities manage grid operations within their territories and also operate markets through which energy, ancillary services, and capacity resources are procured. Seven ISOs currently operate in 
the U.S. (several of which extend operations into Canada). Like all U.S.-based Transmission Service Providers, ISOs are required to file Open Access Transmission Tariffs (OATTs) with the Federal Energy Regulatory Commission (FERC). OATTs define and implement market definitions and operations and specify details of accounting and settlement procedures. Market participants within these areas must file substantial technical and financial paperwork with the ISO, have their generation assets tested and approved to meet the technical engineering standards required to implement North American Electric Reliability Corporation (NERC) reliability standards, and demonstrate that they are financially sound. In formal markets, individual generator owners, merchant plants, independent power producers (IPPs), and demand-side resources bid to provide energy and ancillary services based on financial incentives and profit motive. These productions do not carry the traditional "obligation to serve" end-use demand in a particular service territory.

\section{Non-Market Traditional Scheduling Areas}

Traditional Scheduling Areas (non-market areas) consist of regulated utilities that have maintained their historical vertically integrated organization, planning, and operating models, i.e. Southeast Reliability Corporation (SERC) and the Florida Reliability Coordinating Council (FRCC). They are regulated by state public utility regulatory authorities as well as by FERC and have an obligation to serve the load within their defined territory unlike formal markets. Operators schedule energy and power transactions, and coordinate operations as well as system expansion planning to maintain grid reliability following the same NERC criteria. Entities may engage in bi-lateral trades with other adjacent utilities in order to meet their obligations. No formal markets exist in these traditional scheduling areas.

\section{Mixed Business Model}

The mixed business model is characteristic of NERC Regional Entities, which contain a combination of market and non-market areas within their boundaries. The WECC represents a mixed model due to the presence of formal markets under the California Independent System Operator (CAISO) and Alberta Electric System Operator (AESO) with the balance governed by a system very much like that in the southeast U.S. The presence of formal markets in the WECC, particularly the CAISO market, presents opportunities and obligations to generation asset owners whose assets exist outside of the CAISO borders. They are still used to meet load-serving obligation within their Balancing Areas, but they can also bid their assets into the California market. There are also informal bilateral wholesale markets in the WECC. Having a mixed business model presents the opportunity for more value streams than in solely a traditional scheduling or formal market area.

\section{Significance of Real-Time Markets}

As the competitive business model continues to expand into or influence non-market areas, change will continue to take place. The variety of physical, operational and market organization structures makes it difficult to generalize about the methods, procedures, and effects of hydro generation participation now and in the future. The same can be said for the integrating large amounts of variable generation capacity into the existing capacity mix. However, one ameliorating factor tending to simplify this otherwise complex situation is that fundamental economic behavior driven by cost minimization provides a common foundation that underlies the behavior of participants in both market and non-market segments of the industry. Formal 
electricity markets sharpen the profit incentives of all participants, including those that are subject to some, or even considerable regulation. The role of formal markets is likely to grow in the WECC region; marketers of western hydroelectric power can benefit by responding to these developments.

One set of questions concerns both how and how well models can represent traditional costminimization objectives as well as new market opportunities for increasingly monetizing the value of the hydroelectric assets that it markets. Hydropower resources across the United States contribute significantly to the reliability of the grid in terms of energy, capacity, and ancillary services. Hydro plants have been used to provide spinning and non-spinning reserve, replacement reserve, and regulation or load following. These services are not fully recognized in the current non-market areas due to the hourly scheduling structure. In addition to this study, the DOE is now funding a project led by Argonne National Laboratory. The new project is entitled Detailed Analysis to Demonstrate the Value of Advanced Pumped Storage Hydropower in the U.S. and will focus on modeling finer time scales, on the order of seconds, to capture the value streams available for ancillary services provided by pumped storage facilities that are not being captured in the current market structure. It should be noted that many conventional hydropower plants currently provide the same fast-ramping ancillary services that are offered by pumped storage facilities.

\section{Role of Generation and Contribution of Hydro}

The primary motive of generation in the electric power system is to serve the load by producing electric energy. The power system must be balanced in near real-time so that production and consumption of real and reactive power match. Maintaining this balance along with reliable and low-cost operations requires operational scheduling, planning, and coordination. In addition to providing generation, operators rely on other performance capabilities and services being provided through participating in either the energy market or separately bidding into ancillary services markets. Sometimes a quick response time is critical for these services in order to maintain stability in the real-time balancing. Table 2-1 below outlines the various functions and services generators can provide and the response time for which these services are needed [14].

Table 2-1 Functions and services provided by generation [14]

\begin{tabular}{|l|l|l|}
\hline \multicolumn{1}{|c|}{ Functions and Services } & \multicolumn{1}{|c|}{ Short Description } & \multicolumn{1}{c|}{ Time Frame } \\
\hline $\begin{array}{l}\text { Base load units (non- } \\
\text { regulating) }\end{array}$ & $\begin{array}{l}\text { Energy (firm) scheduled well in advance, } \\
\text { based on availability, price, and long- } \\
\text { term contracts }\end{array}$ & $\begin{array}{l}\text { Long-term } \\
\text { commitments }\end{array}$ \\
\hline $\begin{array}{l}\text { Committed units (usually with } \\
\text { regulation capacity) }\end{array}$ & $\begin{array}{l}\text { Energy (firm) scheduled based on } \\
\text { availability and price to meet block load, } \\
\text { with Loss of Load Expectation and load } \\
\text { forecasts considered }\end{array}$ & $\begin{array}{l}\text { Day before plan, hourly } \\
\text { resolution }\end{array}$ \\
\hline $\begin{array}{l}\text { Load-following or energy- } \\
\text { balancing units }\end{array}$ & $\begin{array}{l}\text { Energy ramping to follow the load, met } \\
\text { by adjusting generation scheduled and the } \\
\text { imbalance energy market }\end{array}$ & $\begin{array}{l}\text { Hourly plan with 5- to } \\
\mathbf{1 0 - m i n u t e ~ r e s o l u t i o n ~}\end{array}$ \\
\hline $\begin{array}{l}\text { Frequency regulation } \\
\text { (regulating reserves) }\end{array}$ & $\begin{array}{l}\text { Service provides capacity based on a } \\
\text { signal from dispatcher, with Automatic } \\
\text { Generation Control to meet CPS1 and } \\
\text { CPS2 and no net energy }\end{array}$ & $\begin{array}{l}\text { Every few minutes, minute-to- } \\
\text { minute resolution }\end{array}$ \\
\hline
\end{tabular}




\begin{tabular}{|c|c|c|}
\hline $\begin{array}{l}\text { Reactive supply and voltage } \\
\text { control }\end{array}$ & $\begin{array}{l}\text { Service of injecting or absorbing of } \\
\text { reactive power to control local } \\
\text { transmission voltages (usually provided } \\
\text { with energy) }\end{array}$ & $\begin{array}{l}\text { Continuous with response in } \\
\text { seconds }\end{array}$ \\
\hline Spinning operating reserve & $\begin{array}{l}\text { Service to provide energy in response to } \\
\text { contingencies and frequency deviations }\end{array}$ & $\begin{array}{l}\text { Begin within } \mathbf{1 0} \text { sec full power } \\
\text { in } \mathbf{1 0} \text { min }\end{array}$ \\
\hline $\begin{array}{l}\text { Non-spinning operating } \\
\text { reserves }\end{array}$ & $\begin{array}{l}\text { Service to provide load/generation } \\
\text { balance in response to contingencies, not } \\
\text { frequency response }\end{array}$ & Respond within 10 minutes \\
\hline Replacement reserves & $\begin{array}{l}\text { Service to restore contingency capacity to } \\
\text { prepare for the next generation or } \\
\text { transmission contingency }\end{array}$ & $\begin{array}{l}\text { Respond within } 60 \text { minutes, run } \\
\text { up to } 2 \text { hours }\end{array}$ \\
\hline System black start & $\begin{array}{l}\text { Service to restore all or a major portion } \\
\text { of the power system without outside } \\
\text { energy after a total collapse }\end{array}$ & As required \\
\hline Firm capacity & $\begin{array}{l}\text { Service to provide an agreed upon } \\
\text { amount of dependable capacity to cover } \\
\text { peak load and contingency situations to } \\
\text { assure resource adequacy and system } \\
\text { reliability }\end{array}$ & As required \\
\hline
\end{tabular}

Hydroelectric resources operate in all of the major electricity operating regions in North America. They contribute significantly to the reliability of the grid in terms of energy, capacity, and ancillary services as outlined in Table 2-1. The historical and current contribution of hydro facilities to electricity generation is greatest in the western U.S. where large federal, multipurpose projects, mostly conventional hydro, were built during the early- to mid-20th century.

Hydro provides the largest percentage of total net generation in the WECC among all regions. Among the market areas, the California ISO has historically had the largest contribution to generation by hydroelectric facilities. These facilities show that approximately half have been used in the past to provide spinning and non-spinning reserves, replacement reserves and regulation or load following. More than half have been used to provide black start, and most have provided voltage support in the past. This historical experience demonstrates that conventional hydro facilities have the potential to provide increased ancillary services in addition to energy; these operating modes offer new revenue opportunities for plant operators. Pumped storage hydro resources, while either energy-limited or a net load, can still provide valuable capacity and ancillary services to the grid. Pumped storage facilities actively participate in ancillary services markets where those markets are available. With increased variable generation (solar and wind), these services are likely to become more critical.

\section{Operational Constraints}

When considering hydropower plant scheduling and operation to provide the grid services discussed in the previous section, operators must also typically abide by a set of operational (including environmental) constraints. These constraints can complicate attempts to maximize profits from grid services, and therefore an understanding of how these constraints limit the participation of hydro is needed. Examples of the restrictions on hydro include: "(1) limitations in maximum and minimum water output which can vary by season, time of day, abnormal events such as flooding and drought, and environmental and regulatory policies; (2) facility restrictions 
such as the vibration of equipment as turbines ramp up and ramp down, optimizing efficiency to ensure maximum return of investment, and minimum and maximum generator production limits; and (3) electrical considerations such as over voltage and under voltage conditions and market prices that ensure that the hydro facility is still profitable" [13].

The operational constraints can be numerous. The challenge is to identify which of these impact the grid services that a hydro facility can provide. The constraints can be categorized in three groups: (1) water, (2) power system, and (3) facility. Within these categories, environmental, market, regulatory, electrical, operating, and equipment limitations can be captured. Figure 2-2 below outlines these categories. For the purposes of operational limits, the water constraints will be outlined in more detail.

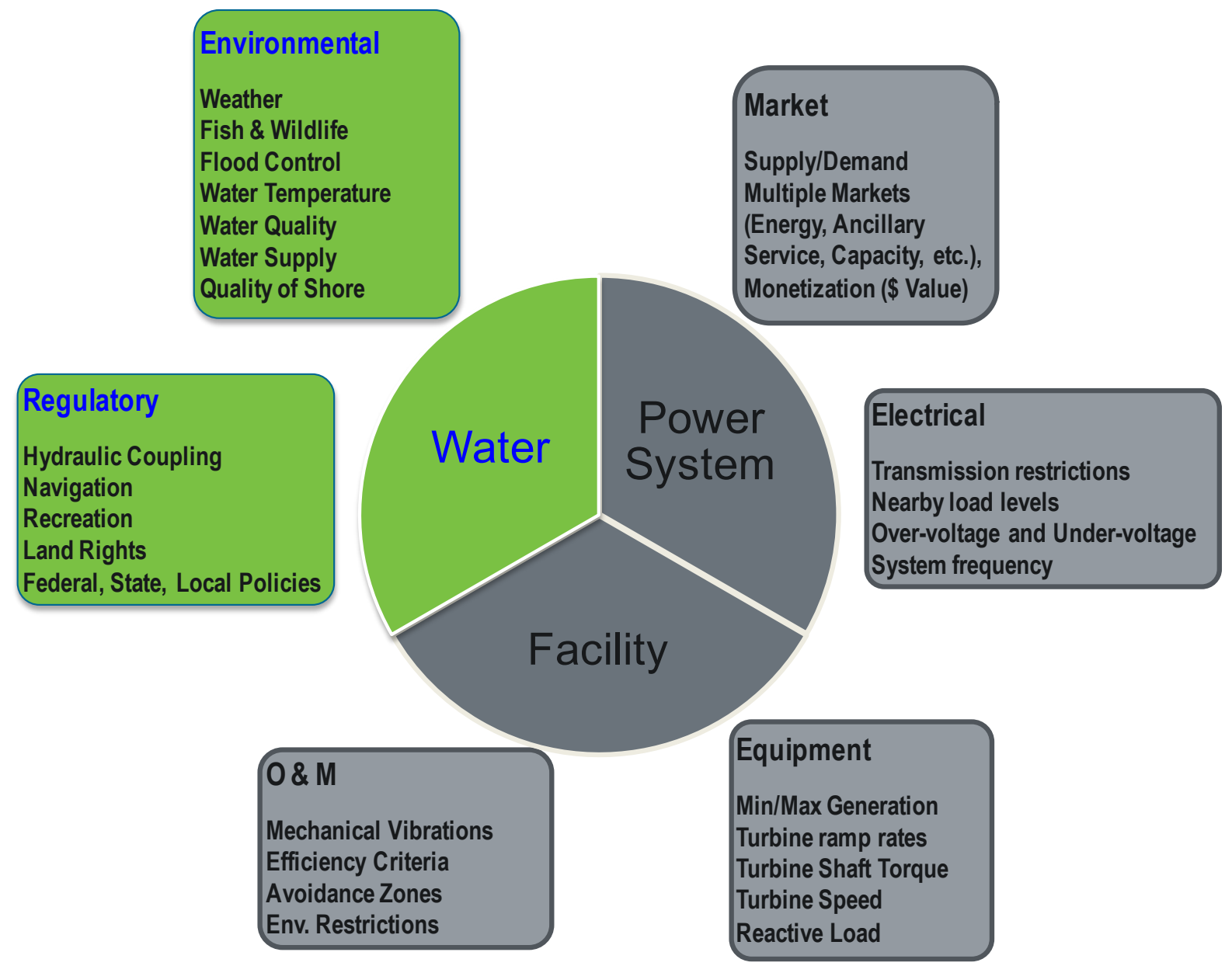

Figure 2-2 Typical operational constraints on hydropower facilities

Constraints related to water include the environmental and regulatory issues associated with water availability and limits to flow and pressure head. As a plant operator, the environmental issues that may have to be considered include protections for fish and wildlife, flood control, weather, water temperature, water quality and supply, and shoreline protection. In addition, regulatory considerations include navigation, recreation, land rights, hydraulic coupling, and any additional federal state or local policies that exist. These factors may limit the amount of generation as well as ancillary services that can be provided by a plant. For more details on the 
specific water constraints experienced at hydro facilities, please refer to the Oak Ridge National Laboratory report from 2012 entitled Case Study: Hydropower Constraints on OSAGE and TAUM SAUK Facilities [13].

\section{Pumped Storage Technologies and Cost [3],[9]}

Pumped storage development started about 120 years ago. The first use of pumped storage occurred in the 1890s in Italy and Switzerland. In 1907, the first storage set in Germany was commissioned. In these early days the typical pumped storage plant consisted of two sets of machines, a motor driving a pump with a separate turbine in the plant turning a generator. Later on, the sets where combined into a ternary unit which consisted of a motor generator, a pump and a turbine, all connected on one shaft. In the 1930s, reversible pumped storage units were developed. These reversible units could operate as both turbine-generators in one rotational direction and in the reverse rotational direction as electric motor driven pumps.

The first use of pumped-storage units in the United States was in 1930 by the Connecticut Electric and Power Company, using a large reservoir located near New Milford, Connecticut, pumping water from the Houstatonic River to the storage reservoir 230 feet above. Another technological milestone was set with the development and delivery of the first large reversible pump turbine in 1937, for the Pedreira project in Brazil. Pumped storage units were originally designed to shift excess energy generation from thermal power plants available during the night to peaking power generation during the times of heavy use during the day, see Figure 2-3.

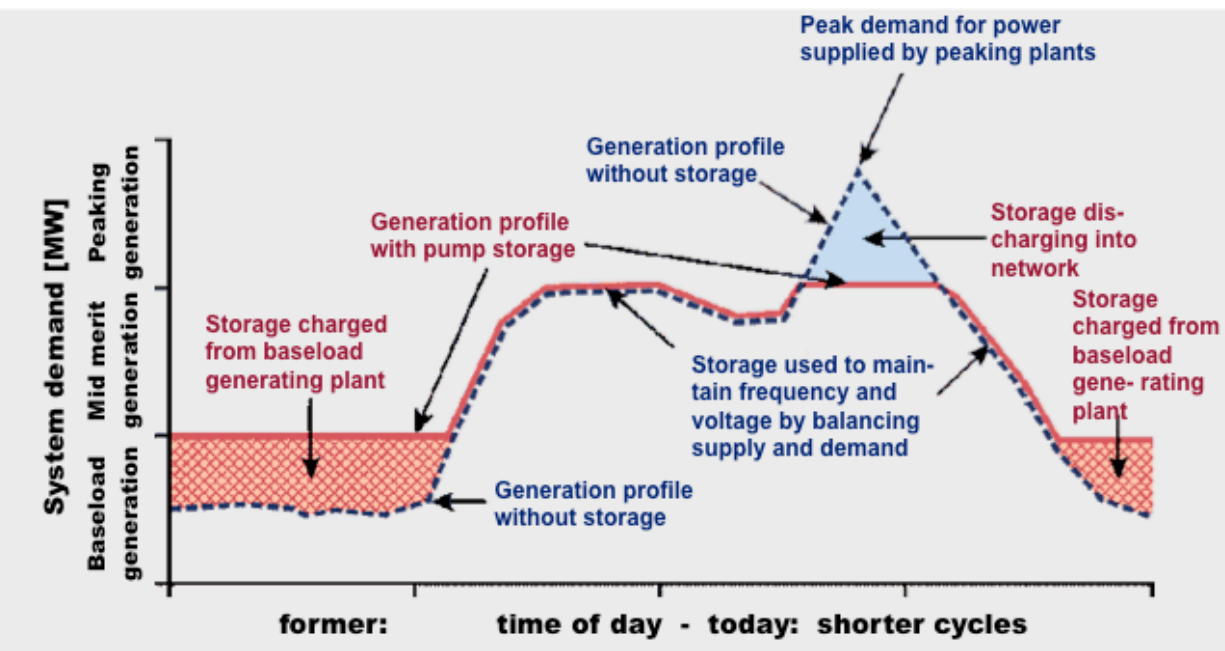

Figure 2-3 Pump Storage use in night to day energy shifting

With the advent of nuclear power generation, a surge in pump storage plant building took place in the time period beginning in the 1960s and continued through the 1970s. Most plants built were designed for Grid Power Control Energy Management service and had operational times for start up, change over and so forth in the order of 10 minutes or more as shown in Figure 2-4. 


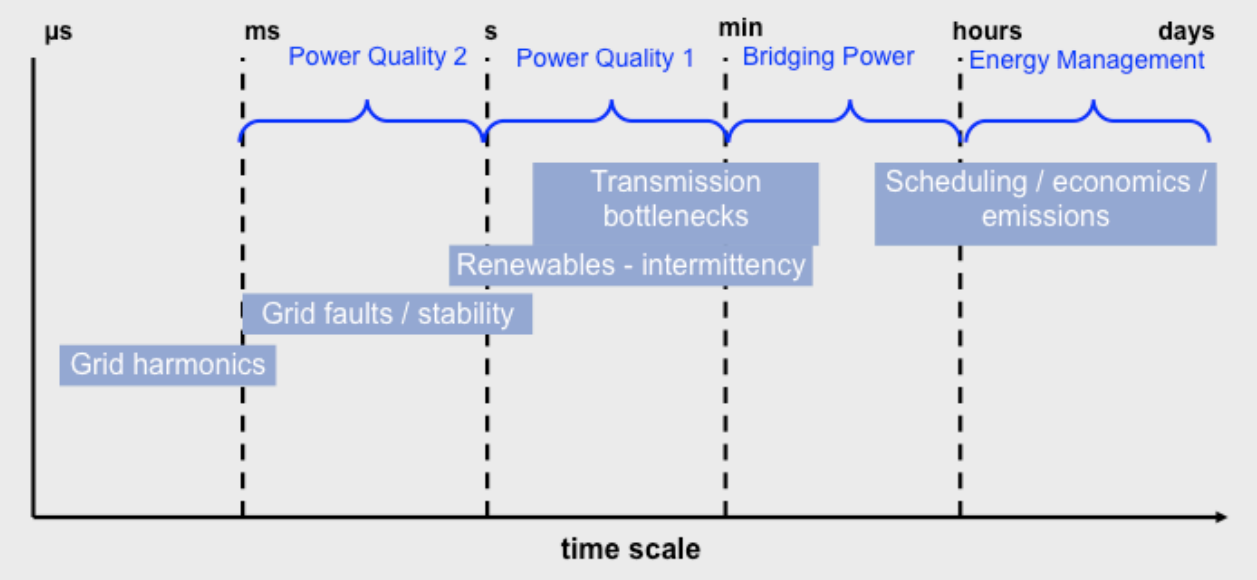

Figure 2-4 Grid power control issue and energy management timeframes

Using technologies of the day, turnaround efficiencies of those plants were typically in the 70$75 \%$ range. The development of these kinds of machines with respect to large capacities started in the 70s, and peaked with the Units at Bath County, still the largest pumped storage plant in the world. As shown in Figure 2-5, after 2000 there was significant anticipation in Europe for growth in wind and solar power generation.

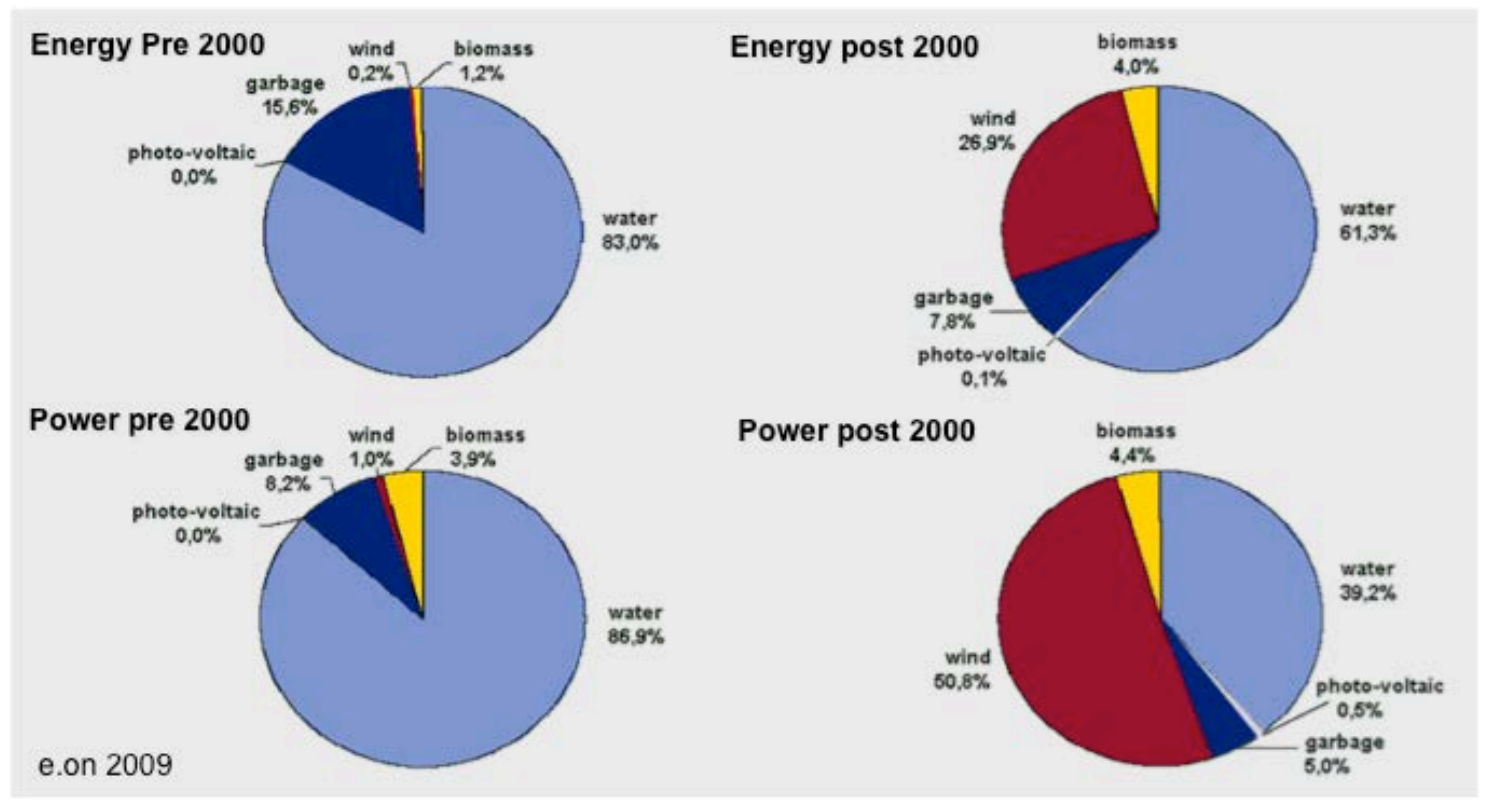

Figure 2-5 Change in renewable energy generation in Germany

The intermittency and variability of the renewable energy generation and the need for more responsive pump storage plants stimulated future owners of such plants to work with equipment designers to develop designs with (a) wider load ranges in the turbine cycle of operation, (b) enhanced design robustness to support many more stops and starts per day, (c) faster start up and mode of operation changeover times, and (d) the ability for regulation in pump cycle of operation. Out of the requirements for operation, a new family of Advanced Pumped Storage 
units and plants were and continue to be developed which provide higher turnaround efficiencies, and more robust and flexible equipment.

\section{Pumped Storage Equipment Overview}

Pumped storage equipment can be classified into several types: separate pump and turbine units, reversible units; and ternary units. The pumped storage equipment described above can be used for various head and power ranges as shown in Figure 2-6.

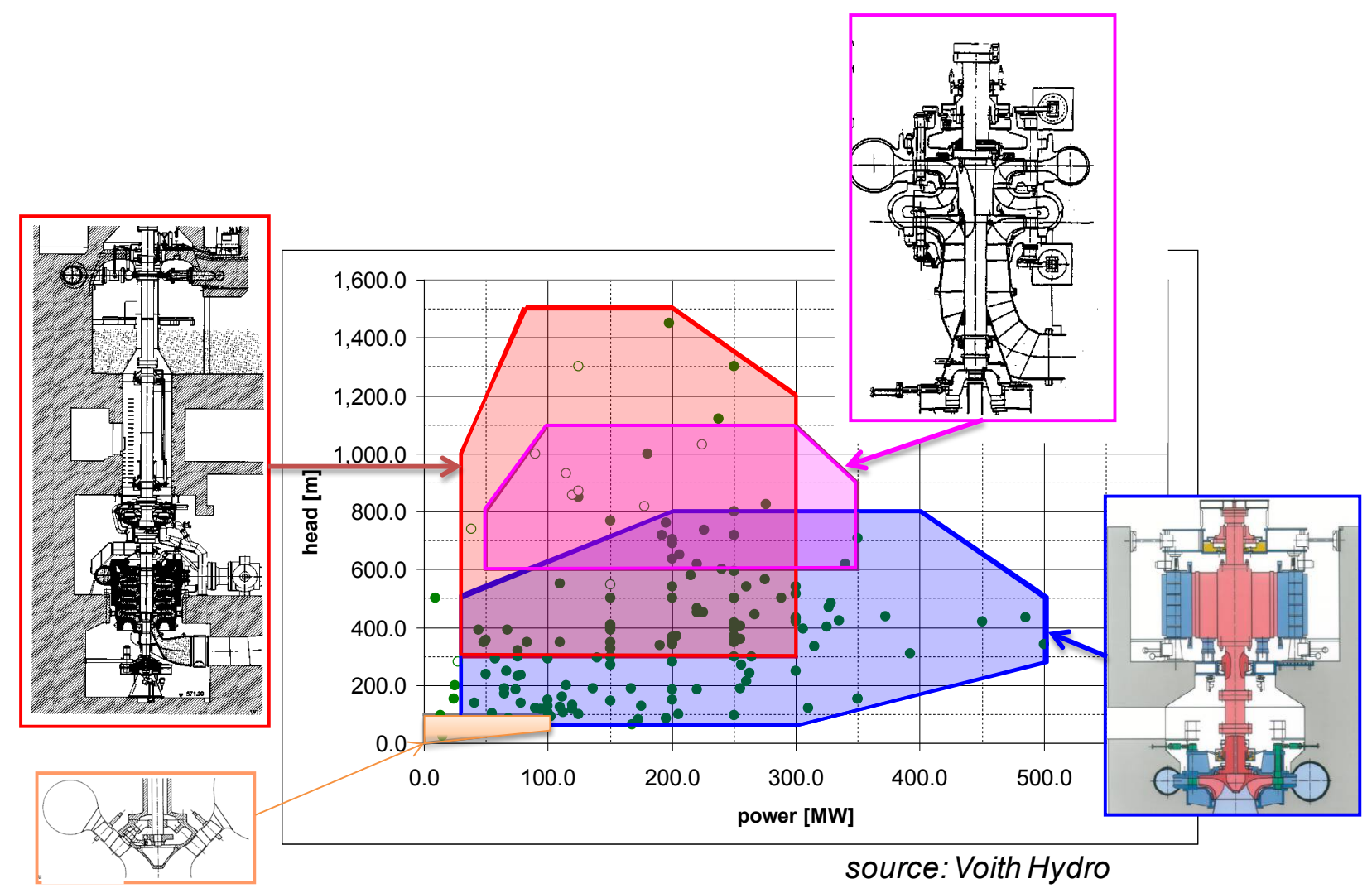

Figure 2-6 Head and power ranges of modern advanced pumped storage equipment

Reversible Pump Turbine units can be found in several configurations: 1) fixed speed single stage reversible; 2) fixed speed multi stage reversible; 3 ) variable speed single stage reversible; 4) fixed speed Ternary units with separate pump and turbine on a single shaft; 5) fixed speed adjustable blade Deriaz units; and 6) fixed speed axial units. Single stage synchronous fixed speed reversible units can be operated in either pump or turbine mode depending on direction of rotation. Multistage reversible units exist which increase the head of application. Power control in the turbine direction of operation occurs usually through opening and closing of wicket gates. With fixed speed motor-generators, power in the pump direction of rotation is not controllable. Reversible units can also be operated with variable speed motor-generators and then are called variable speed pumped turbines. The use of variable speed allows for a wider operational range of turbine power and for a typically $30 \%$ variation in power regulation in the pump cycle of operation.

A special class of reversible pump turbines is usable at low head. This is accomplished by adjustable position turbine blades in the rotating turbine/impeller. These so-called Deriaz pump 
turbines operate at fixed speed. They can be operated at various power levels when pumping as a consequence of the adjustable blade position. Modern advanced technology pumped storage plants are operating which have turnaround plant cycle efficiencies up to $82 \%$.

Ternary pump turbine units have a separate generator, turbine and pump on a single shaft and are operated in a single rotational direction. Ternary units can have turbines that are either impulse

- Conventional reversible unit

- Fast and frequent response reversible unit

- Conventional units in long or hydraulic short circuit operation

- Variable speed reversible unit

- Ternary unit arrangement

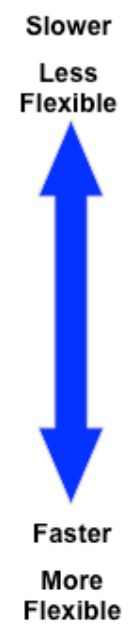

or Francis type, and pump sets on Ternary units are usually multi stage. Advanced ternary units also can have a hydraulic torque converter coupling connecting the pump to the shaft system. Not shown on this figure are special infrequently-used pumped storage equipment applications such as reversible axial flow bulb pump turbines and reversible Kaplan style pump turbines which have been used at low heads and powers for special applications. Separate synchronous speed pumps and turbines have also applied at some plants to provide energy storage services.

Figure 2-7 Relative grid service capability of advanced pumped storage units

Pumped storage equipment can also be characterized based on their regulation responsiveness to grid needs (Figure 2-7). Pump Turbine waterways including penstocks, surge chambers, and discharge tunnels need to be designed in accordance to the speed of response desired from the plant. Modern conventional reversible pumped storage units are typically at the slower and less flexible range. Advanced conventional reversible units have been built for very fast and frequent start up, mode change and fast ramping operation. Multiple units in the same plant or in nearby plants can be operated together in a so called asynchronous balanced (hydraulic short circuit) mode to provide increased flexibility from the plant to support grid needs (i.e. a unit operating in the pump mode while an adjacent unit operates in the turbine mode to provide fast and flexible absorption of power from the plant should it make economic sense based on ancillary service payments). Variable speed Pump Turbine units provide even more flexible responsiveness to grid needs in many cases. They can operate at lower power percentage of their rated capacity than conventional reversible machines and can provide power regulation when operating in the pump mode. For applications providing very fast and flexible operation, Ternary Pump Turbine units are at the most flexible and fastest response range. Figure 2-8 shows typical mode changeover times from/to full load pump or full load turbine operation and startup times to full load achievable from advanced pumped turbines operating today. Figure 2-9 shows timescales in which the advanced pumped storage units operate to provide grid services in Europe today. 


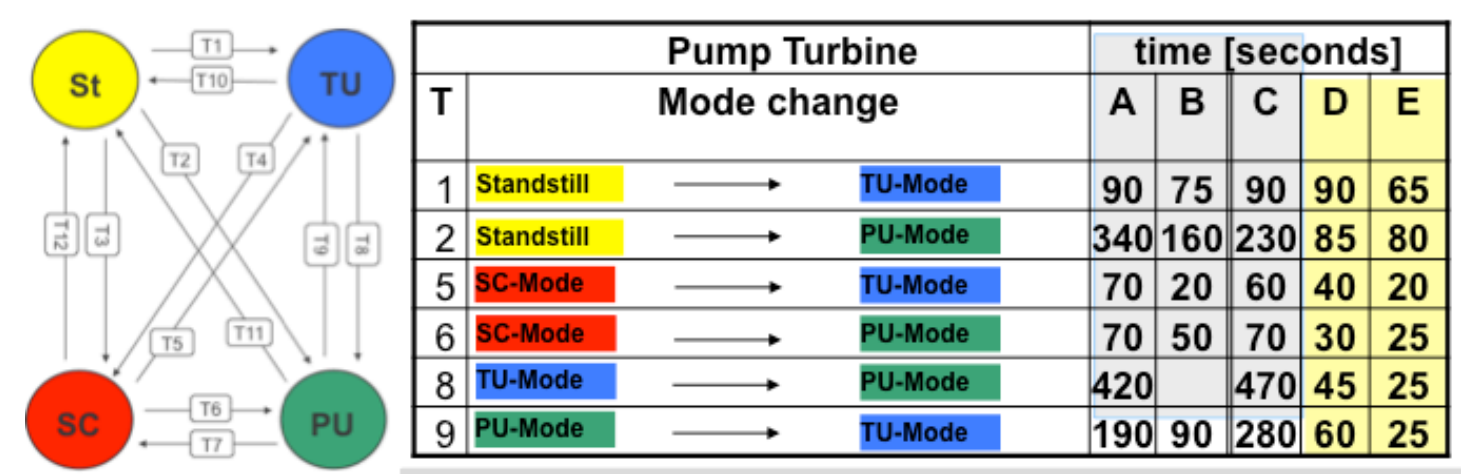

Reversible PT

A - advanced conventional (2012)

B - extra fast response conventional

C - VarSpeed,

Ternary set

D - with hydraulic torque converter + hydr. short circuit, horiz, with Francis Turbine

E - same as E but vertical with Pelton Turbine

Figure 2-8 Mode change times for various advanced PS concepts

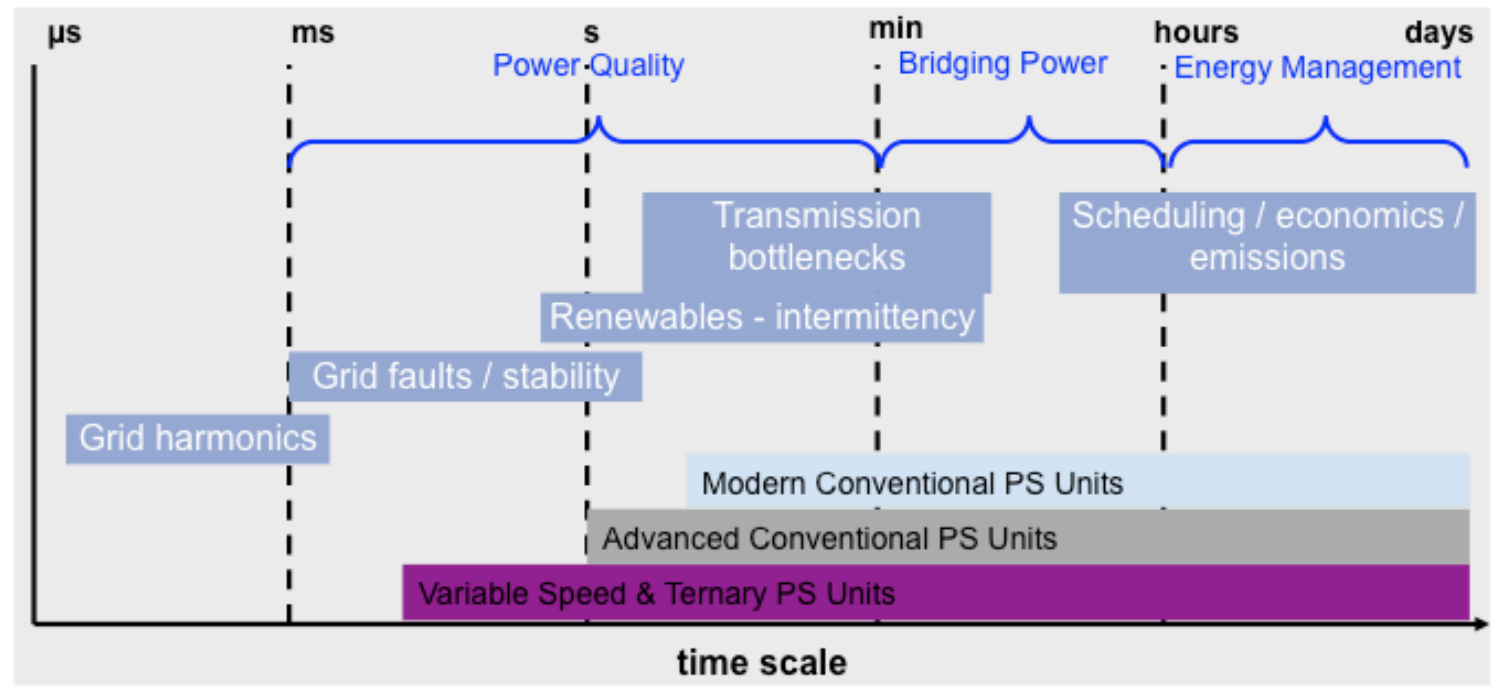

Figure 2-9 Timeframes for modern advanced PS unit regulation

Specific technologies are summarized in more detail in the HydroVision 2012 paper, $A$ Comparison of Advanced Pumped Storage Equipment Drivers in the U.S. and Europe [3].

\section{Cost of Pumped Storage Development}

To determine the cost of pumped storage assets in 2010, a database of current and projected cost elements for alternative pumped storage and options was developed. Specifically, the reference database provides information on current and projected costs for constructing new projects, and increasing efficiency and capacity at pumped storage, and non-powered facilities, including incremental expansions at existing facilities, new pumped storage hydropower at greenfield sites, and control system and optimization improvements.

The work expands on DOE and EPRI research efforts conducted during the 1990s and early 2000s by capturing actual, available costs for various project elements and comparing these to 
the projected costs developed in these previous efforts. Cost data are obtained for the logical grouping of project elements, escalated, and applied to various hydropower applications including greenfield projects and upgrades/improvements at existing facilities.

Updating and escalating techniques include procedures developed by the U.S. Army Corps of Engineers and U.S. Bureau of Reclamation, recent studies and hydropower equipment vendor/contractor opinions, published labor and material indices, and recently completed projects and operations costs, as available. This assures the cost data are comparable for hydropower applications. For more detailed information please see the plant cost element report Quantifying the Value of Hydropower in the Electric Grid: Plant Cost Elements [9].

This study particularly focuses on pumped storage construction costs. Table 2-2 shows the predicted $\$ / \mathrm{kW}$ for recently constructed and planned pumped storage (single speed and variable speed) in estimated escalated 2010 costs for the United States.

Table 2-2 Pumped Storage Construction Cost Data [9]

\begin{tabular}{|c|c|c|c|c|c|c|c|c|}
\hline Project & $\begin{array}{c}\text { Single vs. } \\
\text { Variable } \\
\text { Speed }\end{array}$ & $\begin{array}{c}\text { Stated } \\
\text { Capacity } \\
\text { (MW) }\end{array}$ & $\begin{array}{c}\text { Est. Cost } \\
(\$ / k W)\end{array}$ & $\begin{array}{c}\text { Year of } \\
\text { Cost }\end{array}$ & $\begin{array}{c}\text { Escalation } \\
\text { Factor to } \\
2010\end{array}$ & $\begin{array}{c}\text { Est. Cost } \\
2010(\$ / k W)\end{array}$ & $\begin{array}{c}\text { Max. } \\
\text { Gross } \\
\text { Head (ft) }\end{array}$ & $\begin{array}{c}\text { Ratio } \\
\text { (\$/kW/Head) }\end{array}$ \\
\hline \multicolumn{9}{|c|}{ Projects Constructed in U.S. 1960-1988 (Do not include AFUDC or transmission interconnection costs) } \\
\hline Taum Sauk & $\mathrm{SS}$ & 350 & 462 & 1988 & 2.6 & 1,201 & 267 & 4.50 \\
\hline Yards Creek & $\mathrm{SS}$ & 330 & 332 & 1988 & 2.6 & 863 & 760 & 1.14 \\
\hline Muddy Run & SS & 855 & 322 & 1988 & 2.6 & 837 & 127 & 6.62 \\
\hline Cabin Creek & SS & 280 & 404 & 1988 & 2.6 & 1,050 & 373 & 2.81 \\
\hline Seneca & $\mathrm{SS}$ & 380 & 505 & 1988 & 2.6 & 1,313 & 165 & 7.96 \\
\hline Northfield & $\mathrm{SS}$ & 1,000 & 288 & 1988 & 2.6 & 749 & 252 & 2.97 \\
\hline Blenheim-Gilboa & $\mathrm{SS}$ & 1,030 & 321 & 1988 & 2.6 & 835 & 1,143 & 0.73 \\
\hline Ludington & $\mathrm{SS}$ & 1,890 & 376 & 1988 & 2.6 & 978 & 364 & 2.69 \\
\hline Jocassee & $\mathrm{SS}$ & 628 & 422 & 1988 & 2.6 & 1,097 & 335 & 3.28 \\
\hline Bear Swamp & $\mathrm{SS}$ & 540 & 507 & 1988 & 2.6 & 1,318 & 235 & 5.62 \\
\hline Raccoon Mtn. & SS & 1,530 & 296 & 1988 & 2.6 & 770 & 1,042 & 0.74 \\
\hline Fairfield & $\mathrm{SS}$ & 512 & 586 & 1988 & 2.6 & 1,524 & 169 & 9.02 \\
\hline Helms & $\mathrm{SS}$ & 1,050 & 616 & 1988 & 2.6 & 1,602 & 1,745 & 0.92 \\
\hline Bath County & SS & 2,100 & 639 & 1988 & 2.6 & 1,661 & 1,260 & 1.32 \\
\hline \multicolumn{9}{|c|}{ U.S. Projects Various Stage of Study Development Not Constructed } \\
\hline Eagle Mtn. & SS \& VS & 1,300 & 1,062 & 2010 & 1 & 1,062 & 1,572 & 0.68 \\
\hline Mokelumne & $\mathrm{SS}$ & 1,200 & 2,342 & 2009 & 1.05 & 2,342 & 1,863 & 1.26 \\
\hline Red Mtn Bar & $\mathrm{SS}$ & 900 & 1,851 & 2008 & 1.1 & 1,999 & 830 & 2.41 \\
\hline $\begin{array}{l}\text { Mulqueeney } \\
\text { Ranch }\end{array}$ & $\mathrm{SS}$ & 280 & 1,500 & 2009 & 1.05 & 1,500 & 700 & 2.14 \\
\hline Iowa Hill & VS & 400 & 2,000 & 2010 & 1 & 2,000 & 1,223 & 1.64 \\
\hline Red Mtn Bar & VS & 1,000 & 2,103 & 2008 & 1.1 & 2,342 & 830 & 2.82 \\
\hline
\end{tabular}


In general, building a new large pumped storage plant costs between $\$ 1000-\$ 2500 / \mathrm{kW}$. Another important cost to consider is that of upgrading an existing pumped storage plant to variable speed. This costs is significantly less, $\$ 100-\$ 150 / \mathrm{kW}$, and requires less time. Complete results can be found in the cost report, Quantifying the Value of Hydropower in the Electric Grid: Plant Cost Elements [9].

\section{Modeling Grid Services}

In order to capture the value of hydropower grid services in the future, a model of WECC was developed using UPLAN. In the past, electric capacity expansion models and resource plans have often taken ancillary services for granted and therefore discount the potential value of hydropower resources to the grid. The aim of this study was to account for these previously overlooked services. Significant work was done to update assumptions of plant parameters based on industry feedback as well as efforts to cooptimize energy and ancillary services. The modeling analysis provided an assessment of the value derived from hydropower resources in the provision of the following power system services:

1. Energy to meet demand, including the ability to arbitrage energy prices by utilizing hydro resources with storage capability to store energy at low prices and deliver energy during high-price periods.

2. Regulating reserve capacity to provide frequency regulation.

3. Spinning and non-spinning reserve capacity to respond to system disturbances and restore system frequency.

The modeling was done using an hourly economic dispatch model to simulate the WECC and quantify the existing and potential value of hydropower resources to the grid in 2020. The model looked at both energy and ancillary services provided by hydro plants as well as the effects of adding new pumped storage plants. The approach for electric system modeling first estimates the capacity expansion and generation mix, and then runs a production simulation with economic dispatch. It considers details of expected demand, load profiles, commodity prices, emissions costs, available transmission, and related expansion plans, as well as future renewable portfolio requirements. Results include plant-by-plant energy and ancillary service contributions, unit cycling, start/stops, emissions, and profitability. Sub-hourly modeling differentiates the value of generation functions and services such as energy, regulation, spinning reserve, and non-spinning reserve. The valuation of hydro's contribution to these components is determined from an hourly-resolution security-constrained unit commitment and economic dispatch model.

The production cost simulations performed represent the movement of load and generation from one hour to the next by assuming average demand and supply across the hour. This means that the analysis can effectively represent the value of hydro providing energy, as well as the contribution to the reserve capacity required for providing ancillary services that are needed within the hour (regulating reserve, spin/non-spin reserve). The hourly model does not, however, capture the benefits of the deployment of reserves within the hour. To the extent that the use of fast-ramping hydro units for following within-hour load movements allows other generation resources to operate at more efficient output levels, hydro resources provide additional value to the power system that is not captured with the hourly analysis conducted. A separate generation capacity expansion model was used to define the generation mix with different energy futures. More than 20 different scenarios were run in the model to help provide information about the 
effect of increased renewables (expansion from 15\%-33\% to meet federal renewable portfolio standards), $\mathrm{CO}_{2}$ prices, natural gas prices, and upgraded plants on the overall value to hydropower. These scenarios, shown in Table 2-3, intend to provide insight into energy dispatch and services that a future electricity market structure may need to capture. Selected results from the modeling that speak to the ways to increase the value of hydropower are included below. Complete results can be found in the modeling report, Quantifying the Value of Hydropower in the Electric Grid: Modeling Results for Future Scenarios [10].

Table 2-3 Energy futures and modeling scenarios

\begin{tabular}{|c|c|c|c|c|}
\hline Scenario & $\begin{array}{l}\text { Hydro } \\
\text { Conditions }\end{array}$ & $\begin{array}{l}\mathrm{CO}_{2} \text { Emission } \\
\text { Costs }\end{array}$ & Demand & Notes \\
\hline Base-Wet & Wet & None & Average & NESSIE Generation, Renewable Expansion \\
\hline TEPPC & Normal & None & Average & TEPPC Generation, Renewable Expansion \\
\hline Base-OneNewPS & Normal & None & Average & NESSIE Generation, Renewable Expansion, one new PS plant \\
\hline Base-HighRegReq & Normal & None & Average & $\begin{array}{l}\text { NESSIE Generation, Renewable Expansion, increased regulation } \\
\text { reserve req. }\end{array}$ \\
\hline Base-PumpUpgrade & Normal & None & Average & $\begin{array}{l}\text { NESSIE Generation, Renewable Expansion, variable speed pump } \\
\text { added at one plant }\end{array}$ \\
\hline Base-GenUpgrade & Normal & None & Average & $\begin{array}{l}\text { NESSIE Generation, Renewable Expansion, new technology at } \\
\text { one PS plant }\end{array}$ \\
\hline Base & Normal & None & Average & NESSIE Generation, Renewable Expansion \\
\hline Base-LowRegReq & Normal & None & Average & $\begin{array}{l}\text { NESSIE Generation, Renewable Expansion, reduced regulation } \\
\text { reserve req. }\end{array}$ \\
\hline Base-TransRelax & Normal & None & Average & NESSIE Generation, Renewable Expansion, relaxed transmission \\
\hline Base-Dry & Dry & None & Average & NESSIE Generation, Renewable Expansion \\
\hline Base-NoHydroAS & Normal & None & Average & $\begin{array}{l}\text { NESSIE Generation, Renewable Expansion, hydro cannot } \\
\text { supply ancillary services }\end{array}$ \\
\hline Extreme-Dry & Dry & $\$ 0.02 / \mathrm{lb}$ & High & NESSIE Generation/Renewable Expansion \\
\hline Base-FiveNewPS-Trans Relax & Normal & None & Average & $\begin{array}{l}\text { NESSIE Generation, Renewable Expansion, five new PS plants, } \\
\text { relaxed transmission }\end{array}$ \\
\hline Carbon-Dry & Dry & $\$ 0.02 / \mathrm{lb}$ & Average & NESSIE Generation, Renewable Expansion \\
\hline Extreme-Trans Relax & Normal & $\$ 0.02 / 1 \mathrm{~b}$ & High & NESSIE Generation, Renewable Expansion, relaxed transmission \\
\hline Base-FiveNewPS & Normal & None & Average & NESSIE Generation, Renewable Expansion, five new PS plants \\
\hline Extreme & Normal & $\$ 0.02 / \mathrm{lb}$ & High & NESSIE Generation, Renewable Expansion \\
\hline Extreme-OneNewPS & Normal & $\$ 0.02 / \mathrm{lb}$ & High & NESSIE Generation, Renewable Expansion, CA PS plant \\
\hline Carbon-OneNewPS & Normal & $\$ 0.02 / \mathrm{lb}$ & Average & NESSIE Generation, Renewable Expansion, one new PS plant \\
\hline Carbon & Normal & $\$ 0.02 / \mathrm{lb}$ & Average & NESSIE Generation, Renewable Expansion \\
\hline Extreme-Wet & Wet & $\$ 0.02 / \mathrm{lb}$ & High & NESSIE Generation, Renewable Expansion \\
\hline Carbon-Trans Relax & Normal & $\$ 0.02 / \mathrm{lb}$ & Average & NESSIE Generation, Renewable Expansion, relaxed transmission \\
\hline Carbon-Wet & Wet & $\$ 0.02 / \mathrm{lb}$ & Average & NESSIE Generation, Renewable Expansion \\
\hline
\end{tabular}





\section{WAYS TO INCREASE THE VALUE OF HYDROPOWER}

Finding the value of hydropower in the electricity grid is very application-and case-specific. Value depends not only on plant size, location, and technology, but also other competing resources and the infrastructure to deliver energy and ancillary services. Efforts during this study have addressed operational, market, business, and policy considerations in valuing hydropower. Synthesizing these results, ten different ways have been identified that may better recognize, increase and capture the value of hydropower resources to the grid.

This section of the report will outline each of the potential ways and describe what value can be associated. They include individual plant as well as broader system-wide opportunities. The value is not quantified in every case. Only six of the ten ways were monetized through the case studies and system modeling in this project. To facilitate the discussion and to compare and contrast, these ten ways are divided into in three different categories: (1) operations, (2) technology, and (3) markets.

\section{Operational Improvements}

The first category of ways to increase or better capture the existing value of hydropower resources is in improvements to operations. Within operations, there are three potential ways to increase the value shown in Table 3-1:

Table 3-1 Operational ways to increase the value of hydropower

\begin{tabular}{|c|c|c|c|c|}
\hline No. & $\begin{array}{c}\text { Value } \\
\text { Streams }\end{array}$ & Ways to Increase Value & Beneficiaries & $\begin{array}{c}\text { Potential } \\
\text { Value }\end{array}$ \\
\hline 1 & $\begin{array}{c}\text { Operational } \\
\text { Improvements }\end{array}$ & $\begin{array}{l}\text { Identify and make plant efficiency } \\
\text { improvements by modifying hydro unit } \\
\text { operations while respecting river system } \\
\text { optimizations and constraints }\end{array}$ & Plant owner & $\begin{array}{l}1-3 \% \\
\text { revenue } \\
\text { increase }\end{array}$ \\
\hline 2 & $\begin{array}{c}\text { Operational } \\
\text { Improvements }\end{array}$ & $\begin{array}{l}\text { Use hydro more frequently to address } \\
\text { other generation and load variability in } \\
\text { the power system, providing flexible } \\
\text { reserves, reducing wear and tear on the } \\
\text { thermal fleet, while increasing the } \\
\text { efficiency of other generation }\end{array}$ & $\begin{array}{l}\text { System operator } \\
\text { or vertically } \\
\text { integrated utility }\end{array}$ & $\begin{array}{l}40 \% \\
\text { annual } \\
\text { revenue } \\
\text { increase PS }\end{array}$ \\
\hline 3 & $\begin{array}{c}\text { Operational } \\
\text { Improvements }\end{array}$ & $\begin{array}{l}\text { Recognize hydro for allowing more } \\
\text { generation diversity and options, thus } \\
\text { enhancing energy security and } \\
\text { maintaining power supply reliability in } \\
\text { the face of uncertainties in future energy } \\
\text { resources }\end{array}$ & $\begin{array}{l}\text { National } \\
\text { interest, general } \\
\text { public, and } \\
\text { NERC }\end{array}$ & $\begin{array}{l}\text { Not } \\
\text { quantified }\end{array}$ \\
\hline
\end{tabular}


In this study the first two operational improvements were monetized through case studies and modeling. The third operational improvement is more challenging to monetize. All three are discussed in detail below.

\section{Plant Optimization}

There is potential value in examining operational modifications that can optimize performance, if energy has a greater value than providing ancillary services. Case study analysis was performed on eight plants, including five pumped storage plants, in order to assess the performance and sub-optimization under both market and non-market conditions [7]. Figure 3-1 shows the plants that were analyzed.

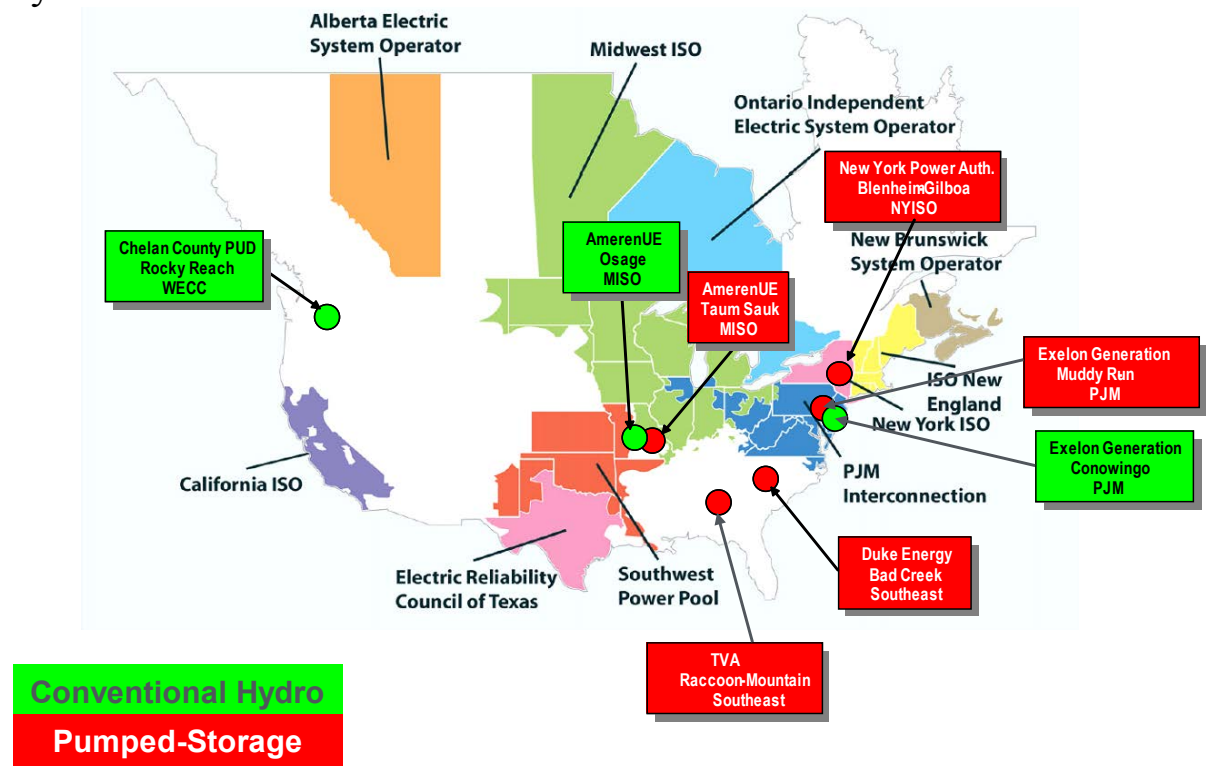

Figure 3-1 Conventional and pumped storage case study locations

Capturing the operations of each plant and its inefficiencies identifies areas where there is a potential to increase the value of the plant. Below is a summary of the performance assessments of conventional hydroelectric plants and pumped storage plants that includes generation improvements based on optimization-based performance analyses for both market and nonmarket plants. It is clear in these results that markets affect the value of the plant. In general, the results show that non-market operations of both conventional hydroelectric plants and pumped storage plants resulted in more efficient performance than the market-based plants [7],[11],[12]:

1. For the five pumped storage plants, the average for the potential plant generation improvements from direct optimization, while producing the same power at the same time, ranged from a low of $0.01 \%$ for a plant which participates in an energy market and provides no regulation services, to a high of $1.1 \%$ for a plant which participates in both energy and ancillary services markets. For the three conventional hydroelectric plants, the average for the potential generation improvements from direct optimization ranged from a low of $0.5 \%$ to a high of $2.7 \%$. Much of the potential generation increase from direct optimization for these conventional and pumped storage case study plants may be cost-effectively achievable through automation and control system improvements. Due to the high levels of annual generation at these plants, even a fractional percentage of improvement has significant economic value. 
2. The average for the potential plant generation improvements from direct optimization was $0.5 \%$ for the two non-market (Southeast) pumped storage plants and $1.0 \%$ for the two pumped storage plants in market regions (PJM and NYISO). One pumped storage plant was not included because the plant does not provide regulation services. The average for the potential plant generation improvements from direct optimization was $0.5 \%$ for the non-market (Northwest) conventional plant and $1.8 \%$ for the two conventional plants in the market regions (PJM and MISO).

3. The average for the potential plant generation improvements based on the generation scheduling analyses ranged from a low of $0.4 \%$ for a pumped storage plant which participates in an energy market and provides no regulation services, to a high of $2.9 \%$ for a pumped storage plant which participates in both energy and ancillary services markets but is primarily dispatched by the market for ancillary services. Comparable results for the conventional plants ranged from a low of $0.4 \%$ to a high of $2.5 \%$

4. The average for the potential plant generation improvements based on the generation scheduling analyses was $0.7 \%$ for the two non-market (Southeast) pumped storage plants and $1.9 \%$ for the two pumped storage plants in market regions (PJM and NYISO). One plant was not included because the plant does not provide regulation services. The average for the potential plant generation improvements based on the generation scheduling analyses was $0.4 \%$ for the non-market (Northwest) conventional plant and $1.5 \%$ for the two conventional plants in market regions (PJM and MISO).

5. The non-market operations of both conventional and pumped storage plants resulted in more efficient performance than the market-based plants. Opportunities exist for plant improvements to reduce avoidable sub-optimization of both conventional plants and pumped storage plants. Opportunities may also exist for market improvements to reduce suboptimization of conventional plants and pumped storage plants.

The long-term maintenance consequences of these operational differences among non-market and market plants are unknown, and additional investigation is warranted. Based on these case studies, a potential increase of $1 \%-3 \%$ in revenue could be expected from optimizing plant operations.

\section{Use Hydro to Address System Variability}

Another potential method to capture value is to incentivize flexible resources, including hydropower, to address system variability by providing flexible reserves, reducing wear and tear on the thermal fleet, and increasing overall system efficiency. Hydro is just one of the resources that can provide this service, so hydro will have to compete to provide this service. In the model, scenarios were run with both a flat level of reserves $(5 \%)$ and an additional scenario was run with increased reserve requirements. These increased requirements are dynamic, with a different value calculated based on the production level of wind and solar power in that hour. The amount of additional reserve was based on a statistical analysis of the variability of wind and solar photovoltaic (PV) resources over different time scales. For regulation, additional regulation capability was procured based on the 10 minute variability of wind and solar PV, with enough carried to cover $95 \%$ of all 10 -minute variability. Similarly, spinning and non-spinning requirements were increased such that hourly variability could be managed. The method used here is the same as that currently being used in the Western Wind 
and Solar Integration Study ${ }^{1}$ and an NREL study relating to the proposed Energy Imbalance Market in $\mathrm{WECC}^{2}$. The average additional regulation carried across WECC was 1,229 MW, with a maximum of 2,835 MW and minimum of $153 \mathrm{MW}$. For this study, the reserve requirements are broken down into three classes by the types of resources required to fulfill them: (1) regulation, (2) spinning reserve, and (3) non-spinning and supplemental reserves. Detailed information on the calculations can be found in the Quantifying the Value of Hydropower in the Electric Grid: Modeling Results for Future Scenarios report [10].

When the increased flexible reserve requirements are considered in 2020, the model showed an increase in ancillary services revenue for conventional hydro plants in WECC as compared to lower levels of reserve requirements. Table 3-2 shows that the conventional hydro in California makes the most profit. However, the average income for the regions remains approximately the same due to the decrease in energy revenue.

Table 3-2 Conventional hydro performance by region with increased reserve requirements ${ }^{3}$

\begin{tabular}{ccccccc}
\hline Region & $\begin{array}{c}\text { Capacity } \\
(\mathbf{M W})\end{array}$ & $\begin{array}{c}\text { Generation } \\
\mathbf{( G W h )}\end{array}$ & $\begin{array}{c}\text { Energy Revenue } \\
\mathbf{( \$ 1 0 0 0 )}\end{array}$ & $\begin{array}{c}\text { Ancillary Service } \\
\text { Revenue } \mathbf{( \$ 1 0 0 0 )}\end{array}$ & $\begin{array}{c}\text { Net } \\
\text { Income } \square(\mathbf{\$ 1} 1 \\
\mathbf{0 0 0})\end{array}$ & $\begin{array}{c}\text { Average } \\
\text { Income } \\
\mathbf{( \$ / k W )}\end{array}$ \\
\hline AZ-NM-SNV & 3,906 & 9,439 & 563,610 & 128,874 & 683,045 & 175 \\
CA-MX US & 9,078 & 42,955 & $2,414,816$ & 271,617 & $2,643,488$ & 291 \\
NWPP & 49,002 & 203,789 & $12,367,189$ & 181,457 & $12,344,857$ & 252 \\
RMPA & 1,151 & 2,861 & 171,813 & 42,136 & 211,088 & 183 \\
WECC & 63,137 & 259,044 & $15,517,428$ & 624,084 & $15,882,478$ & 252 \\
\hline
\end{tabular}

Figure 3-2 shows the difference in revenue by region with the increased reserves. While revenue in most regions changes significantly, the total revenue for conventional hydro is only $\$ 1 / \mathrm{kW}$ more due to the decrease in energy revenue offsetting the increase in ancillary service revenue.

\footnotetext{
${ }^{1}$ See http://wind.nrel.gov/public/WWIS/Reserves.pdf

${ }^{2}$ King, J., Kirby, B., Milligan, M., Beuning, S., “Operating Reserve Reductions From a Proposed Energy Imbalance Market With Wind and Solar Generation in the Western Interconnection", National Renewable Energy Laboratory Technical Report, NREL/TP-5500-54660, Golden, CO, May 2012

${ }^{3}$ Energy Revenue refers to the total revenue collected for power delivered; Ancillary Service Revenue refers to the total revenue collected for the provision of ancillary services; Net Income is total revenue minus expenses including cost of pumping energy; and Average Income is the Net Income divided by the unit size.
} 


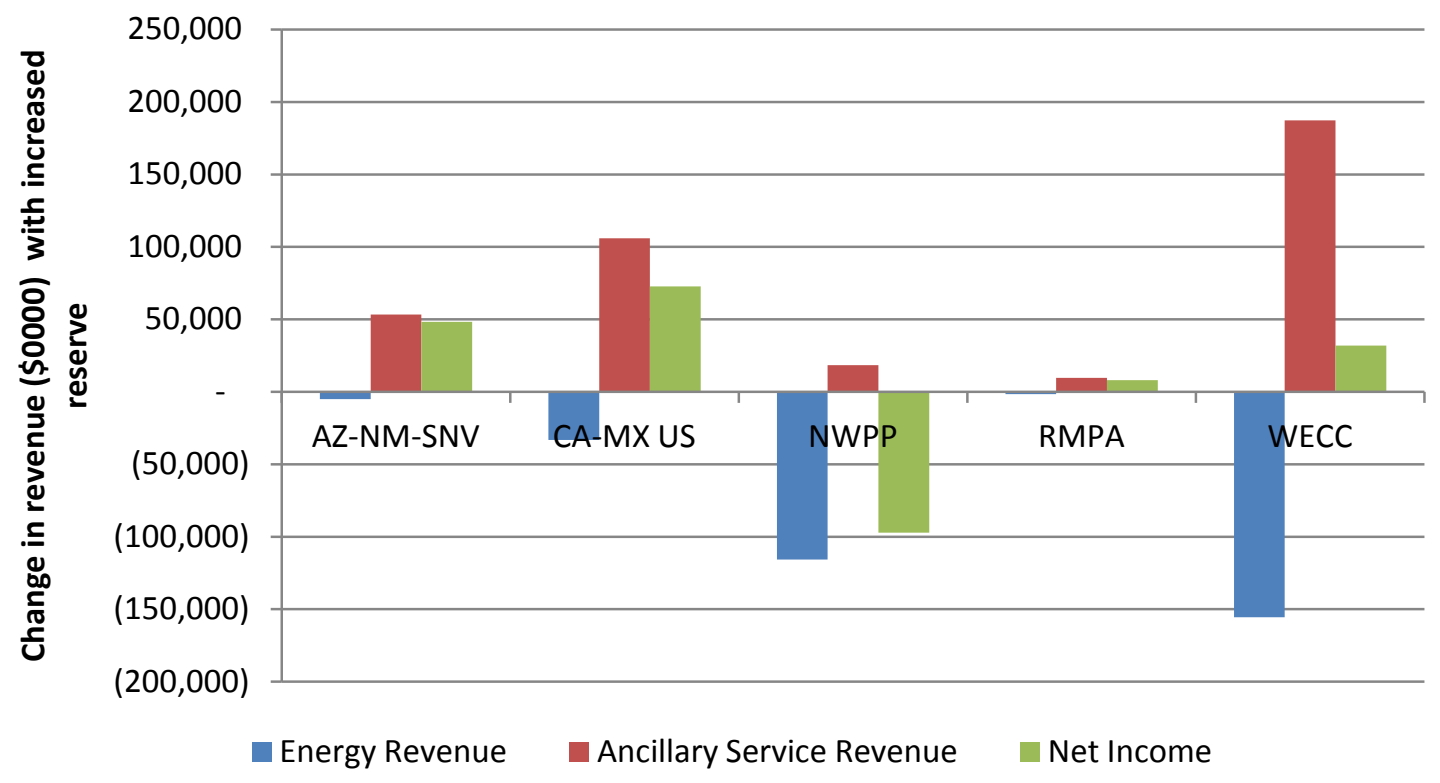

Figure 3-2 Difference in Conventional hydro performance with increased reserves

However, when looking at pumped storage, an increase in flexible reserves led to a significant increase in the average income due to the increase in ancillary service revenue. In Table 3-3 below, an increase from $\$ 18 / \mathrm{kW}$ to $\$ 26 / \mathrm{kW}$ can be seen across WECC.

Table 3-3 Pumped storage performance by region with increased reserve requirements

\begin{tabular}{ccccccc}
\hline Region & $\begin{array}{c}\text { Capacity } \\
\text { (MW) }\end{array}$ & $\begin{array}{c}\text { Generation } \\
(\mathbf{G W h})\end{array}$ & $\begin{array}{c}\text { Energy Revenue } \\
\mathbf{( \$ 1 0 0 0 )}\end{array}$ & $\begin{array}{c}\text { Ancillary Service } \\
\text { Revenue } \mathbf{( \$ 1 0 0 0 )}\end{array}$ & $\begin{array}{c}\text { Net } \\
\text { Income } \\
\mathbf{( \$ 1 0 0 0 )}\end{array}$ & $\begin{array}{c}\text { Average } \\
\text { Income } \\
\mathbf{( \$ / k W )}\end{array}$ \\
\hline AZ-NM-SNV & 198 & 356 & 26,821 & 5,226 & 9,464 & 48 \\
CA-MX US & 3,639 & 5,783 & 413,929 & 47,652 & 80,255 & 22 \\
NWPP & 314 & 598 & 44,519 & 3,815 & 11,251 & 36 \\
RMPA & 560 & 1,116 & 84,294 & 8,510 & 19,315 & 34 \\
WECC & 4,711 & 7,854 & 569,563 & 65,202 & 120,284 & 26 \\
\hline
\end{tabular}

In Figure 3-3, the change in revenue by region can be seen for energy and ancillary services. This shows an increase in revenue of over $40 \%$, which corresponds to a $\$ 35 \mathrm{k}$ increase or $\$ 8 / \mathrm{kW}$ WECC wide with increased reserve requirements. 


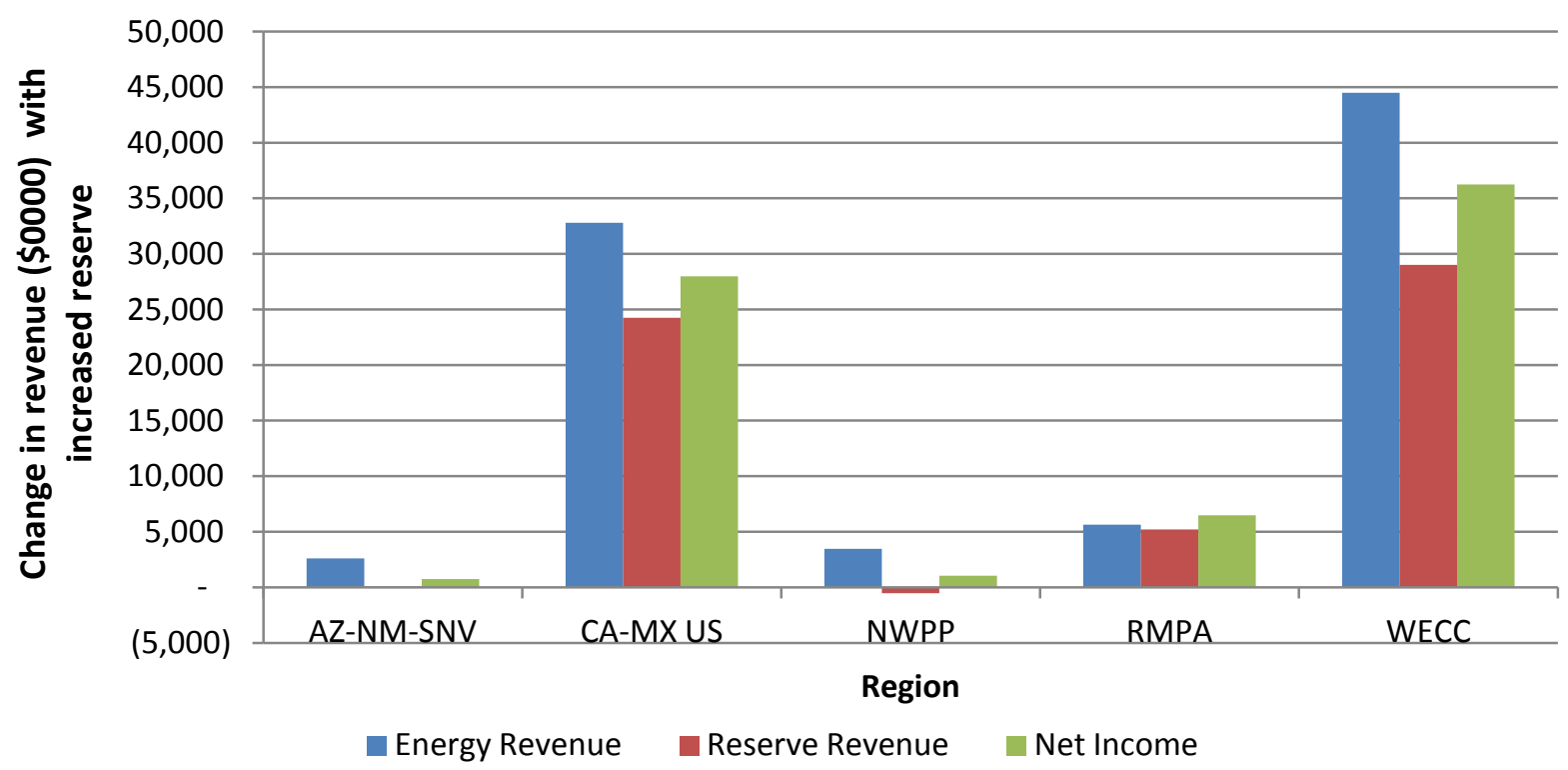

Figure 3-3 Difference in pumped storage performance with increased reserves

The modeling clearly shows an increase in the overall revenue through the increase in flexible reserves. There is also an increase in the use of combined cycle plants. Ultimately, hydro plants will have to compete to provide this resource.

Another aspect related to support system variability is protecting the existing fleet from additional wear and tear. While in the modeling this was not monetized, there were indications of reduced starts and stops on the thermal fleet in WECC. Figure 3-4 shows that when pumped storage is increased in WECC, the number of starts and stops of combustion turbines and coal plants decreases in most regions.

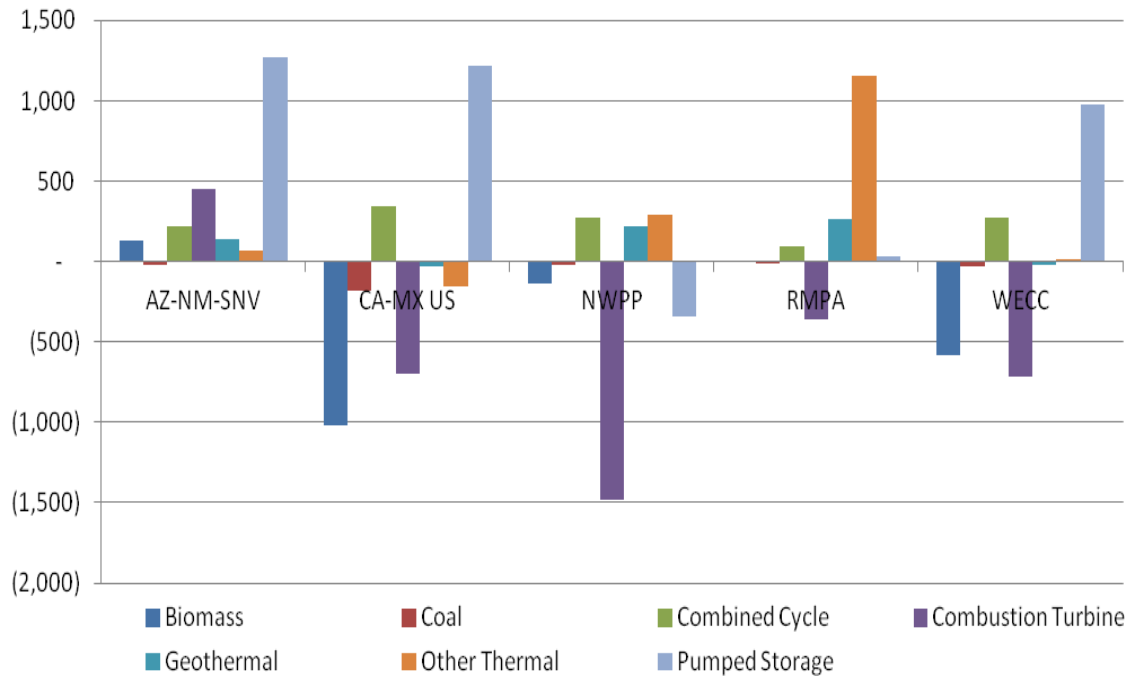

Figure 3-4 Difference in starts and stops with increased pumped storage 
One important thing to note is that while pumped hydro reduces the cycling of other facilities, it increases its own which in turn can cause increased O\&M costs to the hydro plant. More work is needed in this area to better understand the costs of cycling the thermal fleet and the costs associated with cycling pumped storage facilities more often.

\section{Recognize Hydro for Providing Reliability Amidst Resource Diversity}

The last potential way to capture value under operations is to recognize hydro for allowing generation diversity/options, enhancing energy security, and maintaining reliability in the face of uncertainty. Providing reliability was not monetized in this study, as it is not clear how to best account for the value. The modeling showed that conventional and pumped storage hydropower is often relied upon to "keep the lights on" in WECC. Pumped storage was also used to balance unexpected losses in generation in the case studies. One example below in Figure 3-5 shows two pumped storage facilities (shown with red and blue lines) at Duke Energy quickly responding to make up for the forecast error indicated by the area control error (ACE) line in green.

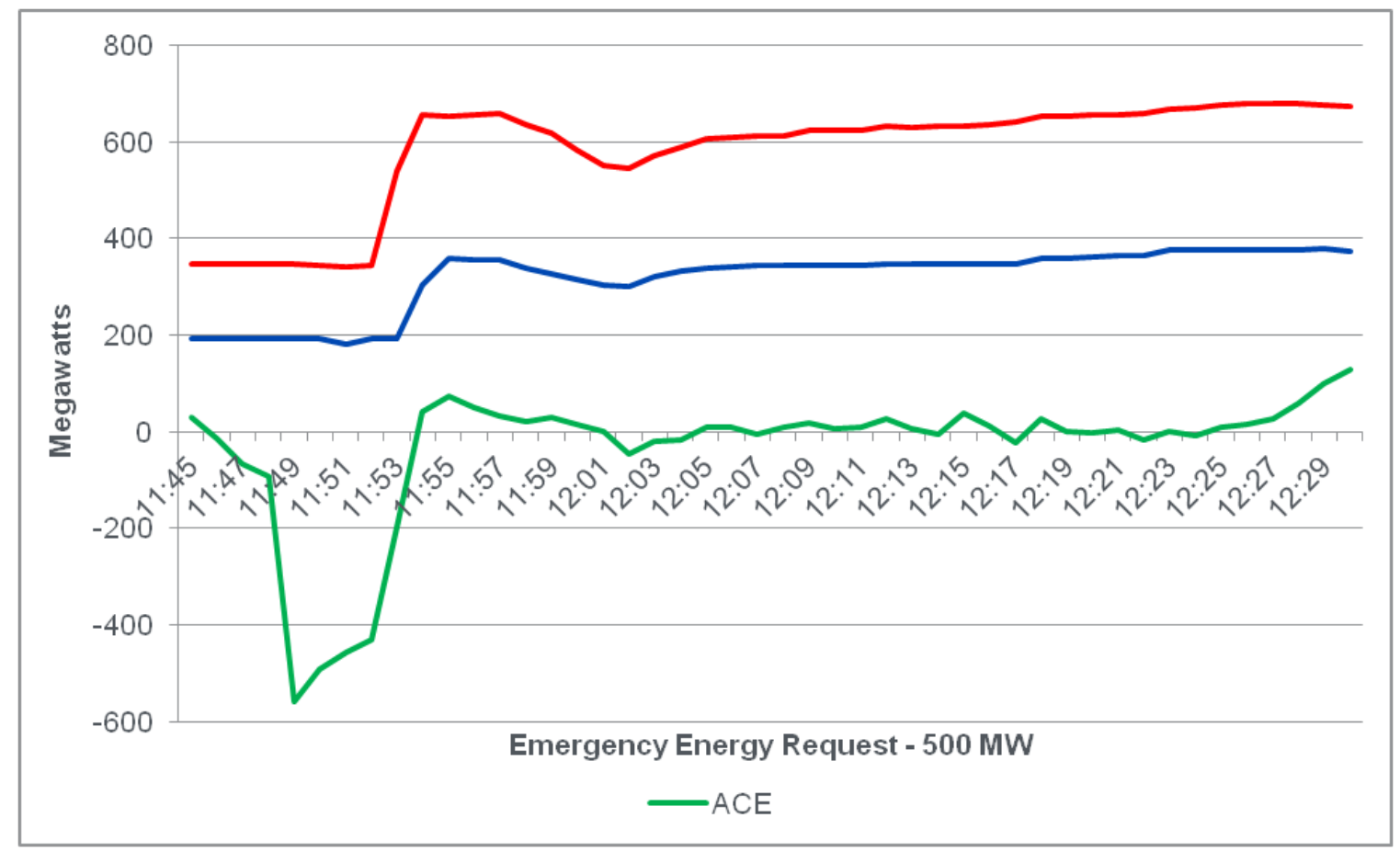

Figure 3-5 Pumped storage units balancing forecast error

Other examples of this can be seen when looking at pumped storage development in other parts of the world. In both Europe and Japan, construction of pumped storage plants has significantly increased. Each has found a case for using this technology to support the grid. In Europe, large amounts of variable generation (solar and wind) have caused utilities to seek storage to stabilize the grid. This has resulted in a surge of variable speed pumped storage installations. In Japan, advanced pumped storage plants were first installed in the 1990s to bring flexibility and reliability to the Japanese grid that is mainly nuclear generation. The following gives a brief look into the experiences that have driven European and Japanese decisions and how that varies from the United States. 


\section{Japanese Pumped Storage Experience}

In Japan, pumped storage makes up a significant portion of their supply. TEPCO reinstated old plants because of the need for power to compensate the loss of generating capacity from Fukushima. In Japan, the motivation for variable speed came in the 1990s because of the need to improve the performance of the pump, have the ability to control the power in pumping mode, and extend the operation in generator mode. All these things allowed for increased power control response time to improve the stability of the grid. Most of Japan's generation comes from nuclear facilities that have little control. Energy storage, and specifically pumped storage in Japan's case, allowed for control and reliability with unexpected outages similar like in 2011 with Fukushima.

\section{European Pumped Storage Experience}

During the first decade of the $21^{\text {st }}$ century, a significant number of new pump storage units were installed in Europe to help the grid manage variability associated with wind and solar energy. There are several factors that have led to more pumped storage than the U.S. These include the basic energy supply, the characteristics of the variability of the renewable resources, the economic and governmental factors influencing the building of pumped storage, and the resulting characteristics of the pumped storage solutions. Table 3-4 below outlines the differences. In particular, the price difference of natural gas is noted as one driving factor. The U.S. currently has low natural gas prices and therefore it is used to support some of this variability, but it is uncertain how long the prices will stay down. In Europe, there are higher penetrations of variable renewables and natural gas prices are higher and there is less supply, so pumped storage is used to support variability. With the uncertainty in the U.S. diversifying now could help long-term stability of electricity prices and grid operations.

Table 3-4 Drivers leading to energy storage investment in Europe

\begin{tabular}{|c|c|c|}
\hline Issue & USA & Europe \\
\hline Carbon & No carbon trading & Carbon trading \\
\hline Social Choices & Pro renewables & More pro renewables than U.S. \\
\hline Governmental Policies & $\begin{array}{l}\text { State RPS stimulus; uncertain tax } \\
\text { incentives; feed in tariffs }\end{array}$ & $\begin{array}{l}\text { Strong EU and country stimulus } \\
\text { (NREAP); economic incentives; feed } \\
\text { in tariffs }\end{array}$ \\
\hline Feed in Tariff Policy & Sometimes; uncertain timeframes & $\begin{array}{l}\text { Yes; generally strong and for a } \\
\text { relatively certain period of time }\end{array}$ \\
\hline $\begin{array}{l}\text { Intermittent Generation (Wind \& } \\
\text { Solar) Penetration }\end{array}$ & $\begin{array}{l}2010: 2.3 \% \\
2020: 3.6 \%\end{array}$ & $\begin{array}{l}2010: 6.6 \% \\
2020: 16 \%\end{array}$ \\
\hline Natural Gas Supply & Abundant and low cost & $\begin{array}{l}\text { Growing but reliability of supply } \\
\text { concerns; price currently pegged to oil }\end{array}$ \\
\hline Transmission & $\begin{array}{l}\text { Regional \& in need of strengthening; } \\
\text { NERC U.S. wide requirements; } \\
\text { industry fragmented w/o common } \\
\text { voice; over } 140 \text { control areas }\end{array}$ & $\begin{array}{l}\text { EU wide; country regulations; more } \\
\text { centralized planning \& strengthening } \\
\text { now }\end{array}$ \\
\hline Curtailment Policy & $\begin{array}{l}\text { Beginning in some regions (BPA), } \\
\text { ERCOT }\end{array}$ & Exists \& expected to increase \\
\hline
\end{tabular}




\begin{tabular}{|l|l|l|}
\hline Markets & $\begin{array}{l}\text { Some active markets for medium \& } \\
\text { longer term energy; evolving with new } \\
\text { payment streams including capacity } \\
\text { payments; markets don't exist } \\
\text { everywhere }\end{array}$ & $\begin{array}{l}\text { Active markets for short \& medium } \\
\text { term energy; still country based, but in } \\
\text { process of unification; addressing } \\
\text { "fflexibility" by new market products } \\
\text { still missing }\end{array}$ \\
\hline Return on Investment & Uncertain & $\begin{array}{l}\text { Energy arbitrage, Ancillary Services } \\
\text { payments, Portfolio effects reward } \\
\text { investment }\end{array}$ \\
\hline Plant Investors & $\begin{array}{l}\text { Principally Generation Utilities } \\
\text { Producers (IPP) in deregulated } \\
\text { markets }\end{array}$ & \\
\hline
\end{tabular}

Not only is Europe installing more pumped storage than the U.S., but they are installing more advanced pumped storage technologies. In Table 3-5 below, a breakdown of installed and planned installations in Europe and North America is compared by technology type. In Europe, more installations of ternary and variable speed units are expected due to the capabilities they can provide in a short time span with increased levels of renewables and the ability for increased revenue opportunities.

Table 3-5 Installed and planned pumped storage developments in Europe and U.S. [3]

\begin{tabular}{|l|c|c|c|c|}
\hline 2000 to 2010 & MW & MW & MW & MW \\
\hline Europe & Total & Conventional PS & Ternary & Variable Speed \\
\hline North America & 2,443 & 836 & 547 & 1,060 \\
\hline 2011 to 2020 & 0 & 0 & 0 & 0 \\
\hline & Total & Conventional PS & Ternary & Variable Speed \\
\hline Europe & 11,562 & 6,849 & 303 & 4,410 \\
\hline North America & 40 & 40 & 0 & 0 \\
\hline
\end{tabular}

\section{New Hydropower Technologies}

The second category of ways to increase or better capture the value of hydropower resources is in the technology. Within technology, there are three potential ways to increase the value shown in Table 3-6:

Table 3-6 Technological ways to increase the value of hydropower

\begin{tabular}{|c|c|l|l|l|}
\hline No. & $\begin{array}{c}\text { Value } \\
\text { Streams }\end{array}$ & \multicolumn{1}{|c|}{ Ways to Increase Value } & Beneficiaries & $\begin{array}{l}\text { Potential } \\
\text { Value }\end{array}$ \\
\hline 4 & $\begin{array}{c}\text { New Hydro } \\
\text { Technologies }\end{array}$ & $\begin{array}{l}\text { Expand the effective operating range of } \\
\text { existing and new hydro units with lower } \\
\text { minimum load and higher peak operating } \\
\text { capabilities }\end{array}$ & $\begin{array}{l}\text { Plant owner } \\
\text { and operator }\end{array}$ & $\begin{array}{l}61 \% \\
\text { increase } \\
\text { annual } \\
\text { average } \\
\text { income PS }\end{array}$ \\
\hline 5 & $\begin{array}{l}\text { New Hydro } \\
\text { Technologies }\end{array}$ & $\begin{array}{l}\text { Apply adjustable speed drive electronics in } \\
\text { new and selected existing pumped storage } \\
\text { units to enable regulation of the pumping } \\
\text { power requirements, particularly at night }\end{array}$ & $\begin{array}{l}\text { Plant owner } \\
\text { and operator }\end{array}$ & $\begin{array}{l}85 \% \\
\text { increase } \\
\text { annual } \\
\text { average } \\
\text { income PS }\end{array}$ \\
\hline
\end{tabular}




\begin{tabular}{|c|c|l|l|l|}
\hline 6 & $\begin{array}{l}\text { New Hydro } \\
\text { Technologies }\end{array}$ & $\begin{array}{l}\text { Design new pumped storage plants that } \\
\text { minimize environmental impacts such as } \\
\text { low profile or closed water supply loop to } \\
\text { shorten licensing lead times and public } \\
\text { approval process as compared to recent } \\
\text { conventional experiences }\end{array}$ & $\begin{array}{l}\text { Plant } \\
\text { developers, } \\
\text { general public }\end{array}$ & $\begin{array}{l}\text { Not } \\
\text { quantified }\end{array}$ \\
\hline
\end{tabular}

In this study, the first two were monetized by the electric system operations modeling. The third is more challenging to monetize, as it is a mix of societal benefit and time value of resources and capital. All three are discussed in detail below.

\section{Expand Operating Range of Existing Units}

The first technological way to increase the value of hydropower is to expand effective operating range of existing units. This change would not require upgrading or installing a new unit, but simply making a mechanical change to increase the capacity. Using the model, a sensitivity analysis was performed where the minimum load of an existing pumped storage plant was reduced to $40 \%$ of the capacity from the assumed $70 \%$ capacity in previous simulations. By making this change, the plant saw a $61 \%$ increase in the average income of the plant. This change is something that is relatively inexpensive and not time sensitive. Table 3-7 below shows the change in average income from the expanded operating range as scenario "Base_GenUp." The energy revenue increases, but the revenue from ancillary services more than doubles with this change.

Table 3-7 Performance of pumped storage plants with upgrades

\begin{tabular}{|c|c|c|c|c|c|c|c|c|}
\hline Scenario & $\begin{array}{l}\text { Unit Size } \\
\text { (MW) }\end{array}$ & $\begin{array}{c}\text { Capadity } \\
\text { Factor (\%) }\end{array}$ & $\begin{array}{c}\text { Energy } \\
\text { Pevenue } \\
(\$ 1000)\end{array}$ & $\begin{array}{l}\text { Andillary } \\
\text { Serviœ } \\
\text { Revenue }\end{array}$ & $\begin{array}{l}\text { Fuel Cost } \\
(\$ 1000)\end{array}$ & $\begin{array}{c}\text { Net Inœme } \\
(\$ 1000)\end{array}$ & $\begin{array}{c}\text { Average } \\
\text { Pevenue } \\
(\$ / \mathrm{KW})\end{array}$ & $\begin{array}{l}\text { Average } \\
\text { Income } \\
(\$ / K W)\end{array}$ \\
\hline Base & 132 & 15.9 & 9,790 & 605 & 8,465 & 1,745 & 79 & 13 \\
\hline Base_GenUp & 132 & 19.6 & 11,995 & 1,989 & 10,983 & 2,774 & 106 & 21 \\
\hline
\end{tabular}

\section{Apply Adjustable Speed Drives}

In addition to operational changes, technology upgrades to existing plants or adding plants with new technologies can potentially add even greater value. Hydropower technologies, specifically pumped storage, have continued to evolve to enable more efficient operation, wider operational ranges, and more flexibility including faster speed of response and regulation in the pump cycle of operation (Fisher et al, 2012). Figure 3-6 gives a snapshot of which technologies can provide different grid support functions and the timeframes of regulation. Recent advancements to variable speed or adjustable speed drives have enabled pumped storage plants to be more flexible and offer grid services while pumping allowing for increased revenue from ancillary services. 


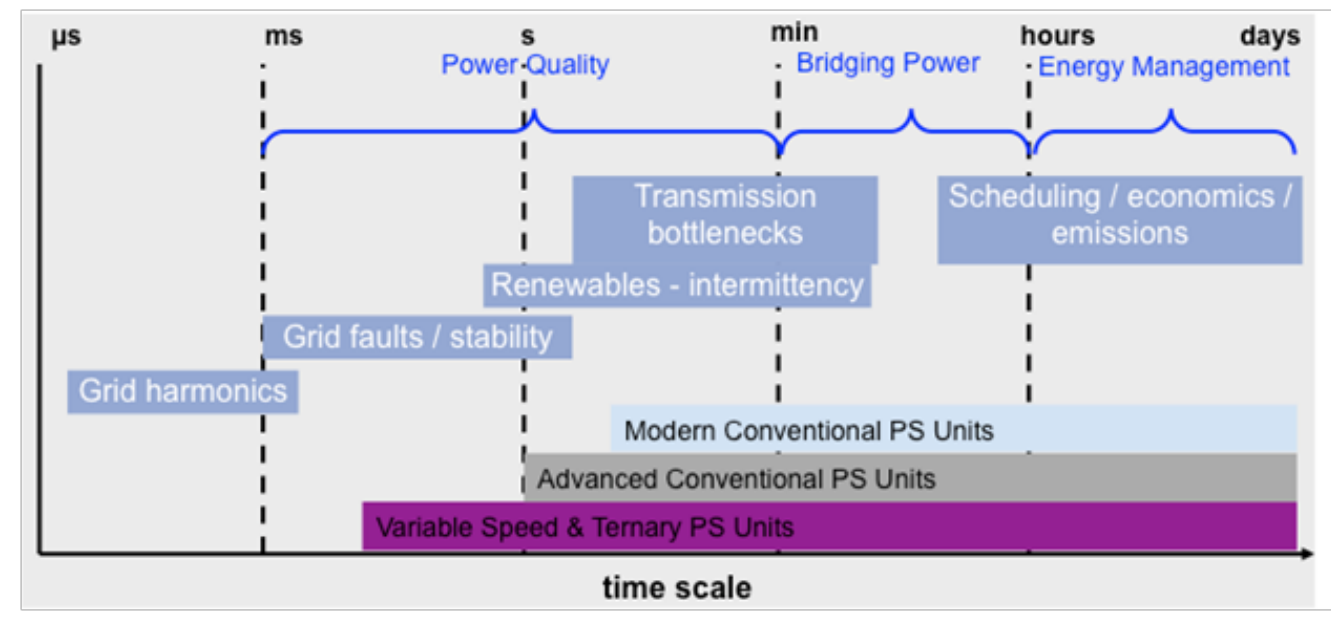

Figure 3-6 Timeframes for advanced pumped storage unit regulation

Table 3-8 below summarizes some of the main expected benefits and features of variable/adjustable speed pumps as outlined in the Challenges and Opportunities for New Pumped Storage Development [6].

Table 3-8 Features and benefits of variable speed pumped storage [6]

\begin{tabular}{|l|l|l|}
\hline Feature & Technological Advantages & Economic Advantages \\
\hline \multirow{5}{*}{ Adjustable pumping } & $\begin{array}{l}\text { Frequency regulation in pumping } \\
\text { mode by accommodating variable } \\
\text { supply }\end{array}$ & $\begin{array}{l}\text { Additional ability to quickly ramp up } \\
\text { and down to support more variable } \\
\text { renewable energy resources }\end{array}$ \\
\hline & $\begin{array}{l}\text { More efficient use of equipment, } \\
\text { reducing the need for thermal plant } \\
\text { cycling; critical for avoiding } \\
\text { greenhouse gas emissions }\end{array}$ & $\begin{array}{l}\text { Operations and maintenance cost } \\
\text { reduction and increase of equipment } \\
\text { lifespan; greenhouse gas offsets if } \\
\text { market develops }\end{array}$ \\
\hline & $\begin{array}{l}\text { Able to take advantage of shifts in } \\
\text { grid dynamics to effectively manage } \\
\text { variable energy supply and capture } \\
\text { and store lower cost energy }\end{array}$ & $\begin{array}{l}\text { Cost minimization and operation of } \\
\text { existing units at peak efficiency; } \\
\text { support growth of additional } \\
\text { renewable energy resources }\end{array}$ \\
\hline & $\begin{array}{l}\text { There is an increase in energy } \\
\text { generation due to the fact that the } \\
\text { turbine can be operated at its peak } \\
\text { efficiency point under all head } \\
\text { conditions }\end{array}$ & $\begin{array}{l}\text { This results in an estimated increase } \\
\text { in energy generated on the order of } \\
3 \% \text { annually }\end{array}$ \\
\hline $\begin{array}{l}\text { Faster power adjustment and reaction } \\
\text { time }\end{array}$ & $\begin{array}{l}\text { Improved balancing of variable } \\
\text { energy units (wind/solar) and } \\
\text { coordination of overall energy mix }\end{array}$ & $\begin{array}{l}\text { More stable equipment translates into } \\
\text { risk reduction and increased } \\
\text { reliability of the domestic grid }\end{array}$ \\
\hline
\end{tabular}

Because of the potential impact of this technology, another scenario was simulated in which an existing pumped storage plant was modeled as a new variable speed pump, "Base_PumpUp". This would require a wholesale change out of equipment. The characteristics of the variable speed pump are a minimum load of $40 \%$, round-trip efficiency of $80 \%$ and range of operations of 
$60 \%$. These changes increased efficiency by about $5 \%$ and would allow participation in regulation markets when in the pump mode. The result is an increase of almost $85 \%$ in the plant income as can be seen in Table 3-9. Such increases, however, are very market dependent.

Table 3-9 Performance of variable speed pumped storage units

\begin{tabular}{|c|c|c|c|c|c|c|c|c|}
\hline Scenario & $\begin{array}{l}\text { Unit Size } \\
\text { (MW) }\end{array}$ & $\begin{array}{c}\text { Capadity } \\
\text { Factor }(\%)\end{array}$ & $\begin{array}{c}\text { Energy } \\
\text { Pevenue } \\
(\$ 1000)\end{array}$ & $\begin{array}{l}\text { Andllary } \\
\text { Serviœ } \\
\text { Pevenue }\end{array}$ & $\begin{array}{l}\text { Fuel Cost } \\
(\$ 1000)\end{array}$ & $\begin{array}{l}\text { Net Inøome } \\
(\$ 1000)\end{array}$ & $\begin{array}{c}\text { Average } \\
\text { Pevenue } \\
(\$ / K W)\end{array}$ & $\begin{array}{l}\text { Average } \\
\text { Income } \\
(\$ / K W)\end{array}$ \\
\hline$\overline{\text { Base }}$ & 132 & 15.9 & 9,790 & 605 & 8,465 & 1,745 & 79 & 13 \\
\hline Base_GenUp & 132 & 19.6 & 11,995 & 1,989 & 10,983 & 2,774 & 106 & 21 \\
\hline Base_Pumplp & 132 & 20.5 & 11,988 & 2,863 & 11,483 & 3,131 & 113 & 24 \\
\hline
\end{tabular}

To further understand the value from variable speed pumps, a new pumped storage plant (BaseOneNewPSVS) was added to the WECC model. This new plant had a minimum load of $20 \%$ of the nameplate capacity, a round-trip efficiency of $80 \%$, and the ability to contribute $30 \%$ of the total capacity to regulation reserve both in pumping and generating mode. As can be seen in Table 3-10, the overall net income of the plant increases with the variable speed capability and this increase can be attributed to higher ancillary services revenue. The energy revenue actually decreases in this scenario.

Table 3-10 New variable speed pumped storage plant performance

\begin{tabular}{lcccccccc}
\hline \multicolumn{1}{c}{ Scenario } & $\begin{array}{c}\text { Plant } \\
\text { Size } \\
\mathbf{( M W )}\end{array}$ & $\begin{array}{c}\text { Generation } \\
\mathbf{( G W h )}\end{array}$ & $\begin{array}{c}\text { Energy } \\
\mathbf{C o s t} \\
\mathbf{( \$ 1 0 0 )}\end{array}$ & $\begin{array}{c}\text { Energy } \\
\text { Revenue } \\
\mathbf{( \$ 1 0 0 0 )}\end{array}$ & $\begin{array}{c}\text { Ancillary } \\
\text { Service Revenue } \\
\mathbf{( \$ 1 0 0 0 )}\end{array}$ & $\begin{array}{c}\text { Net } \\
\text { Income } \\
\mathbf{( \$ 1 0 0 0 )}\end{array}$ & $\begin{array}{c}\text { Average } \\
\text { Revenue } \\
\mathbf{( \$ \mathbf { k W } )}\end{array}$ & $\begin{array}{c}\text { Average } \\
\text { Income } \\
\mathbf{( \$ / k W )}\end{array}$ \\
\hline Base-OneNewPS & 399 & 812 & 39,043 & 43,331 & 9,770 & 14,058 & 133 & 35 \\
BaseOneNewPSVS & 399 & 692 & 32,369 & 35,278 & 15,213 & 18,121 & 126 & 45 \\
\hline
\end{tabular}

These results support the belief that more flexible pumped storage plants can expect increasing revenues from providing ancillary services for several future energy scenarios.

\section{Design New Pumped Storage Plants to Minimize Environmental Impact}

The last potential method related to technology is to design new pumped storage plants such as low profile or closed loop, which minimize environmental impacts and therefore could save time in licensing. Currently, licensing for new pumped storage plants represents a significant amount of project time and cost. One recent trend is for pumped storage plants to be built "off-channel," adjacent to existing river systems -- called "closed-loop" plants. Of the current FERC filings, more than half are closed-loop. These facilities tend to have fewer environmental impacts and therefore have reduced licensing times and often more opportunity with decreased hydrological constraints. The shortened licensing time leads to more time in operations and less upfront cost, which could ultimately result in an increased lifetime value from the facility. This increased operation time for closed-loop plants was not monetized as part of this study, but further research should be done to quantify the potential value compared to open-loop plants.

\section{Electricity Markets}

The third category of ways increase or better capture the value of hydropower resources is in electricity markets. FERC and others are currently reexamining the rules surrounding market operations that may be more favorable to hydropower. Within this market category, there are four potential opportunities for value shown in Table 3-11: 
Table 3-11 Market ways to increase the value of hydropower

\begin{tabular}{|c|c|l|l|l|}
\hline No. & $\begin{array}{c}\text { Value } \\
\text { Streams }\end{array}$ & \multicolumn{1}{|c|}{ Ways to Increase Value } & Beneficiaries & $\begin{array}{l}\text { Potential } \\
\text { Value }\end{array}$ \\
\hline 7 & $\begin{array}{c}\text { Electricity } \\
\text { Markets }\end{array}$ & $\begin{array}{l}\text { Settle energy markets sub-hourly, } \\
\text { increasing conventional and pumped } \\
\text { storage energy arbitrage opportunities with } \\
\text { grid demand load leveling benefits }\end{array}$ & $\begin{array}{l}\text { Everybody } \\
\text { decrease in } \\
\text { electricity } \\
\text { prices }\end{array}$ \\
\hline 8 & $\begin{array}{l}\text { Electricity } \\
\text { Markets }\end{array}$ & $\begin{array}{l}\text { Have the Independent System Operators } \\
\text { (ISOs) scheduling hydro to co-optimize } \\
\text { energy and ancillary services within a } \\
\text { balancing authority }\end{array}$ & Everybody & $\begin{array}{l}63-77 \% \\
\text { increase in } \\
\text { profits PS }\end{array}$ \\
\hline 10 & $\begin{array}{c}\text { Electricity } \\
\text { Markets }\end{array}$ & $\begin{array}{l}\text { Treat pumped storage as a new storage } \\
\text { asset class capturing the full value of } \\
\text { services and improving the economics in } \\
\text { areas } \text { with resource constraints }\end{array}$ & $\begin{array}{l}\text { Developers, } \\
\text { owners, and } \\
\text { general public }\end{array}$ & $\begin{array}{l}\text { Not } \\
\text { quantified }\end{array}$ \\
\hline Markets & $\begin{array}{l}\text { Credit hydro for its very fast regulation } \\
\text { response in situations } \text { where resource } \\
\text { adequacy is a power system reliability } \\
\text { issue }\end{array}$ & $\begin{array}{l}\text { Developers, } \\
\text { owners, NERC } \\
\text { and general } \\
\text { public }\end{array}$ & $\begin{array}{l}\text { Not } \\
\text { quantified }\end{array}$ \\
\hline
\end{tabular}

In this study, the first two were studied through various modeling analysis. The third and fourth was not modeled, as it requires modeling for very fast time scales and speculation of market situations where such fast response can be used. All four are discussed in detail below.

\section{Settle Energy Markets Sub-hourly}

One potential model is to allow open markets, including sub-hourly energy markets, to allow for wider participation. Sub-hourly energy scheduling benefits the power system by providing access to the full flexibility of all generators. Sub-hourly markets allow generators to profit by compensating generators for their flexibility. This is especially important for flexible hydro and pumped storage generators. Development of forward markets also has the potential to benefit hydro and pumped storage resources that must schedule their production based on limited energy resources. Finally, developing a workable system through which demand response can be brought to the market would help to reduce market power in both energy and reserves markets, allowing all generators to receive competitive energy and ancillary service prices. The new FERC ruling on the Integration of Variable Energy Resources is a step towards this. The ruling removed the barriers by requiring utility transmission owners to offer intra-hourly transmissions scheduling.

The approach for electric system modeling first estimates the capacity expansion and generation mix, and then runs a production simulation with economic dispatch. Sub-hourly modeling differentiates the value of generation functions and services such as energy, regulation, spinning reserve, and non-spinning reserve. The valuation of hydro's contribution to these components is determined from an hourly-resolution security-constrained unit commitment and economic dispatch model. The production cost simulations performed represent the movement of load and generation from one hour to the next by assuming average demand and supply across the hour. This means the analysis can effectively represent the value of hydro providing energy, as well as 
the contribution to the reserve capacity required for providing ancillary services that are needed within the hour (regulating reserve, spinning reserve, and non-spinning reserve). Using the model, the value of settling energy markets on a sub hourly basis with existing facilities was captured. Below are some of the results showing the impact. Overall, the modeling shows two key points about hydropower:

1. In the WECC region, operation of existing hydropower is needed to keep the lights on, and

2. Existence of hydropower to participate in ancillary services markets supports grid operations, significantly reduced the cost of electricity in WECC.

Conventional hydropower accounts for $25 \%$ of the energy production in WECC. Removing this hydro from the mix, as a way to value its contribution, was not possible because the electrical laws for real time delivery of energy to load and for balancing supply and demand could not be solved. A valuation was possible for excluding and including existing hydropower in providing ancillary services. It was found that hydropower participation in providing ancillary services decreases the overall production costs of electricity in WECC by $\$ 1.35$ billion or $6 \%$. Electricity prices were estimated to increase by 5\% when hydro is not allowed to participate. Figure 3-7 below shows the technologies that are required to provide ancillary services in the place of hydro in red and the technologies that provide when hydro can participate in blue.

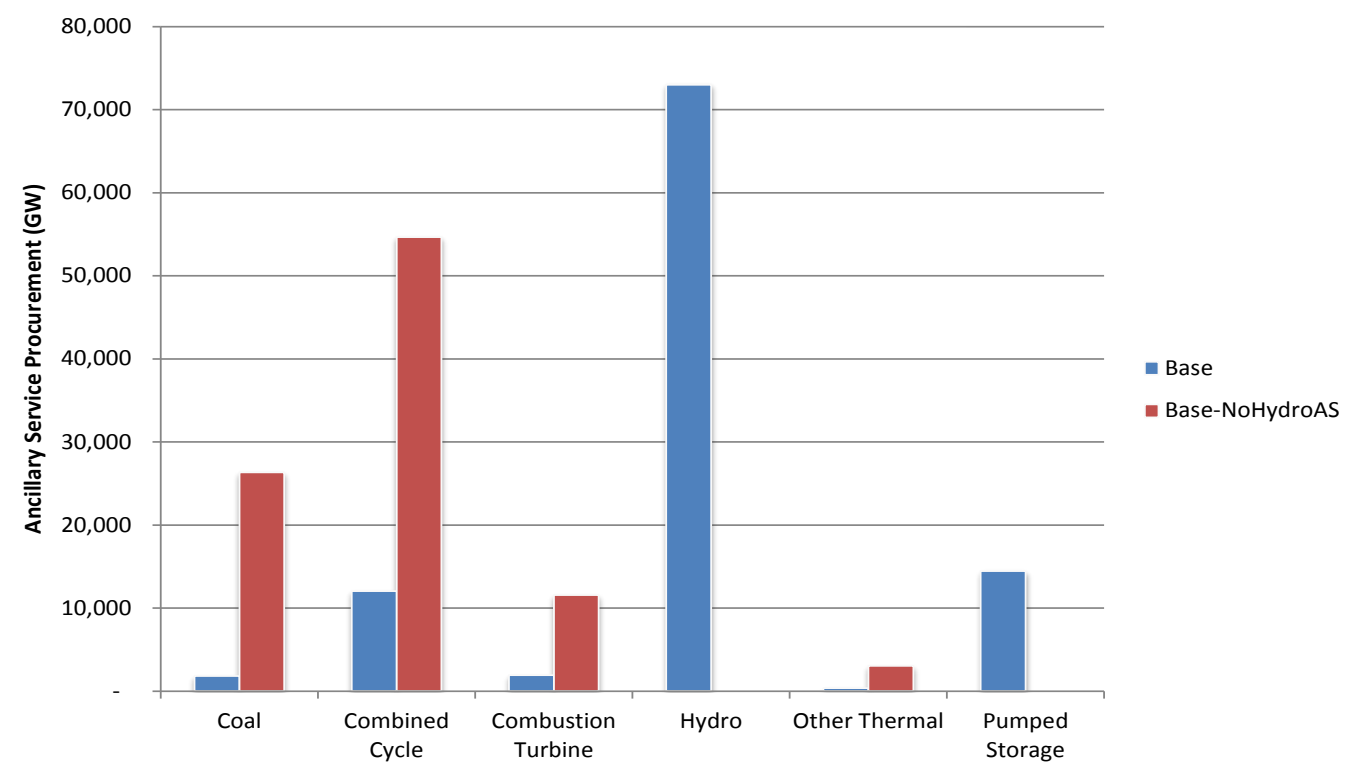

Figure 3-7 Ancillary service procurement with and without hydro participation

\section{Conventional Hydro Plants}

The modeling and scenario simulation results showed that while conventional hydro plants make a significant amount of money from ancillary services, these still remain a small portion of the overall revenue of the plant. This is seen in Figure 3-8 below. It should be noted that these results represent the entire fleet of conventional hydropower resources within the WECC; individual plant revenue proportions vary widely depending on operating constraints and dispatch preferences. 


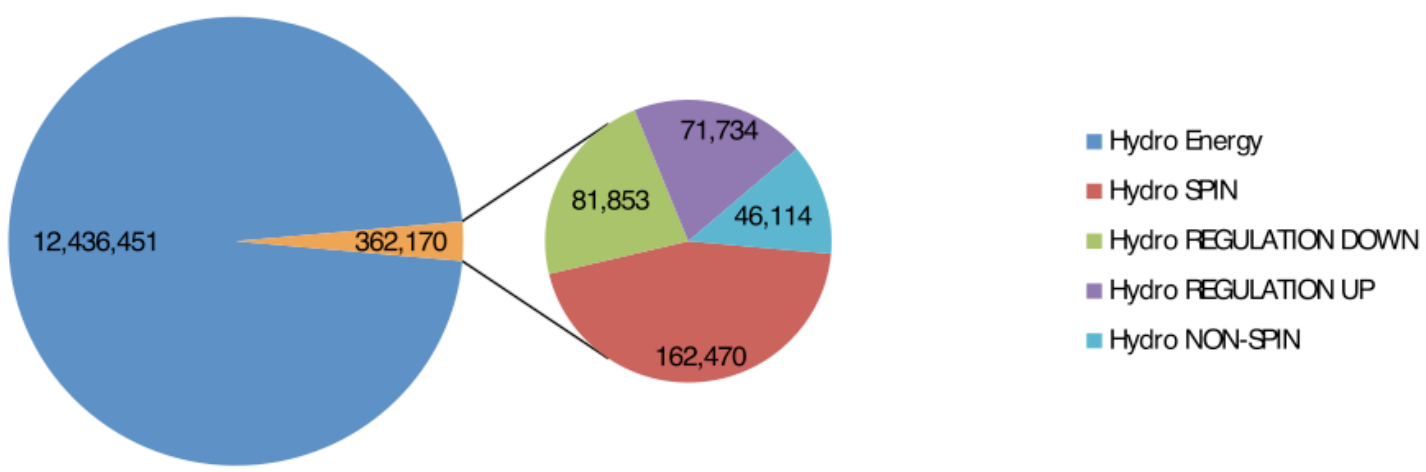

Figure 3-8 Conventional plant revenues $(\$ 1000)$ in base case

Also for conventional plants, adding variable generation and thus increasing the system reserve requirements increased total ancillary service revenue by $\$ 23$ million with an average ancillary service income increase of $\$ 1.5 / \mathrm{kW}$. In general, the average conventional hydropower plant received revenues ranging from $\$ 134$ to $\$ 230 / \mathrm{kW}$ in the base case 2020 prior to the increase of reserve requirements from variability discussed previously.

\section{Pumped Storage Plants}

A significant potential future value stream for pumped storage plants will be in providing ancillary services in WECC. Figure 3-9 below shows the income when adding one new pumped storage plant in three different scenarios (Base-OneNewPS, Carbon-OneNewPS, ExtremeOneNewPS). The ancillary service revenue is a significant portion in each scenario, but in the extreme case when there is high demand, increased renewables and high natural gas prices, the pumped storage plant sees a significantly higher portion of ancillary service revenues.

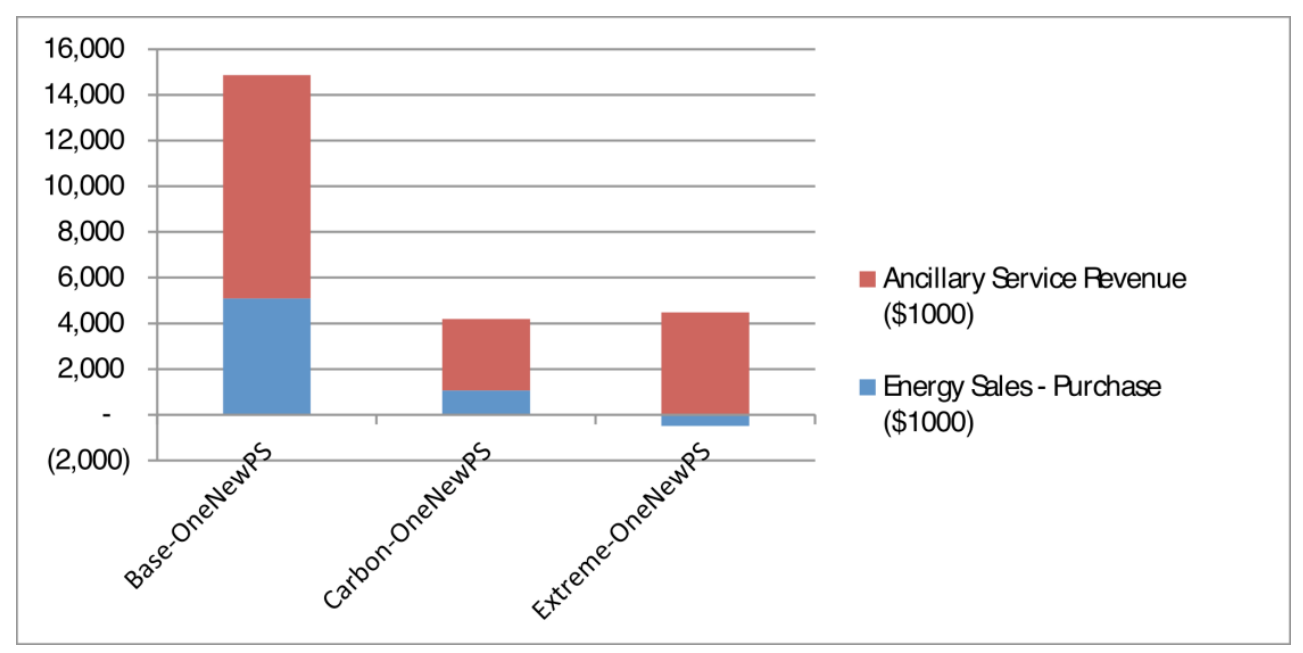

Figure 3-9 Ancillary service and energy revenue when adding one new pumped storage plant

When looking WECC-wide across all the future scenarios, it was found that a pumped storage unit can receive $30 \%-50 \%$ of its revenues from ancillary services and the remaining from energy arbitrage. This can be seen in Figure 3-10 below. In addition, simulation results show that eight of the cases have greater than $40 \%$ of the 2020 revenues from ancillary services. 


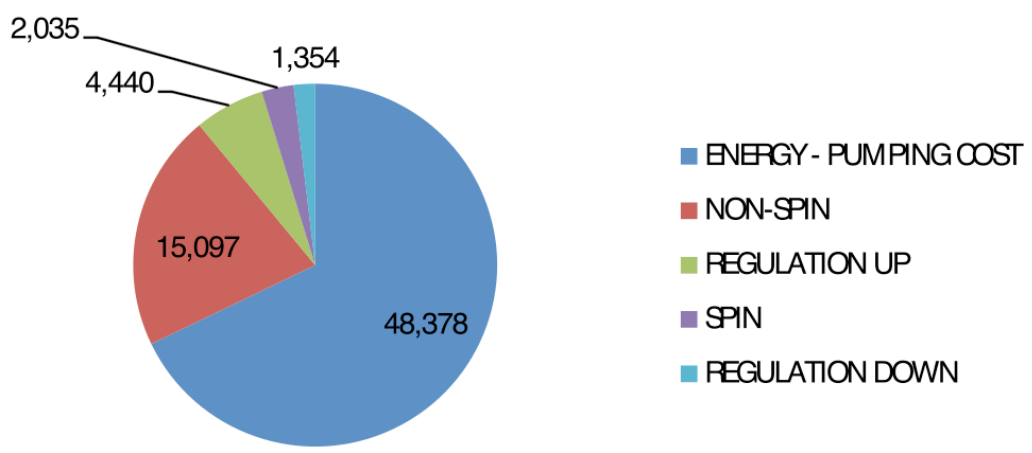

Figure 3-10 Pumped storage revenues $(\$ 1000)$ in base scenario

\section{ISOs Scheduling Hydro to Co-optimize Resources}

Allowing ISOs to schedule hydropower resources over multiple hours or days is another model that could provide more value for hydropower. This model would broaden the current practice where ISOs co-optimize energy and ancillary scheduling over a single time period to include scheduling energy-limited hydro and pumped storage resources over multiple time periods up to a day or longer. The ISO would know the capabilities, limitations, and costs for each pumped storage and hydro plant. ISOs could then use the plant knowledge along with forecasting capabilities to schedule the pumping, generation, and ancillary services in a system-wide beneficial way. The ISO is more equipped to forecast these needs than the traditional plant operator. As the importance and potential income of ancillary services increases, ISO scheduling allows for optimal scheduling and increased profitability. Preliminary analysis shows that an example pumped storage plant could increase profits by $63 \%$ to $77 \%$ if the ISO optimized scheduling compared with the pumped storage plant relying on a fixed pumping and generating schedule [4].

\section{Scheduling Energy}

Power systems require both energy and flexibility to continuously balance generation and load. Regions with organized electricity markets (about half of the U.S.) obtain energy and flexibility through a series of energy and ancillary service market products. We briefly discuss how different types of generators interact with these organized markets. For simplicity, we start by looking at energy alone and then extend the discussion to look at ancillary services. Current market structures work well for conventional generators and reasonably well for variable renewable generators. Current market structures do not work as well for energy-limited hydro or for pumped storage.

All of the organized markets are structured to allow generators to maximize their profits by bidding their capabilities and costs into these markets, at least to a first approximation. ${ }^{4}$ For energy, the system operator ranks the offers by price each hour, starts selecting the least cost generation first, and continues selecting generation until the hours energy requirements are met. The market clears and all selected generators are paid the price set by the last generator to be selected. If a generator bids above its actual cost it risks not being selected and missing the

\footnotetext{
${ }^{4}$ Generators may modify their bids for some or all of their capacity to hedge imbalance risks or to try to influence scarcity prices, depending on the exact market rules, but a generator will very nearly maximize profits by simply bidding capabilities and costs.
} 
opportunity to make a profitable sale. If a generator bids below its cost, it risks setting the clearing price at a level where it loses money. The result is that the system selects the least cost mix of generation that can meet each hour's energy requirements and each generator maximizes its profits, given the construct of a fair market with no one exercising market power. Figure 3-11 illustrates how a fossil fueled generator with a variable operating cost of $\$ 35 / \mathrm{MWh}$ (fuel plus variable O\&M) can bid the $\$ 35 / \mathrm{MWh}$ cost into the market and get selected to operate whenever the market clears at $\$ 35 / \mathrm{MWh}$ or higher. The generator maximizes its profit by bidding its actual variable cost.

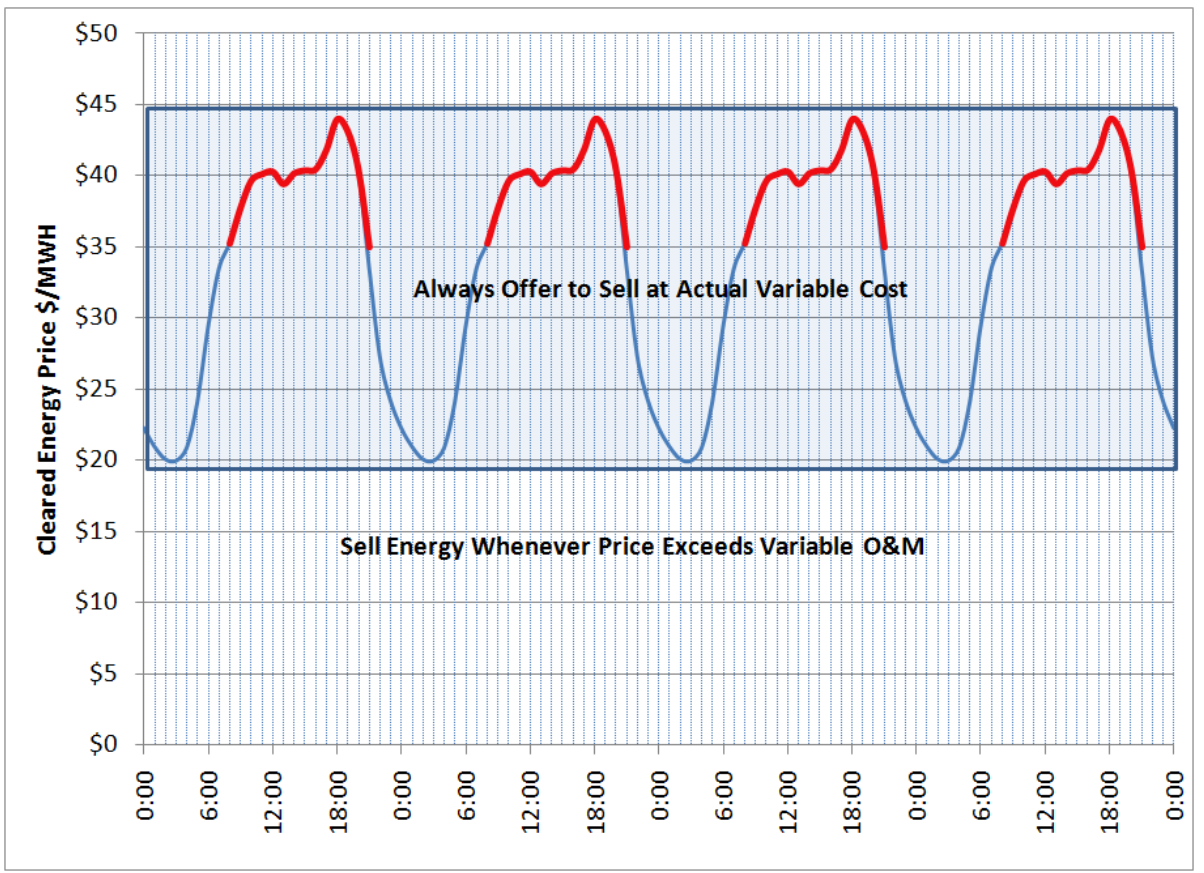

Figure 3-11 A fossil fueled generator maximizes its profits by bidding its variable cost; $\$ 35 / M W h$ in this example

Variable renewables such as wind, solar, and run-of-river hydro also maximize profits by bidding their variable cost, which is typically either near zero or negative if the plant is receiving production tax credits or renewable energy credits. The only real difference from how fossil fueled generators bid is that the variable renewable generator will bid a quantity based on the short-term wind, solar, or hydro forecast rather than being based on the generator's nameplate capacity. Figure 3-12 shows that the variable renewable energy source will be selected for operation most hours (unless there is transmission congestion) because the bid price (marginal cost) is lower than the market clearing price. 


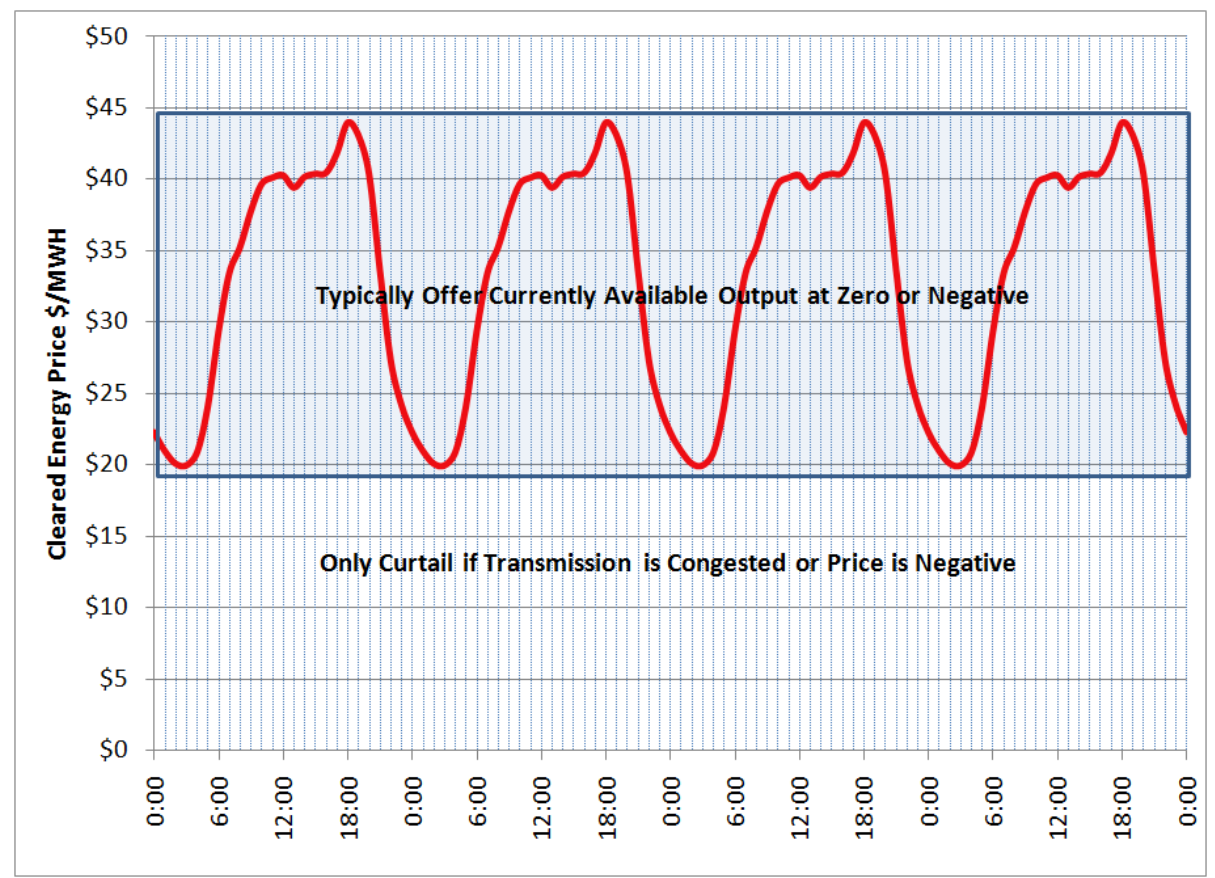

Figure 3-12 Variable renewables bid zero or negative and typically clear the market every hour they are available.

This concept is extended to include ancillary services through co-optimization. Each generator bids its energy costs as well as its ancillary service capabilities (basically ramp rate and control range) along with any direct costs for supplying ancillary services (degraded heat rate for supplying regulation, for example). The system operator then calculates the total cost, including opportunity costs, for each generator to provide energy and each of the ancillary services. An hourly market clearing price for energy and each of the ancillary services is determined based on the marginal cost (including opportunity costs) for each service. As with the energy-only example above, total system costs are minimized and each generator's profits are maximized through the hourly co-optimized procurement of energy and ancillary services. This allows generator operators to focus on their primary job of efficiently operating generation rather than having to spend effort on guessing at the amounts and prices of services they should offer each hour.

Unfortunately this organized energy and ancillary service market concept that works so well for conventional generators does not work for energy-limited hydro or pumped storage. This is because the markets treat each hour as a distinct and independent market. This works for conventional generators because the generator costs are largely time independent. ${ }^{5}$ A generator has a fixed amount of capacity it can offer into the market each hour. It either burns fuel and generates during one hour, or, if the market clearing price does not cover the fuel cost, it saves the fuel for some future hour. The operation during one hour does not change what can be sold in future hours. Each hourly market is essentially independent. This is not the case for energylimited hydro or pumped storage. Energy-limited hydro cannot operate at its full output indefinitely; it will run out of water. Figure 3-13 shows the results if an energy-limited hydro

\footnotetext{
${ }^{5}$ The markets do recognize and accommodate conventional generator intertemporal constraints like minimum run times, minimum down times, and startup costs.
} 
plant bids its marginal cost for as-available energy, similar to the optimal method for thermal plant bidding. This simplified hypothetical plant receives enough water each day to fill its 6-hour reservoir. If it simply offers this capability to the hourly energy market it will likely be selected every hour until the water runs out (midnight to 6am since each trading day starts at midnight) and it will miss the opportunity to sell during later higher priced hours.

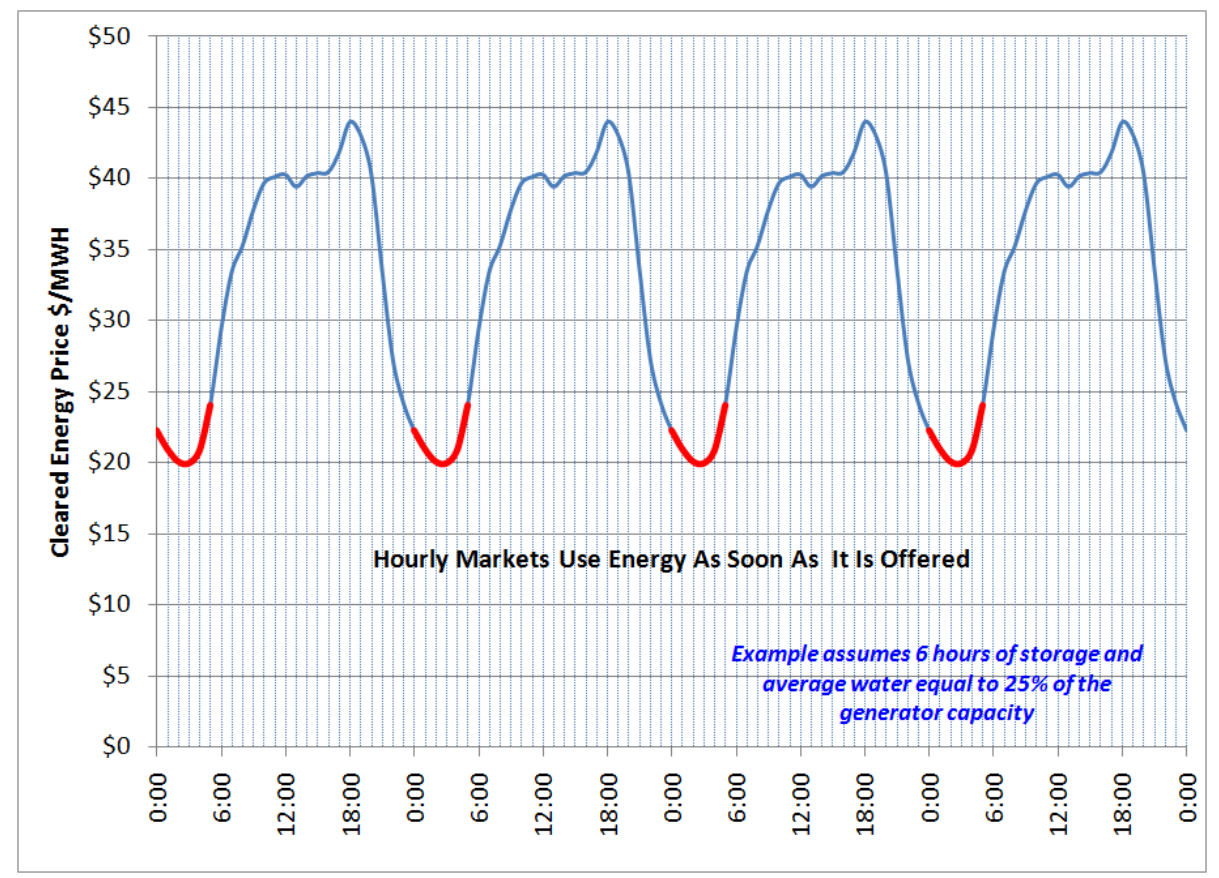

Figure 3-13 Hourly energy markets do not optimize the scheduling of energy-limited hydro.

Instead, the energy-limited hydro plant should ration its production and sell during the highestprice hours it is able, given a forecast window that may span days or weeks. This is best for the hydro plant because it maximizes profits and it is best for society because it reduces overall production costs. Figure 3-14 shows how the plant must not offer its capacity at cost. Instead it should guess at the expected energy market clearing prices and either: only offer during the expected six highest-price hours; or bias its offer price up during the expected lower-price hours and bias it down during the expected highest-price hours. The plant operator must forecast both the clearing prices and their timing. 


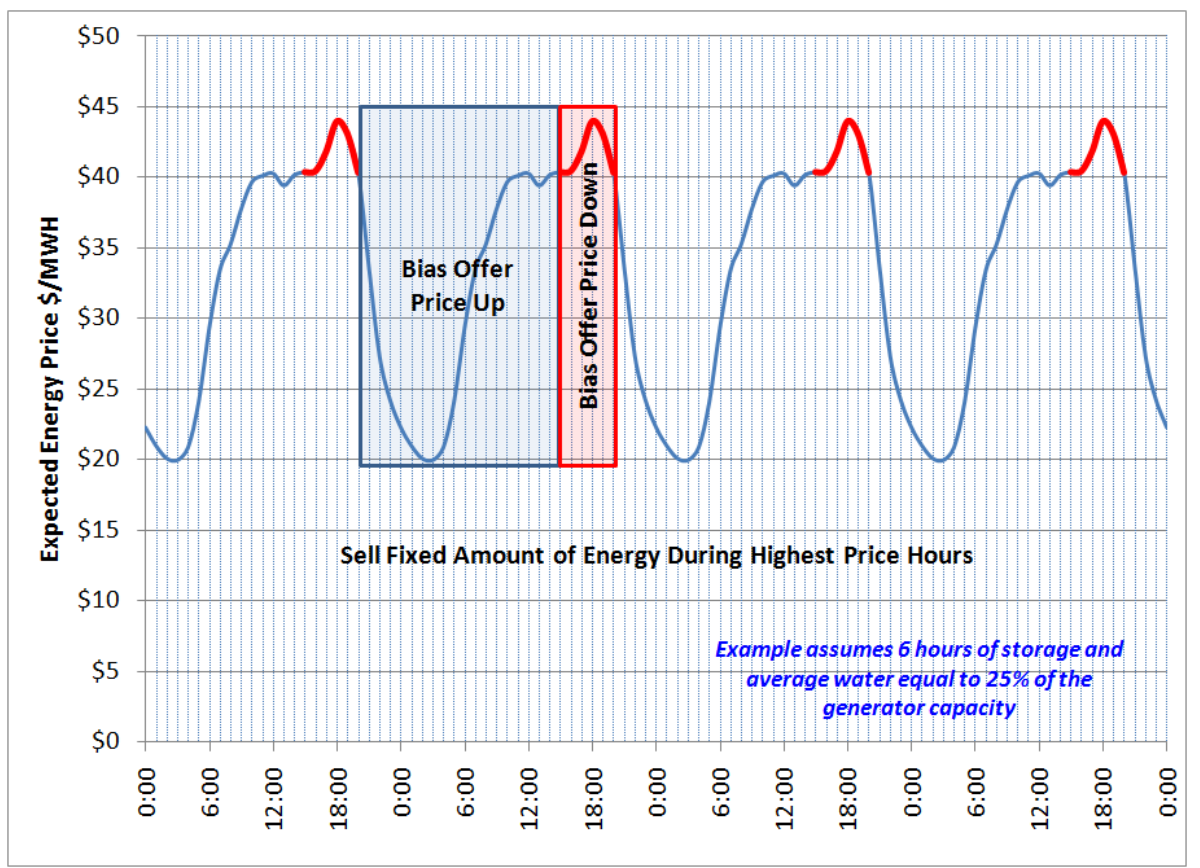

Figure 3-14 Energy-limited hydro must either explicitly schedule production during expected high price hours or it must bias its offer price during expected lower price hours

The situation for pumped storage is more complex, as shown in Figure 3-15. Like thermal generation, pumped storage has a variable O\&M cost. The "fuel" cost is not fixed but instead is based on the cost of purchased energy and the round-trip storage efficiency. Like energy-limited hydro generation, pumped storage needs to schedule when it is best to sell its limited energy output. Unlike thermal and conventional hydro, scheduling pumped storage requires forecasting both the energy purchase price and the energy sale price.

The pumped storage plant operator must forecast when prices will be minimum so that storage can be filled at least cost (green curve in Figure 3-15). Similarly, the plant operator must forecast when sale prices will be at a highest to maximize profits. But energy should only be sold if the sale price is greater than the purchase price divided by the plant round-trip efficiency. After filling but before the expected peak price, the plant should offer to sell at somewhat below the expected peak price (red box). Once the time of the expected peak price arrives, the plant should offer to sell based on the expected next purchase price divided by the plant round-trip efficiency (green box). Once the time of peak price is reached, the storage plant does not want to miss the opportunity to sell, even if that peak price is not as attractive as expected. The plant does not want to sell, however, if it will cost more to replace the energy than is made from the sale. 


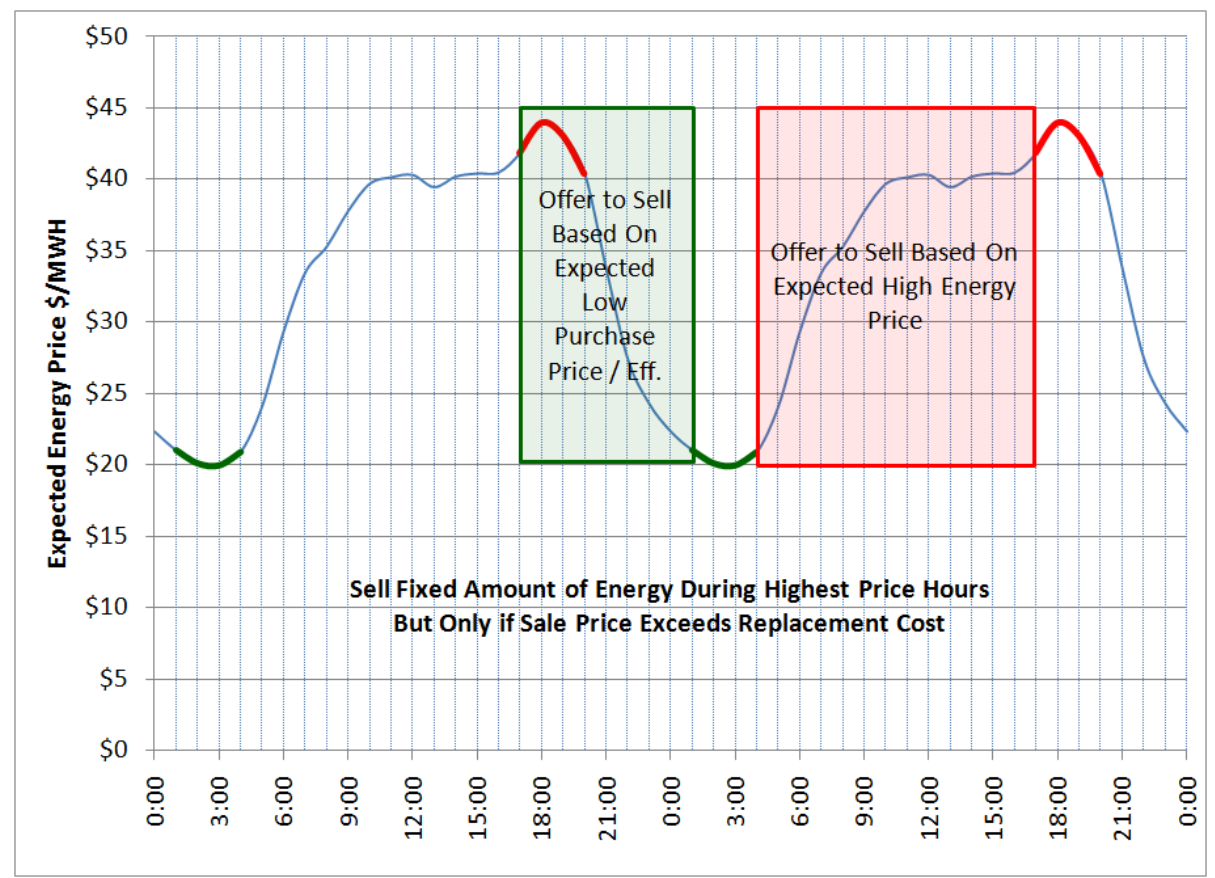

Figure 3-15 Pumped storage operators must forecast both high and low prices and adjust both the buy and sell bids based on both the expected buy and sell prices

\section{Ancillary Services}

Ancillary services further complicate the scheduling of energy-limited hydro and pumped storage. Determining ancillary service offer prices for thermal plants is reasonably straightforward. The cost to supply regulation and spinning reserve is dominated by opportunity costs that hour. A thermal plant with a \$35/MWh variable O\&M cost selling into a $\$ 44 / \mathrm{MWh}$ energy market looses $\$ 9 / \mathrm{MWh}$ in profit if it backs down to provide reserves. So the offer price for spinning reserve is $\$ 9 / \mathrm{MWh}$. The offer price for regulation is somewhat higher because the plant will also incur an efficiency penalty when it regulates. Variable renewables have higher opportunity costs because they have lower variable costs: they do not save any fuel costs when they are curtailed to provide reserves. Still, the calculation of the opportunity costs and the appropriate ancillary service bid price are the same.

The opportunity cost for energy-limited hydro is more complex to calculate. Though the fuel source (water) is free, it is generally not lost if the plant withholds production in order to sell reserves: the water can be used for energy production during another hour as long as there is adequate reservoir storage space. Consequently, the cost for energy-limited hydro to provide spinning reserve depends not only on the current price of energy but also on the price of energy during the next best hour (within a prescribed forecast window) to sell. This can be seen in Figure 3-16. In order to provide spinning reserve during hour 18:00, the plant gives up selling some $\$ 43.96 / \mathrm{MWh}$ energy. The next best time to sell additional energy is at 12:00 when the price is $\$ 40.28 / \mathrm{MWh}$. The plant looses $\$ 3.68 / \mathrm{MWh}$ in energy profits and must charge at least $\$ 3.68 / \mathrm{MWh}$ for the spinning reserve. If the spinning reserve market clears at a higher price, the plant makes additional profit. The spinning reserve price is calculated the same way for hours 15:00 through 20:00. The 12:00 hour is always the next best hour for an energy sale but the 
energy market price varies and consequently the opportunity cost and the spinning reserve cost varies too.

For hours 0:00 through 14:00 and 21:00 through 0:00, the plant was not planning to sell energy. With only 6 hours of storage, these hours are not as attractive for energy sales. In order to sell spinning reserve during these hours the plant would have to operate at minimum load (assumed to be $50 \%$ for this example). That means that the plant would have to forego energy sales during a more profitable hour (20:00 at $\$ 40.35 / \mathrm{MWh}$, the lowest energy price hour when the plant was planning on generating), and sell energy during a less profitable hour (3:00 at \$19.99/MWh, for example) in order to be able to sell spin during that hour. The 3:00 cost for spin would then be $\$ 20.36 / \mathrm{MWh}$ to compensate for the lost energy profit.

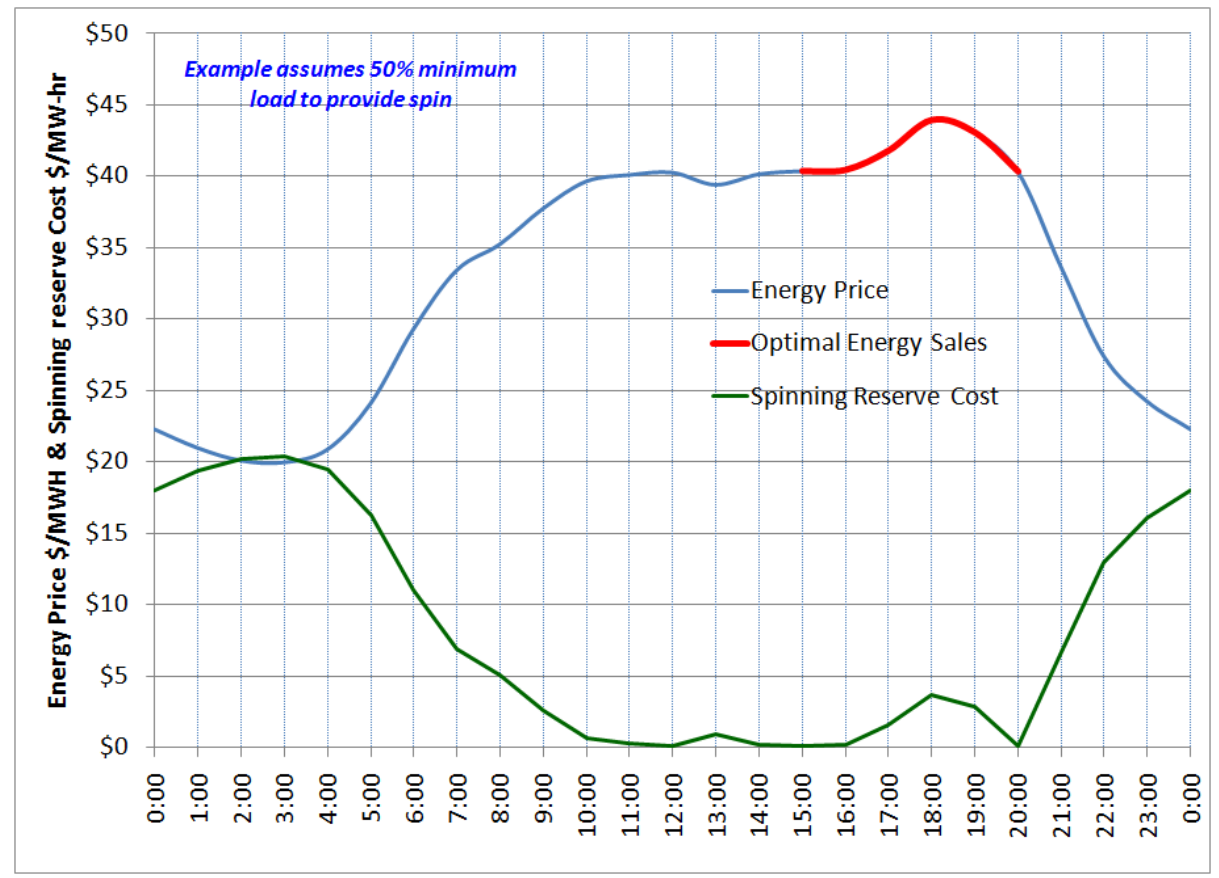

Figure 3-16 Energy-limited hydro cost to supply spinning reserve depends on the hour it is delivered and on how many other hours of spin are being provided

Spinning reserve costs rise if spin is to be provided for multiple hours. If spin is to be provided for a second hour between 15:00 and 20:00, then the excess energy could still be sold during the $12: 00$ hour selling $100 \%$ output instead of $50 \%$ so the opportunity costs are the same. If spin is to be sold for a third hour, the cost rises because a lower price hour (14:00 at \$40.17) must be selected to sell the excess energy. Spin costs continue to rise as spin is provided for additional hours.

Pumped storage adds another layer of complexity with the necessity of considering full distribution of forecasted prices by hour, with the goal of establishing threshold prices for pumping as well as generating. 


\section{Extending Co-optimization}

ISOs co-optimize energy and ancillary services for conventional generators every hour because this optimizes the use of generation resources. Both the generators and society benefit. The generators no longer have to guess at the likely energy and ancillary services market clearing prices. They simply offer their capabilities and costs and their plant is optimally scheduled by the system operator each hour. Society benefits because co-optimization makes the most efficient use of all the resources and minimizes total costs. Unfortunately, co-optimization typically treats each hour independently.

It may be appropriate to extend this co-optimization to cover the multi-hour scheduling horizon of energy storage. As with conventional generation, this would benefit both the storage plants and the rest of the power system customers by optimizing the use of the limited resources. Society does not benefit from making hydro and pumped storage guess at future power prices; indeed, these resources could be operated to provide much greater grid benefits with an improved scheduling horizon.

\section{Treat Pumped Storage as a New Storage Asset Class}

Another potential option is for pumped storage plants to be treated as a new storage asset class. The current regulatory structure does not allow resources to be compensated for providing regulated transmission support while also supplying competitive energy and ancillary services. The National Hydropower Association has recommended that a new asset class be created to allow storage to be compensated for being able to support the grid during both low and high demand periods. Included in the recommendation are contracts to allow for procurement of long-term ancillary services in which pumped storage can help mitigate the effects of increased variable renewable generation capacity. Figure 3-17 gives an example of how this asset class could work. This model could provide increased value by compensating pumped storage for the grid support and functionality they can provide specifically. This model is similar to a "Pay for Performance" method. 


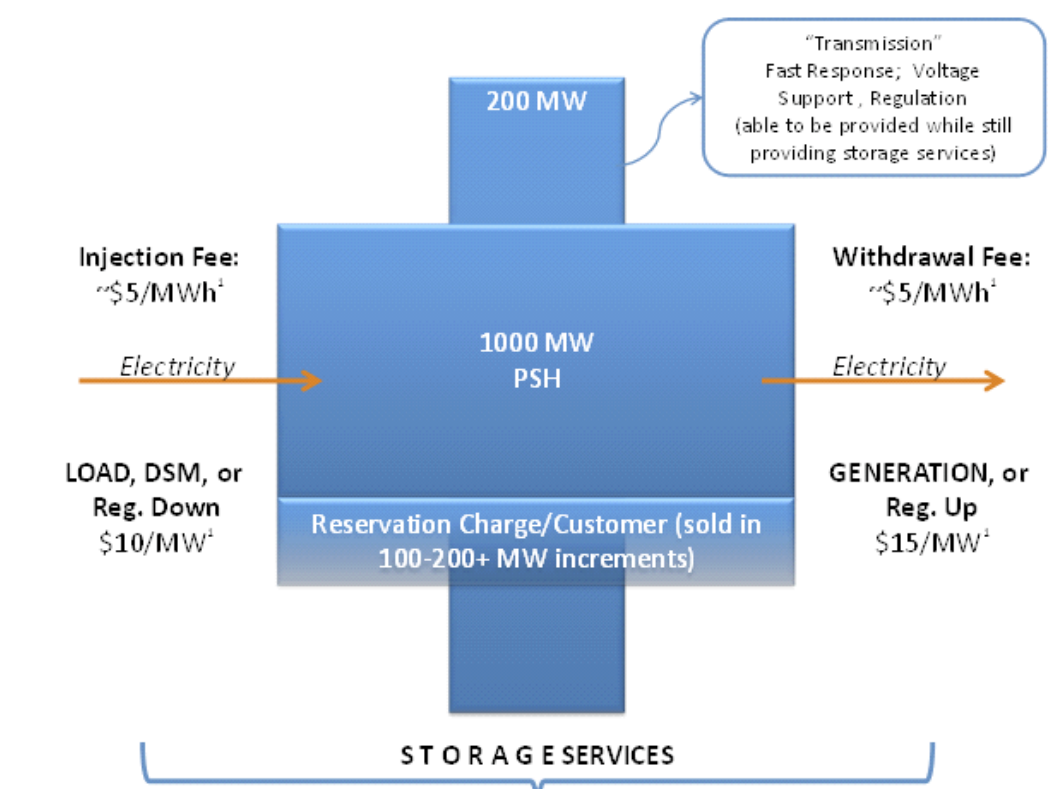

1.All numbers are hypothetical, actual injection, withdrawal and reservation charges to be determined on a project specific basis and sold via an open season on a tariff.

Figure 3-17 Example of pumped storage as a new storage asset

Based on the recent adoption of FERC's Pay for Performance rules, markets for ancillary services will likely become more transparent and more accessible to a wider variety of resources. In addition, the pay for performance rules likely will lead to definition of new products that can result in new revenue streams for generators. Moves in this direction by ISO/RTO organizations are already evident-MISO is considering a product for "flexible ramping" as is CAISO. ISONE already has such a product in effect in its "mileage payments."

Accordingly, flexibility and rapid, accurate response, such as can be obtained by energy storage resources, will likely become relatively more valued in these future markets. Furthermore, flexibility can be used to take advantage of spikes in energy markets such as those seen in the recent past. This requires market "savvy" and an institutional arrangement based on quick decision making. Finally, due to long-term changes in the nature of U.S. electricity demand, it is possible that the current trend to a more predominant peak load may provide hydro operators with opportunities to obtain more revenue from energy markets. Whether hydro can play a larger role in the new grid future may depend on the willingness of hydro facility operators to operate their facilities to provide the maximum amount of flexibility to the power system.

\section{Credit Hydro for Fast Regulation}

The last method under the market is to capture the value of allowing hydro to receive credit for providing very fast regulation. Hydropower could gain additional value by providing dynamic reactive power support, primary frequency response, and within-hour deployment services. In this study, this value was not captured because the study used an hourly model. A new project has been initiated by the Department of Energy entitled Detailed Analysis to Demonstrate the Value of Advanced Pumped Storage Hydropower in the U.S. The goal of the project is to create a model that will evaluate pumped storage hydro's contribution on the second and sub-second basis (the conclusions of this study should be applicable to large conventional hydropower units 
as well). More work needs to be done in this area to understand what value there may be in this very fast timeframe, and whether hydropower or other resources can benefit from it. 



\section{CONCLUSIONS \& FUTURE RESEARCH}

The study confirmed that hydropower resources across the United States contribute significantly to operation of the grid in terms of energy, capacity, and ancillary services. With approximately $75 \mathrm{GW}$ of conventional and $22 \mathrm{GW}$ of pumped storage, hydro represents about $9 \%$ of generation capacity and about 7\% of electric generation in the US. Although new dams have not been an active option, there are many plant upgrades ongoing for within this existing US conventional hydropower fleet. Significant upgrades have also been undertaken in many of the existing pumped storage plants. Construction of new pumped storage continues to be in active discussion, although siting and justifying the cost remains very challenging. But, pumped storage remains a viable option for large new hydro capacity assets in the U.S.

In this study a significant effort was applied to modeling and simulation to predict the future role of hydropower with many different possible energy scenarios. For this part of the project, the value of hydro power was quantified using current electricity market rules and the best available security-constrained economic dispatch modeling tools. Of the ten different potential value streams identified, we were able to quantify six and apply these to specific scenarios in the WECC region of the U.S.

The value was quantified from operating efficiency improvements, fleet support, technology upgrades to increase operating range and services, and faster settling time and co-optimization in electricity markets. These were considered to look at adding pumped storage in WECC. Over a wide range of possible energy futures, up to 2020, and using current market rules, none of the cases investigated in the region were found to bring revenues sufficient to justify new construction.

It should be noted that considering additional potential value streams and extending the time horizon of the analysis may change this result. Regarding the value streams, this study was not able to quantify several of the values identified. For example, capturing very fast regulation and providing flexibility reserves to accommodate larger penetration of variable renewable energy resources (wind and solar) may increase the ancillary service revenue opportunities for pumped storage. Also increasing the research time horizon, and the related electric system assumptions, beyond 2020 could be explored. Considering these factors in future research is recommended.

\section{Ten Ways to Increase the Value of Hydropower Assets}

From the step-by-step project development, tasks areas of investigation, and interactions with key stakeholders, we are able to point out ten ways to potentially increase the value of hydropower to the electric grid. This final report focused on the ten different value streams identified during the study and describes each one. These are intended to be non-overlapping and can be conveniently categorized as operational improvements, new hydro technology, and 
electricity market opportunities. In each instance, the beneficiary of the value may be different and is identified. These hydro value increase opportunities are summarized below in Table 4-1:

Table 4-1 Ways to increase the value of hydropower

\begin{tabular}{|c|c|c|c|c|}
\hline No. & $\begin{array}{c}\text { Value } \\
\text { Streams }\end{array}$ & Ways to Increase Value & Beneficiaries & $\begin{array}{c}\text { Potential } \\
\text { Value } \\
\end{array}$ \\
\hline 1 & $\begin{array}{c}\text { Operational } \\
\text { Improvements }\end{array}$ & $\begin{array}{l}\text { Identify and make plant efficiency } \\
\text { improvements by modifying hydro unit } \\
\text { operations while respecting river system } \\
\text { optimizations and constraints }\end{array}$ & Plant owner & $\begin{array}{l}1-3 \% \\
\text { revenue } \\
\text { increase }\end{array}$ \\
\hline 2 & $\begin{array}{c}\text { Operational } \\
\text { Improvements }\end{array}$ & $\begin{array}{l}\text { Use hydro more frequently to address } \\
\text { other generation and load variability in the } \\
\text { power system, providing flexible reserves, } \\
\text { reducing wear and tear on the thermal } \\
\text { fleet, while increasing the efficiency of } \\
\text { other generation }\end{array}$ & $\begin{array}{l}\text { System } \\
\text { operator or } \\
\text { vertically } \\
\text { integrated } \\
\text { utility }\end{array}$ & $\begin{array}{l}40 \% \\
\text { annual } \\
\text { revenue } \\
\text { increase } \\
\text { PS }\end{array}$ \\
\hline 3 & $\begin{array}{l}\text { Operational } \\
\text { Improvements }\end{array}$ & $\begin{array}{l}\text { Recognize hydro for allowing more } \\
\text { generation diversity and options, thus } \\
\text { enhancing energy security and } \\
\text { maintaining power supply reliability in } \\
\text { the face of uncertainties in future energy } \\
\text { resources }\end{array}$ & $\begin{array}{l}\text { National } \\
\text { interest, } \\
\text { general public, } \\
\text { and NERC }\end{array}$ & $\begin{array}{l}\text { Not } \\
\text { quantified }\end{array}$ \\
\hline 4 & $\begin{array}{l}\text { New Hydro } \\
\text { Technologies }\end{array}$ & $\begin{array}{l}\text { Expand the effective operating range of } \\
\text { existing and new hydro units with lower } \\
\text { minimum load and higher peak operating } \\
\text { capabilities }\end{array}$ & $\begin{array}{l}\text { Plant owner } \\
\text { and operator }\end{array}$ & $\begin{array}{l}61 \% \\
\text { increase } \\
\text { annual } \\
\text { average } \\
\text { income PS }\end{array}$ \\
\hline 5 & $\begin{array}{l}\text { New Hydro } \\
\text { Technologies }\end{array}$ & $\begin{array}{l}\text { Apply adjustable speed drive electronics } \\
\text { in new and selected existing pumped } \\
\text { storage units to enable regulation of the } \\
\text { pumping power requirements, particularly } \\
\text { at night }\end{array}$ & $\begin{array}{l}\text { Plant owner } \\
\text { and operator }\end{array}$ & $\begin{array}{l}85 \% \\
\text { increase } \\
\text { annual } \\
\text { average } \\
\text { income PS }\end{array}$ \\
\hline 6 & $\begin{array}{l}\text { New Hydro } \\
\text { Technologies }\end{array}$ & $\begin{array}{l}\text { Design new pumped storage plants that } \\
\text { minimize environmental impacts such as } \\
\text { low profile or closed water supply loop to } \\
\text { shorten licensing lead times and public } \\
\text { approval process as compared to recent } \\
\text { conventional experiences }\end{array}$ & $\begin{array}{l}\text { Developers, } \\
\text { general public }\end{array}$ & $\begin{array}{l}\text { Not } \\
\text { quantified }\end{array}$ \\
\hline 7 & $\begin{array}{l}\text { Electricity } \\
\text { Markets }\end{array}$ & $\begin{array}{l}\text { Settle energy markets sub-hourly, } \\
\text { increasing conventional and pumped } \\
\text { storage energy arbitrage opportunities } \\
\text { with grid demand load leveling benefits }\end{array}$ & Everybody & $\begin{array}{l}5 \% \\
\text { decrease } \\
\text { in } \\
\text { electricity } \\
\text { prices }\end{array}$ \\
\hline 8 & $\begin{array}{l}\text { Electricity } \\
\text { Markets }\end{array}$ & $\begin{array}{l}\text { Have the Independent System Operators } \\
\text { (ISOs) scheduling hydro to co-optimize } \\
\text { energy and ancillary services within a }\end{array}$ & Everybody & $\begin{array}{l}63-77 \% \\
\text { increase in } \\
\text { profits PS }\end{array}$ \\
\hline
\end{tabular}




\begin{tabular}{|c|l|l|l|l|}
\hline 9 & $\begin{array}{l}\text { balancing authority } \\
\text { Electricity } \\
\text { Markets }\end{array}$ & $\begin{array}{l}\text { Treat pumped storage as a new storage } \\
\text { asset class capturing the full value of } \\
\text { services and improving the economics in } \\
\text { areas with resource constraints }\end{array}$ & $\begin{array}{l}\text { Developers, } \\
\text { plant owners, } \\
\text { and general } \\
\text { public }\end{array}$ & $\begin{array}{l}\text { Not } \\
\text { quantified }\end{array}$ \\
\hline 10 & $\begin{array}{l}\text { Electricity } \\
\text { Markets }\end{array}$ & $\begin{array}{l}\text { Credit hydro for its very fast regulation } \\
\text { response in situations where resource } \\
\text { adequacy is a power system reliability } \\
\text { issue }\end{array}$ & $\begin{array}{l}\text { Developers, } \\
\text { plant owners, } \\
\text { NERC and } \\
\text { general public }\end{array}$ & $\begin{array}{l}\text { Not } \\
\text { quantified }\end{array}$ \\
\hline
\end{tabular}

As shown for these value streams, the benefits are spread around among different stakeholders, some are not well defined and recognized and others highly dependent on local conditions and the state of competing energy resources. A standard cost-benefit analysis is complicated with time-dependent variables and cannot by itself capture full future value. This study has aimed to highlight all of the different elements of the actual costs and benefits from hydropower projects that are not fully recognized under existing policies and market structures.

\section{Looking Ahead}

Deployment of more variable renewable generation will result in increased demand for flexible generation resources and will increase necessary reserve generation margins. This study has aimed to help the utility and hydroelectric industries better understand the value and economic viability of existing and potential future hydropower assets for providing both energy and ancillary services. It shows how value will be sensitive to different future energy scenarios including high levels of renewable integration, variations in fossil plant operations and commodity prices such as $\mathrm{CO} 2$ credits and natural gas. Results will also be useful in formulating policies and regulations, for developing fair markets, and for investing in energy and transmission infrastructure to ensure energy security and to address climate change concerns. Uses include quantifying benefits provided by conventional and pumped storage hydro projects to the transmission grid, validating a power and market systems model, analyzing scenarios, and examining the implications of alternative market structures.

While this study looked at several aspects of value, the general conclusion is that more work needs to be done to quantify the full value stream of hydropower resources. Specifically, modeling on shorter time scales may be beneficial to capture the value on a within-hour basis. A new Department of Energy project led by Argonne National Laboratory will follow the work discussed here and focus directly on the value of hydropower technologies at more a granular level. Additionally, work needs to be done to better understand hydropower's role in supporting a reliable grid and preparing the power system for an uncertain energy market future. These are items that benefit the electric grid (e.g. quality and speed of regulation), but are hard to quantify and attribute to one technology or another on a nationwide scale. Ultimately, hydropower will have to compete with other power system improvements such as generation resources, demand response, and forecasting improvements, to effectively capture the value of adding flexibility. 



\section{5 \\ REFERENCES}

1. EPRI. 1990. Pumped-Storage Planning and Evaluation Guide, EPRI GS-6669, January 1990.

2. EPRI. 1995. Application of Adjustable Speed Machines in Conventional Pumps Storage Hydro Projects, EPRI TR-105542, November 1995.

3. Fisher, R.K.,Koutnik, J.,Meier, L.,Loose, V.,Engels, K., and Beyer, T., A Comparison of Advanced Pumped Storage Equipment Drivers in the U.S. and Europe, HydroVision 2012, July 2012.

4. Kirby, B., Co-optimizing Energy and Ancillary Services from Energy-Limited Hydro and Pumped Storage Plants, HydroVision 2012, July 2012.

5. Loose, V.W., Quantifying the Value of Hydropower in the Electric Grid: Role of Hydropower in Existing Markets. Sandia National Laboratories Report, SAND20111009. January 2011.

6. Manwaring, M., Mursch, D., Tilford, K. Challenges and Opportunities for New Pumped Storage Development: A White Paper developed by NHA's Pumped Storage Development Council. April 2012.

7. March, P.A., P. Wolff, and T. Key, Effects of Electricity Markets on Suboptimization of Pumped storage Hydroelectric Plants, HydroVision 2012, July 2012.

8. Quantifying the Value of Hydropower in the Electric Grid: Modeling Approach and Base Case Scenario. EPRI, Palo Alto, CA: 2011a. 1023139.

9. Quantifying the Value of Hydropower in the Electric Grid: Plant Cost Elements. EPRI, Palo Alto, CA: 2011b. 1023140.

10. Quantifying the Value of Hydropower in the Electric Grid: Modeling Results for Future Scenarios. EPRI, Palo Alto, CA: 2012a. 1023141.

11. Results from Case Studies of Pumped Storage Hydroelectric Plants: Quantifying the Value of Hydropower in the Electric Grid. EPRI, Palo Alto, CA: 2012b. 1023142.

12. Results from Case Studies of Conventional Hydroelectric Plants: Quantifying the Value of Hydropower in the Electric Grid. EPRI, Palo Alto, CA: 2012c. 1023143.

13. Starke, M., Snyder, L., and Smith, B. Case Study: Hydropower Constraints on OSAGE and TAUM SAUK Facilities. Oak Ridge National Laboratory Report, ORNL/TM2012/232.

14. Wind Power Integration Technology Assessment and Case Studies, EPRI, Palo Alto, CA: 2004. 1004806. 



\section{RECENT ENHANCEMENTS TO MARKET ACCESS FOR ENERGY STORAGE TECHNOLOGIES}

Most ISO/RTOs have recently made a variety of adjustments to their rules, market protocols, and settlements to enhance the market access of energy storage technologies. Most of the changes have taken the form of broadening the definition of what sort of resources can bid into ancillary services markets. For example, there have been:

- Reductions in the duration of continuous, sustained energy output required to qualify to bid

- Relaxation of requirements to bid into energy markets in order to participate in ancillary services markets

- Changes to net energy settlement provisions calculated based on the net of injections and withdrawals

- Frequency-based signals for energy storage resources

- Exclusion of energy used for charging energy storage devices from the definition of

"station power" and the related provision that energy used to charge is FERC jurisdictional, therefore it's commerce

- Creation of new markets

- Measurement of energy injected from the time of injection rather than at the end of an arbitrarily specified ramp period

The variety of adjustments and changes listed above reflects the many complexities evident in the market protocols and rules of the ISOs. These adjustments are helpful to increase access to markets and therefore to competition but more changes are required to fully encourage participation of energy storage devices.

Furthermore, many of these changes were made to accommodate the engineering characteristics of smaller capacity energy storage devices - batteries, flywheels, and to some extent, compressed air. Accordingly, the enhancements recently adopted are not particularly relevant or helpful to PSH technologies.

As noted, energy and ancillary services markets are evolving and recognition of essential grid services being provided by generators is increasing. For example, concern for the evident decline in and future maintenance of adequate inertia in the system from rotating machinery has arisen in the context of renewable portfolio standards regarding renewable energy technologies. The latter do not contribute much inertia to the system so it may be that generators that do need to be compensated for this aspect of their operations. Another externality type of service being provided by some generators is reactive power. For the system to remain stable and reliable 
adequate incentives to provide these services must be instituted. ${ }^{6}$ If revenues covered every service that is provided by generators, then it should be the case that sufficient compensation is available so that the required reserves of capacity and energy are available to the system and asset owners would have the continued incentive to make investments.

Beyond these constraints there is an issue facing PSH operators that merits serious attentionmarket power. FERC is very concerned about market power as evidenced by the recent NOI on Ancillary Service, much of which is focused on market power issues. Operators of ISO/RTOs are equally concerned about competitiveness in bidding into both energy and reserves markets; every one of the ISOs has a market monitoring function that regularly assesses the competitiveness of bidding. Market power concerns are particularly acute in reserves markets because fewer generators are capable of bidding into them and the markets are generally smaller in terms of the amount of energy or capacity transacted within them. Bidding into reserves markets by owners of conventional generators is already restricted to only those generators that possess the technical characteristics that render them capable of meeting the requirements for the particular type of reserve. Many balancing areas will have a reserve requirement that is less than the capacity of a typical PSH project. Thus, one large bidder (a 1,000 MW PSH plant?) might be competing with a number of bidders whose assets are much smaller - on the order of $1 \mathrm{MW}$ or less. Because of the way in which economists evaluate the potential for market power the concentration ratio (market shares of the largest competitors) in this situation might indicate a serious potential problem. Behavioral measures tend to suggest the exercise of market power. These include pivotal bid frequency, ratios of bid volumes to required volumes, and ratio of actual prices to competitive prices.

There are ways to mitigate this potential problem. New competition can be encouraged by further reducing the restrictions and definitions that competitors see as barriers to entry. Also, wider geographic participation can be encouraged; in particular, larger balancing areas might greatly reduce the concentration ratio problems of smaller balancing areas. Development of forward markets also has the potential to reduce market power potential. Finally, developing a workable system through which demand response can be brought to the market would help to reduce market power in both energy and reserves markets.

\section{Previous Studies on the Role of Hydropower with Renewables}

Development of new hydro generation assets has stalled for many years. Stakeholders stated that policy and market incentives have been insufficient to overcome permitting difficulties and financial risks. However, hydro resources, particularly PSH are expected to play a more prominent role as the need for flexibility in the system increases, i.e. as the penetration of variable renewable increases. Furthermore, as the evolution to wholesale markets expands and markets become more fine-tuned through application of "Pay for Performance," compensation opportunities to flexible and quick-response resources such as PSH will increase the financial

\footnotetext{
${ }^{6}$ Externalities are benefits (or costs) provided to the system generally that do not pass through a market and for which no mechanism for compensation (or payment) is available in the system.
} 
and economic incentives to more fully utilize existing facilities. ${ }^{7}$ This should, in turn, provide incentives to construction of new PSH facilities.

\section{Eastern and Western Interconnection Wind Integration Studies}

Several recent studies have investigated high penetrations of renewable generation-mostly wind turbines - and have analyzed strategies for offsetting the increase in net-load variability and uncertainty that this would introduce into reliability management of the interconnected electrical grid. Most hydro facilities have the ability to cycle to help manage net-load variability and uncertainty that results with high wind and solar penetration. The assumption is that used in this manner, hydro facilities would be able to provide a more valued service to the grid than the manner in which they have historically been used and that hydro facilities would, accordingly, be compensated more for this service. Further, this greater compensation would then provide the economic impetus for more hydro facilities to be developed.

Two key studies, both commissioned by the Department of Energy (DOE) through the National Renewable Energy Laboratory (NREL), have focused on integration of significant new renewable generation, particularly wind generation capacity. One of these studies focused on the Eastern Interconnection (Eastern Wind Integration and Transmission Study - EWITS) ${ }^{8}$ while the other focused on the WestConnect portion of the Western Interconnection (Western Wind Integration Study - WWIS) ${ }^{9}$. Both studies released findings and reports during $2010 .^{10}$

The generation expansion portion of the EWITS did not deploy additional hydro by assumption. "Before using the capacity expansion model, the project team eliminated other alternatives such as integrated gasification and combined cycle (IGCC) units with sequestration, biomass, and hydro facilities as options because they were not economically competitive with the conventional resources under the assumptions applied to the analysis.", 11

The Western Wind and Solar Integration Study (WWSIS) provided somewhat more analysis of the potential for hydro to play a more significant role. The contribution of hydro was benchmarked in the base cases (no wind and solar) and changes to hydro scheduling were examined in the three renewable penetration scenarios- $10 \%, 20 \%$, and $30 \%$ renewable penetration. ${ }^{12}$ The authors note that as more wind was added, particularly in the $30 \%$ renewable scenario, the hourly schedule of hydro did change but the total monthly energy remained constant as well as the monthly minimum and maximum power output levels. These latter two constraints - minimum and maximum power output levels - typically arise from constraints on hydro operations requiring minimum and maximum water spillage constraints and could thus not be treated as variables in the simulations analyses.

\footnotetext{
${ }^{7}$ The FERC issued its Final Rule adopting the principles of Pay for Performance on 20 October 2011. (137 FERC Paragraph 61,064, 18 CFR Part 35, entitled "Frequency Regulation Compensation in the Organized Wholesale Power Markets"). Available at: http://www.ferc.gov/whats-new/comm-meet/2011/102011/E-28.pdf

${ }^{8}$ Eastern Wind Integration and Transmission Study; Prepared for the National Renewable Energy Laboratory by EnerNex Corporation; Sub contract report number NREL/SR-5500-47078 Issued January 2010, Revised February 2011.

${ }^{9}$ Western Wind and Solar Integration Study; Prepared for the National Renewable Energy Laboratory by GE Energy; Sub contract report NREL/SR-550-47434 Issued May 2010.

${ }^{10}$ Another study conducted by the European associations of transmission system operators with the European Commission is also on the scale and scope of these two studies for portions of the North American grid.

${ }^{11}$ Ibid, EWITS, p 96, revised version

${ }^{12}$ Penetration levels are based on energy delivered to load.
} 
Despite the relatively unchanged hourly hydro scheduling noted by the authors they do conclude that "Because there are no thermal cycling issues involved, hydro generation offers a potentially critical source for both inter-hour and intra-hour flexibility. Limits to this flexibility should be assessed at all of the hydro plants to further refine their role in renewable integration." 13

\section{More Detailed Focus on Hydro Contribution in WWSIS}

A companion study to WWIS conducted further investigations of hydro contributions to obtain a more complete picture of the potential hydropower role in renewables integration and provide a more robust foundation for the findings from the main study. ${ }^{14}$ The focus of this study was sharpened to include plant level analysis at seven hydroelectric facilities within the larger WWSIS study footprint, including one pumped storage facility. A number of the questions addressed as well as the analysis methodology are directly pertinent to the present project. Among the most pertinent questions are: ${ }^{15}$

- What is the magnitude and character of change in generation and operations at individual hydropower and pumped storage plants when high penetration levels of variable and uncertain renewables are incorporated into the grid system?

- What is the overall value of hydropower as a balancing resource?

- What is the value to hydropower utilities in participating in wind integration?

- What is the impact of integrating renewables on pumped storage hydro operations?

To answer these and other questions a technical analysis was conducted using multiple approaches based on the output of a series of production cost simulations. Results from the simulations were compared to actual production patterns and to each other. In particular, the studies were conducted to assess the modeling capabilities, the impact of renewables on hydropower operation, and the benefits of using hydropower in wind and solar integration. Among the study findings most pertinent to the Hydro Grid Services Project are the following:

- Results of Renewable Generation Impact on Hydro Operations. As the wind generation penetration level increased little change in overall hydro generation pattern was observed at the system level. This was interpreted as an artifact of the model's preference to dispatch hydro on peak and not for balancing. Nevertheless, at certain larger hydro plants, their use increased as the penetration level increased. The use of hydro flexibility was found to increase at each of the two larger plants investigated in detail (Hoover and Glen Canyon). The greatest differences in hydro operations occurred during the spring months when high winds occur in the west leading to full use of the storage and flexibility of hydro facilities. Several different scenarios for siting the renewable facilities involved different combinations of in-area and out-of-area locations. As more of the new renewable projects were located in remote regions outside of the study footprint, less of the flexibility of hydro was needed due to the lower variability of net load. This led to changes in operations at the plants as between different scenarios of build-out strategies.

- Results of hydropower used as a balancing resource. Using hydro to balance variability would result in an overall increase of system costs involving increased costs for thermal

\footnotetext{
${ }^{13}$ Ibid, p 146-7.

${ }^{14}$ Western Wind and Solar Integration Study: Hydropower Analysis, prepared for National Renewable Energy Laboratory, Prepared By Dr. Tom Acker and Mr. Carson Pete, Northern Arizona University. October 2010.

${ }^{15}$ Ibid, p. v, Executive Summary 
resources and lost revenue for hydro (as compared with base case). The greatest impact would be felt again at the two largest dams-Hoover and Glen Canyon.

- Results of hydro participation in wind integration. This involves dispatching hydro to load only (without accounting for renewable generation) result in more use of thermal generation (mostly natural gas units) so that, together with the hydro, operating costs for the system would increase slightly at the lower penetration levels but increase with increased renewable penetration.

- Results of renewable impact on pumped storage hydro operations. Results show that a new 100 MW pumped storage plant would not be economically justified if used solely for balancing renewables integration. This is due to the effect that large penetrations of renewables would reduce spot prices enough in an open, liquid market so that balancing energy prices would be relatively low.

The focus among hydro advocates today is the capability of hydro to provide added value by acting as a counter-balance to the variability of solar and wind generation which is thought to, or expected to increase the requirement for reserves, particularly reserves devoted to ancillary services. ${ }^{16}$ Ancillary services, particularly the regulation component, have typically experienced higher clearing prices than energy prices in wholesale market areas. While the permanence of this price relationship may be open to debate it is thought that hydro facilities could provide quick response ancillary services and thereby increase revenue to owners and operators.

This study was the broadest and most detailed when completed to focus on the effects of high penetration renewable capacity into the electric grid, including an examination of the most effective role for hydro facilities. It has the additional feature of a close examination of the effects of this investment strategy on hydro facilities and on how hydro can help ease the transition into this new future. While it has valuable insights into the role that hydro could perform, that role may be restricted by site-specific requirements on how much hydro flexibility is actually available.

\footnotetext{
${ }^{16}$ Expanding the geographic area contained within each balancing area is a competing approach to mitigation of the expected increase of reserves required to balance wind and solar variability; the idea is that weather conditions are less likely to be consistent over a larger geographic area. In theory, if wind and solar generation sites are widely dispersed over the balancing areas territory then it is less likely to be cloudy or calm throughout the entire area. However, experience has shown that wind and solar build out concentrate where the greatest fuel resource occurs, and achieving geographic diversity is a challenge.
} 


The Electric Power Research Institute Inc., (EPRI, www.epri.com) conducts research and development relating to the generation, delivery and use of electricity for the benefit of the public. An independent, nonprofit organization, EPRI brings together its scientists and engineers as well as experts from academia and industry to help address challenges in electricity, including reliability, efficiency, affordability, health, safety and the environment. EPRI also provides technology, policy and economic analyses to drive long-range research and development planning, and supports research in emerging technologies. EPRI's members represent approximately 90 percent of the electricity generated and delivered in the United States, and international participation extends to more than 30 countries. EPRI's principal offices and laboratories are located in Palo Alto, Calif.; Charlotte, N.C.; Knoxville, Tenn.; and Lenox, Mass.

Together...Shaping the Future of Electricity

\section{Program:}

Bulk Power System Integration of Variable Generation

(C) 2013 Electric Power Research Institute (EPRI), Inc. All rights reserved. Electric Power Research Institute, EPRI, and TOGETHER...SHAPING THE FUTURE OF ELECTRICITY are registered service marks of the Electric Power Research Institute, Inc.

1023144 